\title{
STRUCTURE ET IDENTITÉ DES STYLES CÉRAMIQUES DU NÉOLITHIQUE ANCIEN ENTRE RHÔNE ET EBRE
}

\author{
Claire MANEN*
}

\begin{abstract}
Mots-clés. Néolithique ancien, Languedor, Catalogne, Méditerranée ocridentale, néolithisation, céramique, décoration céramique, quantificalion.
\end{abstract}

Key-words. Early Neolithic, Languedoc, Catalonia, Western Mediterranean, the process of neolithisation, ceramic, decoration on pottery, quantification.

Résumé. Résumé. L'auancée des recherches n'a de cesse de démontrer limportant polymorphisme caractérisant les premières sociétés agropastorales du sud de la France el, à une échelle plus largé, de la Méditerranée occidentale. La constitution d'un corpus de référence

II d'assemblages céramiques homogènes et le traitement de leurs caractéristiques stylistiques par le biais de l'analyse quantitative ont permis de proposer un nonzeau cadre chronoculturel du Néolithique ancien entre Rhône et Eibre. Le schéma développé comporte lrois grandes phases chronologiques. La première phase voit limplantation des faciès à céramiques imprimées sur les côtes languedociennes el catalanes. Ils s'expriment au travers de caractéristiques stylistiques variées qui suggèrent la multiplicité de leur origine. La deuxième phase identifiée voit l'úvolution en parallèle de deux styles réramiques, Cardial récent et épicardial ancien, dont l'origine et la nature sont disculées. I al troisième el dernière phase chronologique voil, au contraire de la précédente, une homogénéisation stylistique de la décoration céramique. La répartition géographique de l'épicardial récent montre l'exploitation de territoires de plus en phus éloignés du littoral. On observe enfin une consolidation du système économique el les prémices de certains réseaux d’échanges qui connaîtront leur apogée au quatrième millénaire avount notre ère.

\begin{abstract}
The adrance of archaeological research ceaselessly demonstrates the important polymorphism that characterizes the first agropastoral communities in Southern France, and, on a larger scale, in the Western Mediterranean. Through the construction of a referential corpus of homogenous ceramic assemblages and the treatment of their stylistic characteristics by quantitative analysis, a new framework is suggested for the Larly Neolithic between Rhône and Lbro river. This scheme includes three main chronological phases. In the first one, impressed zuctes appear along the Languedocian and Catalonian coastlines with various stylistic characteristics suggesting a multiplicity of origins. The second identified phase concerns the parallel evolution of two ceramic styles, Recent Cardial and Early Epicardial, the origins of which are being discussed. The third and last chronological phase shows a stylistic homogeneity in ceramic decoration in opposition to the previous phase. The geographical extension of Recent Epicardial shows, with farming and herding plans, an exploitation of territories more and more distant from the coastline. Finally we observe a consolidation of the economic system and the first steps of exchanges networks which will greatly increase during the fourth millenium before (hrist.
\end{abstract}

Les premières manifestations néolithiques du sud de la France et de la péninsule Ibérique ont d'abord été considérées comme monophylétique: succession
Cardial/Épicardial (Escalon de Fonton, 1970; Martí Oliver, 1978). Puis, la progression des recherches a permis d'en démontrer, au contraire, le caractère

* LNR 855 du CNRS. Centre d'anthropologie. 39 allées Jules Guesde, F-31000 Toulouse. 
polymorphe (Guilaine, 1976, 1986, 2000 ; Guilaine $e t$ al., 1979, 1993 ; Roudil, Soulier, 1983 ; Bernabeu Aubán, 1989 ; Binder éd., 1991 ; Binder, 1995, 2000). Il a été possible, d'une part, d'identifier de nouveaux faciès culturels impliqués dans la genèse et le développement des premières communautés paysannes de la France méditerranéenne et, d'autre part, de mettre en évidence au sein de chacun de ces faciès une variabilité culturelle et économique. Ces nouvelles données ont ainsi progressivement imposé une relecture du processus de néolithisation et la proposition de nouvelles alternatives.

Un récent travail universitaire (Manen, 2000b), synthétisé dans cet article, présente une révision du schéma de mise en place et de développement des premières communautés paysannes, dans les régions situées entre le Rhône et l'Ėbre. Ce domaine géographique présentait plusieurs atouts :

- une longue façade méditerranéenne susceptible de recevoir les influx du monde italique ;

- un espace géographique et orographique varié contribuant au développement du Cardial ;

- enfin, un axe ayant pu a priori participer à la formation de toute une série de phénomènes continentaux.

Ce travail repose essentiellement sur la révision et la critique des données disponibles et sur l'analyse de la variabilité du système céramique, ceci par le biais d'un protocole d'étude particulier. Les aspects chronoculturels et socio-économiques des premières communautés néolithiques sont ensuite discutés à la lumière des résultats obtenus et en intégrant les vestiges archéologiques non céramiques.

Les bornes chronologiques de cette étude coïncident d'une part avec l'implantation des premières sociétés néolithiques sur le littoral languedocien et catalan, vers 5800-5700 avant J.-C., et d'autre part avec l'apparition des multiples horizons à céramiques dites lisses, vers 4500 avant notre ère.

\section{CADRE GÉNÉRAL ET MÉTHODOLOGIE}

Cette réflexion, basée sur une révision du cadre chronoculturel du Néolithique ancien languedocien et catalan, s'ouvre ensuite sur un domaine géographique plus large, celui de la Méditerranée occidentale. Il s'agit en effet de satisfaire les exigences explicatives d'un

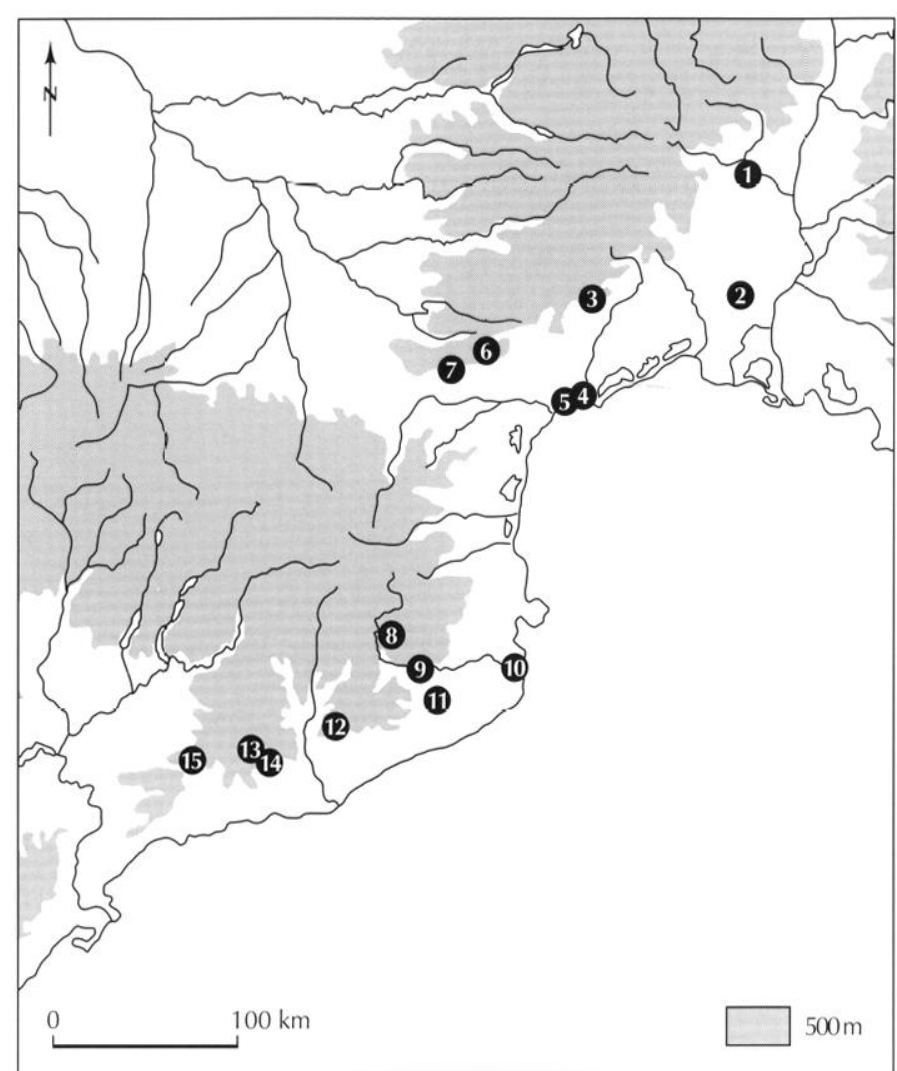

Fig. 1 - Carte de répartition des gisements sélectionnés entro Rhône et Ebre :

I, baume d'Oullins (Le Garn, Card) ; 2, baume Bourbon (Cabrieres, (Gard) ; 3, (irotle IV (Saint-Pierre-de-la-Iage, Hérault); 4, Pont de Roque-Haute (Portiragnes, Hérault) ; 5, Peiro Signado (Portiragnes, Hérault) ; 6, grotte de Camprafaud (Ferrières-Poussarou, Héranli) ; 7, grotte (Gazel (Salleles-Cabardès, Aude) ; 8, Plansallosa (Tortelli, (ierona) ; 9. Reclau Vixer (Serinyà, Gerona) ; 10, Puig Mascaró (Torroella de Montgri, Gerona) ; 11, La Draga (Banyoles, Cerona); 12, cova del Frare (Matadepera, Barcelona);13, Esquerda de les Roques del Pany (Torrelles de Foix, Barcelona) ; 14, Les (suixeres de Vilobi (Sant Marti Sarroca, Barrelona) ; 15, cova de la Font Major (Conca de Barberi, Tarragona).

processus basé sur la propagation d'un nouveau savoirfaire techno-économique.

C'est le document céramique, outil particulièrement bien adapté pour l'appréhension des stratégies identitaires, qui a servi de base de réflexion, ceci à travers l'étude de la variabilité des assemblages. D'un point de vue purement méthodologique, l'approche quantitative des caractéristiques de la céramique constitue un aspect important du travail que nous nous proposons de résumer. La nécessité de l'utilisation de données quantifiées ainsi que les tenants méthodologiques de cette 
démarche sont plus fréquemment abordés par les milieux antiquisants et médiévistes (Arcelin, TuffreauLibre éds, 1998). L'essentiel des études consacrées à la céramique du Néolithique ancicn ćtait en cffet réalisć jusqu'ici sur la base d'observations qualitatives. Comme l'avait souligné D. Binder (éd., 1991, p. 98) « on ne peut généralement se fonder pour les comparaisons que sur des indications d'ordre qualitatif, notamment des mentions de la présence ou de l'absence de tel ou tel élément, ce qui est, on en conviendra, très insuffisant ".

Choisissant de raisonner en termes quantitatifs, il nous était indispensable de réfléchir au problème de l'échantillonnage. Ainsi, l'ensemble de la documentation disponible (plus de 125 sites répartis entre le Rhône et l'Èbre) a été recensé selon une fiche descriptive permettant d'cffectuer un tri rigoureux des gisements en fonction de la fiabilité de l'échantillon céramique proposé et de sa représentativité statistique. Ce tri nous a permis de constituer un corpus de départ réduit mais fiable, grâce auquel il était possible d'étudier l'évolution chronoculturelle du Néolithique ancien languedocien et catalan. Ce premier niveau d'analyse a par la suite été précisé et complété par les données des gisements " rejetés".

Le corpus de référence ainsi constitué comprend 15 sites équitablement répartis entre le LanguedocRoussillon et la Catalogne (fig. 1) : baumc d'Oullins (Lc Garn, Gard) ; baume Bourbon (Cabrières, Gard) ; Grotte IV (Saint-Pierre-de-la-Fage, Hérault); Pont de Roque-Haute (Portiragnes, Hérault); Peiro Signado (Portiragnes, Hérault); grotte de Camprafaud (Ferrières-Poussarou, Hérault) ; grotte Gazel (SallèlesCabardès, Aude) ; Plansallosa (Tortellà, Gerona) ; Reclau Viver (Serinyà, Gerona); Puig Mascaró (Torroella de Montgrí, Gerona) ; La Draga (Banyoles, Gerona) ; cova del Frare (Matadepera, Barcelona) ; Esquerda de les Roques del Pany (Torrelles de Foix, Barcelona); Les Guixeres de Vilobi (Sant Martí Sarroca, Barcelona) ; cova de la Font Major (Conca de Barberá, Tarragona).

Certains de ces sites proposent une longue stratigraphie permettant de suivre l'évolution du système céramique. Les autres offrent l'avantage de l'ensemble clos. Pour compléter ce panorama, nous avons ajouté à notre analyse les données de trois gisements, situés dans l'aire rhodano-provençale, dont les caractéristiques du système céramique étaient disponibles en bibliographie. Il s'agit de la grotte Lombard, Saint-Vallier-de-Thiey, Alpes-Maritimes (Binder éd., 1991), de la baume de
Fontbrégoua c. 47-46, Salernes, Var (Échallier, Courtin, 1994) et de l'abri de La Tardive, Berrias-et-Casteljau, Ardèche, (Roudil et al., 1991).

En cc qui concerne les critères descriptifs retenus pour l'analyse des assemblages céramiques, plusieurs remarques sont nécessaires. Notre étude laisse de côté l'aspect technologique de la fabrication de la céramique. Ce type d'information est difficilement accessible et ceci à deux points de vue. Le premier concerne le problème de la fragmentation. Il est en effet malaisé d'appréhender les traces de fabrication et les traitements de surface sur la simple observation de tessons. Le second concerne les matières premières employées pour fabriquer la céramique. Ce sujet nécessite un travail particulier et rigourcux (analysc pćtrographiquc ct chimique) et l'examen à l'œil nu ne livre que de simples observations ponctuelles. Cependant, nous bénéficions d'un important travail de référence réalisé sur la céramique du Néolithique ancien languedocien (Barnett, 1989).

Pour l'analyse morphologique des récipients, il a fallu faire face au problème de la fragmentation, c'est-à-dire mettre en place deux systèmes de classement, l'un pour les fragments distinguant les différentes parties d'un vase, l'autre pour les formes complètes. Pour ces dernières, une sériation a été réalisée par le biais d'une analysc cn composantes principales des mesures du volume, du diamètre maximum, du diamètre à l'ouverture et de la hauteur, puis d'une classification ascendante hiérarchique. Ces calculs sont basés sur la description de 124 vases complets ou graphiquement restituables, recensés en Provence, Languedoc et Catalogne'. Un classement en 8 types différents a ainsi été obtenu (fig. 2). Le premier type, non figuré, correspond aux récipients de grande dimension, dont le volume dépasse 20 litres. Ceux-ci, peu nombreux, ne permettent pas de classement particulier. Ils offrent des formes très variables bien que l'on puisse noter une préférence pour les récipients hémisphériques et cylindriques très ouverts.

Trois critères principaux ont été retenus pour décrire la variabilité décorative : la technique utilisée, les thèmes figurés et la situation du décor sur le vase. Le classement des techniques décoratives n'a pas posé de problèmes. Il a été couplé à une approche expérimentale (fig. 3). En

1. Afin d'asseoir le caractère quantitatif de l'échantillon analysé, nous avons choisi, pour les questions de morphologie, d'intégrer les données provençales. 

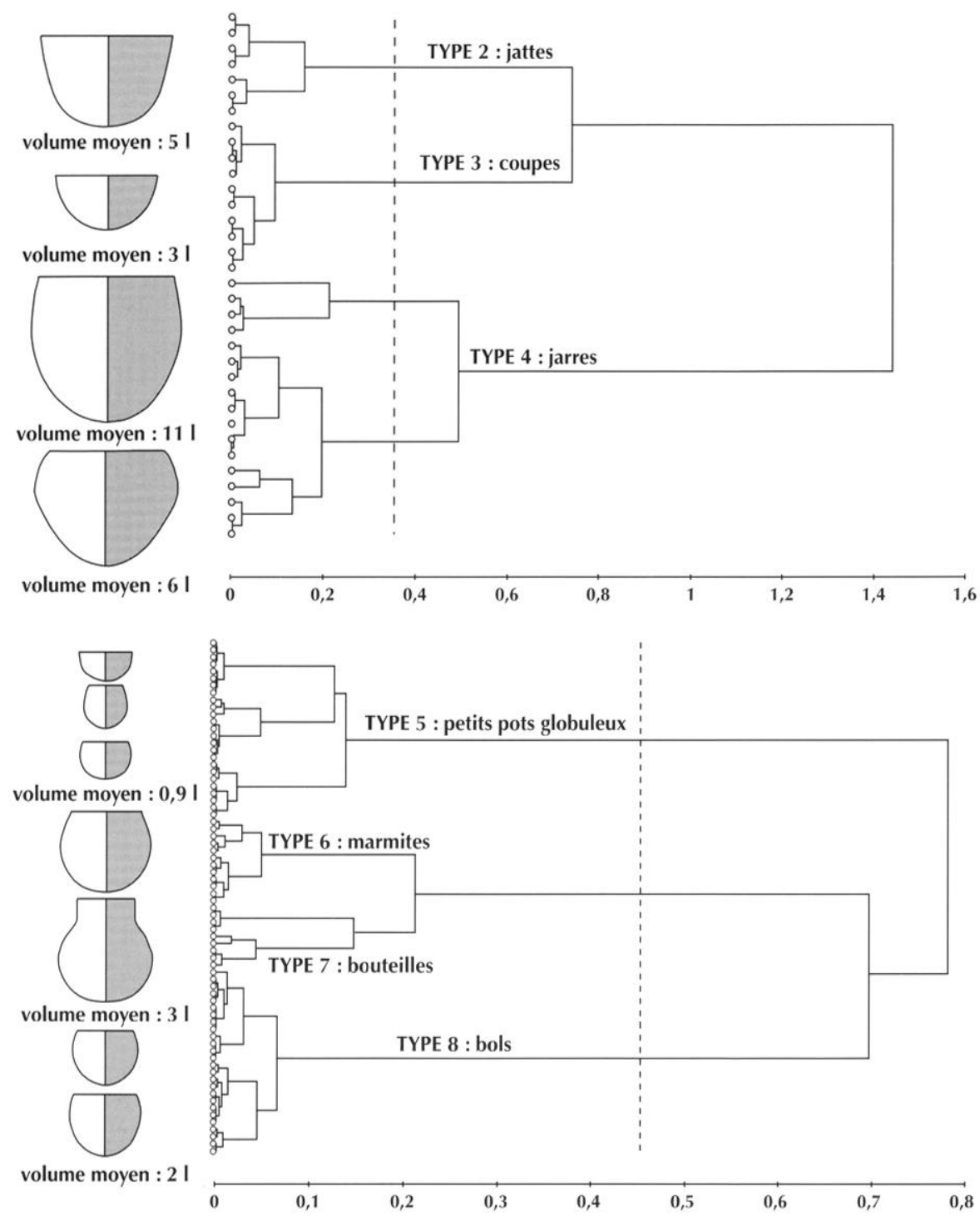

Fig. 2 - Classification hierarchique des reases du Néolithique ancien (124 individus classés en fonction de leur volume et de leurs dimensions). En haut les rases de moyenne contenance, en bas les vases de petite contenance. revanche, le classement des thèmes décoratifs ainsi que l'étude de la position du décor sur le vase se sont heurtés au problème de la fragmentation. Le classement que nous avons établi (tabl. I) est basé sur quatre notions complémentaires (Guilaine et al., 1984 ; Binder éd., 1991). Une première distinction est faite parmi les grandes catégories de techniques et par là même parmi les éléments décoratifs. Les trois grandes notions structurant notre classement sont la gestion de l'espace (ou " zonage "), le mode de remplissage, et l'encadrement (limitation de l'espacc défini au préalable). Le "zonage ", ou organisation de l'espace, correspond à la manière dont le décor occupe la surface du vase. On trouve le ruban horizontal, le ruban vertical et la plage couvrante. I. ruban correspond à une volonté de limiter l'extension du décor, tandis que la plage correspond à une volonté de remplissage (plus ou moins importante) de la surface du vase par le décor. Le remplissage de ces rones est simple ou géométrique (zigzag, chevron, etc.). Enfin, pour chacun des types ainsi définis, nous avons étudié, lorsque cela ćtait possible, leur position préférentielle sur le vase.

\section{SÉRIATION DES DONNÉES ET INTERPRÉTATION}

Chacun des assemblages céramiques sélectionnés a été décrit selon les critères définis précédemment. Dans le cas des gisements stratifiés, une analyse chronostratigraphique était au préalable nécessaire (Mancn, 2000) ). 


\begin{tabular}{|c|c|c|c|c|}
\hline TECHNIQUE & ZONAGE & REMPLISSAGE & ENCADREMENT & TYPE \\
\hline \multirow{11}{*}{$\begin{array}{l}\text { A. Impressions } \\
\text { orientables }\end{array}$} & \multirow{4}{*}{ Ruban horizontal } & \multirow{2}{*}{ Géométrique } & oui & A1 \\
\hline & & & non & A2 \\
\hline & & \multirow{2}{*}{ Simple } & oui & A3 \\
\hline & & & non & A4 \\
\hline & \multirow{3}{*}{ Ruban vertical } & Géométrique & non & A5 \\
\hline & & Simnl & oui & A6 \\
\hline & & опाрте & non & A7 \\
\hline & \multirow{2}{*}{ Plage couvrante } & Géométrique & & A8 \\
\hline & & Simple & & A11 \\
\hline & $\begin{array}{l}\text { Rubans verticaux } \\
\text { et horizontaux }\end{array}$ & $\begin{array}{l}\text { Géométrique } \\
\text { Simple }\end{array}$ & & A9 \\
\hline & $\begin{array}{l}\text { Plage couvrante } \\
\text { et ruban horizontal }\end{array}$ & $\begin{array}{l}\text { Géométrique } \\
\text { Simple }\end{array}$ & & A10 \\
\hline \multirow{3}{*}{$\begin{array}{l}\text { B. Impressions } \\
\text { non orientables }\end{array}$} & Ruban horizontal & Simple & non & B1 \\
\hline & Ruban vertical & Simple & non & B2 \\
\hline & Plage couvrante & Simple & non & B3 \\
\hline \multirow{10}{*}{$\begin{array}{l}\text { C. Cannelures } \\
\text { Sillons } \\
\text { Incisions }\end{array}$} & \multirow{3}{*}{ Ruban horizontal } & Géométrique & non & $\mathrm{C} 1$ \\
\hline & & \multirow{2}{*}{ Simple } & oui & C2 \\
\hline & & & non & C3 \\
\hline & \multirow{2}{*}{ Ruban vertical } & \multirow{2}{*}{ Simple } & oui & $\mathrm{C} 4$ \\
\hline & & & non & C5 \\
\hline & \multirow{3}{*}{ Plage couvrante } & Géométrique & non & C6 \\
\hline & & Simple & oui & C7 \\
\hline & & & non & $\mathrm{C} 8$ \\
\hline & $\begin{array}{l}\text { Plage couvrante } \\
\text { et ruban horizontal }\end{array}$ & $\begin{array}{l}\text { Géométrique } \\
\text { Simple }\end{array}$ & & C9 \\
\hline & $\begin{array}{l}\text { Rubans verticaux } \\
\text { et horizontaux }\end{array}$ & $\begin{array}{l}\text { Géométrique } \\
\text { Simple }\end{array}$ & & C10 \\
\hline \multirow{4}{*}{$\begin{array}{l}\text { D. Ajout } \\
\text { plastique }\end{array}$} & Simple & & & D1 \\
\hline & Composé & & & D2 \\
\hline & Simple imprimé & & & D3 \\
\hline & Composé imprimé & & & D4 \\
\hline \multirow{4}{*}{$\begin{array}{l}\text { E. Mixtes } \\
\text { Poinçon/Cannelure }\end{array}$} & Ruban horizontal & & & E1 \\
\hline & Ruban vertical & & & E2 \\
\hline & Plage couvrante & & & E3 \\
\hline & Rubans verticaux et horizontaux & & & E4 \\
\hline Impressions et cordons & & & & E5 \\
\hline Cordons/Cannelures & & & & E6 \\
\hline
\end{tabular}

Tabl. I - Classement simplifié des principaux thèmes décoratifs du Néolithique ancien méridional.

Celle-ci a permis de distinguer plusieurs horizons au sein des stratigraphies de la grotte Gazel (Gazel A, Gazel B et Gazel C), de la grotte de Camprafaud (c. 19, c. 18-16) et de la cova del Frare (c. 6-5c, c. 5b).

Le traitement des données a été réalisé en deux temps. Nous arons d'abord choisi de baser notre analyse sur la stylistique décorative. En effet, les critères morphologiques ne sont guère pertinents en termes de varia- bilité. Le problème de la fragmentation des vases est en très grande partie responsable de ce fait. Notre étude étant ciblée sur la variabilité du système céramique, et ce en terme quantitatif, nous sommes obligée d'admettre que seule l'analyse du comportement de la décoration peut, à l'heure actuclle, nous renseigner sur la structure chronoculturelle du Néolithique ancien (Manen, à paraitre). Les thèmes décoratifs ont été analysés dans un 


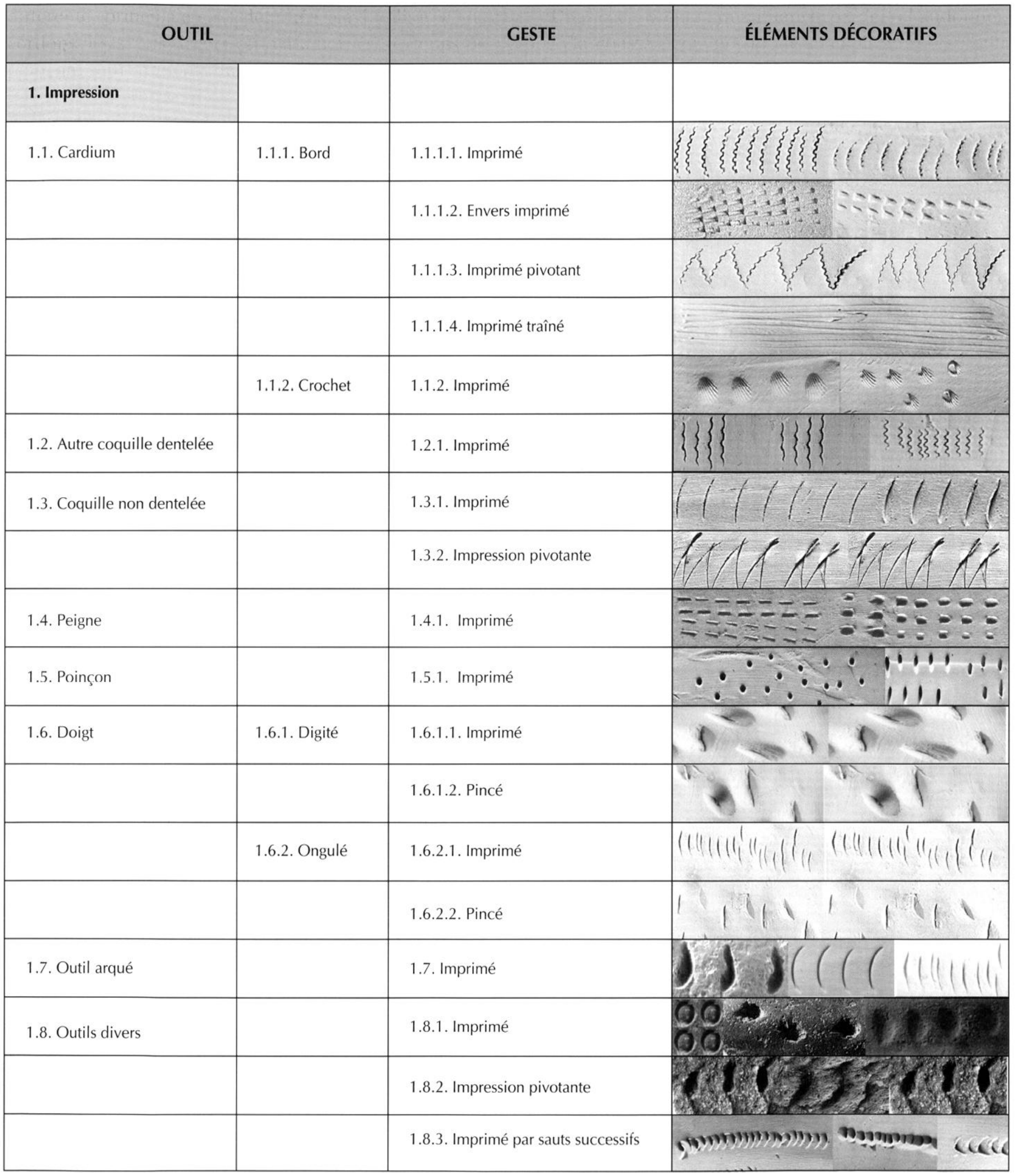

Fig. 3 - Classement simplifié des principales techniques décoratives du Néolithique ancien méridional. 


\begin{tabular}{|c|c|c|c|}
\hline \multicolumn{2}{|c|}{ OUTIL } & GESTE & ÉLÉMENTS DÉCORATIFS \\
\hline \multirow[t]{5}{*}{ 2. Incision / Cannelure } & 2.1. Pointe mousse & 2.1.1. Trâné court & \\
\hline & \multirow[b]{2}{*}{ 2.2. Pointe aiguë } & 2.1.2. Traîné long & $\longrightarrow$ \\
\hline & & 2.2.1. Traîné court & 4 \\
\hline & & 2.2.2. Traîné long & $\bar{L}$ \\
\hline & & 2.2.3. Traîné courbe & (), $, 2,2, \geqslant)$ \\
\hline 3. Gravure & & 3.1. Traîné & \\
\hline 4. Argile modelée & & 4.1. Pastille & ( \\
\hline & & 4.2. Cordon & 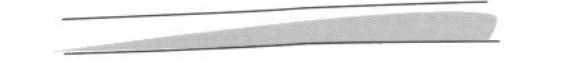 \\
\hline & & 4.3. Crête & 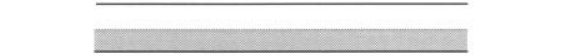 \\
\hline & & 4.4. Ajouts divers & \\
\hline 5. Décor coloré & & 5.1. Ocre & \\
\hline & & 5.2. Peinture & \\
\hline & & 5.3. Incrustation & \\
\hline
\end{tabular}

Fig. 3 - Classement simplijéé des principales techniques décoratives du Néolithique ancien méridional (suite).

second temps car ils n'ont pu être quantifiés de la même manière que les techniques et nécessitent une approche statistique différente.

Les caractéristiques des assemblages de tradition cardiale et épicardiale ont été confrontées par le biais de l'analyse factorielle des correspondances (tabl. II et fig. 4). Les deux sites de Peiro Signado et Pont de RoqueHaute ont été traités séparément dans la mesure où ils font directement appel au domaine italien ${ }^{2}$ (Manen, 2000a et p. 150-154).

2. Une première analyse factoriclle des correspondances regroupant les assemblages de tradition cardiale, épicardiale et d'obédience italienne
L'AFC effectuée indique une inertie de $67 \%$ sur les 2 premiers axes ( $48 \%$ pour l'axe 1 et $19 \%$ pour l'axe 2 ). Le premier axe est construit par l'opposition cardium/poinçon + cannclure. Les meilleures contributions absolues concernent, sur la gauche, le cardium, et sur la droite, la cannelure et, dans une moindre mesure, le poinçon. L'axe 1 permet donc d'établir une coupure significative entre ce que l'on nomme traditionnellement, dans la zone étudiée, Cardial et Épicardial. À

a été effectuée. Cependant le résultat de celle-ci proposait une image peu nuancée opposant le Cardial et l'F́picardial aux sites de Peiro Signado et de Pont de Roque-Haute. 


\begin{tabular}{|c|c|c|c|c|c|c|c|c|c|}
\hline & Cardium & Peigne & Poinçon & Doigt & Imp. diverses & Cannelure & Incision & Cordon imp. & Cordon lisse \\
\hline Gazel B & 11 & 8 & 32 & 1 & 3 & 43 & 27 & 4 & 22 \\
\hline Gazel C & 0 & 0 & 46 & 3 & 0 & 32 & 12 & 2 & 2 \\
\hline Oullins c.6 & 333 & 0 & 2 & 98 & 39 & 14 & 4 & 121 & 21 \\
\hline Bourbon & 3 & 8 & 9 & 12 & 0 & 39 & 1 & 11 & 49 \\
\hline Fage II & 0 & 0 & 30 & 0 & 0 & 22 & 0 & 0 & 2 \\
\hline Camprafaud c.19 & 7 & 0 & 9 & 3 & 5 & 13 & 1 & 1 & 15 \\
\hline Camprafaud c.18-16 & 0 & 0 & 10 & 3 & 0 & 35 & 4 & 0 & 8 \\
\hline La Draga & 18 & 18 & 1 & 0 & 8 & 0 & 1 & 3 & 22 \\
\hline Plansallosa I & 8 & 2 & 5 & 27 & 10 & 5 & 0 & 2 & 39 \\
\hline Puig Mascaró & 0 & 5 & 4 & 13 & 1 & 29 & 0 & 5 & 8 \\
\hline Reclau Viver & 1 & 8 & 0 & 5 & 1 & 4 & 0 & 20 & 12 \\
\hline Frare c.5b & 0 & 0 & 42 & 1 & 7 & 195 & 35 & 0 & 18 \\
\hline Frare c. $6-5 \mathrm{c}$ & 54 & 4 & 0 & 0 & 1 & 0 & 0 & 2 & 0 \\
\hline Pany & 82 & 0 & 3 & 0 & 0 & 3 & 0 & 32 & 2 \\
\hline Vilobi & 139 & 0 & 1 & 0 & 0 & 1 & 0 & 16 & 0 \\
\hline Font Major & 28 & 31 & 1 & 0 & 0 & 4 & 1 & 11 & 0 \\
\hline Lombard & 75 & 0 & 5 & 1 & 3 & 0 & 23 & 2 & 9 \\
\hline Fontbrégoua c.47-46 & 64 & 0 & 0 & 6 & 8 & 8 & 0 & 7 & 7 \\
\hline La Tardive & 12 & 0 & 0 & 6 & 5 & 0 & 0 & 15 & 15 \\
\hline
\end{tabular}

Tabl. II - Distribution en fréquence des techniques décoratives de chaque assemblage céramique analysé.

gauche, se rassemblent les sites d'ambiance cardiale (Vilobi, Pany, Frare c. 6-c. 5c, Fontbrégoua c. 47-46, Oullins c. 6), parmi lesquels Oullins c. 6 montre la meilleure contribution absoluc. Leur céramique est riche en décoration effectuée à la coquille mais également en décor de cordon imprimé. À droite, ce sont les sites dont les décors sont dominés par la cannclure, le poinçon et l'incision qui se regroupent (Gazel (C, Fage II, Frare c. 5b, Camprafaud c. 18-16). Les contributions relatives montrent une forte participation de la variable Frare c. 5b, mais également de (razel (.)

En parallèle de ces deux ensembles bien individualisés et opposés, la projection des assemblages sur l'axe 1 fait apparaître deux autres associations intermédiaires. Il s'agit, d'une part, du groupe formé par la Font Major, Reclau Viver, Plansallosa I, La Draga et La Tardive et, d'autre part, du groupe formé par Bourbon, Puig Mascaró, Camprafaud c. 19 et Gazel B. Le premier n'est pas nettement séparé de "l'ensemble cardial". Nous verrons que ce groupe prend cependant toute sa cohérence sur l'axe 2. La seconde association se rapproche davantage de "l'ensemble épicardial ", tout en s'en distinguant clairement, si l'on excepte Gazel B.

Pour résumer, la projection sur l'axe 1 montre quatre groupes plus ou moins bien individualisés les uns des autres. L'assemblage de la grotte Lombard n'est pas clairement rattaché à l'un de ces quatre groupes. En projection sur l'axe 1, il semble davantage lié au groupe formé par la Font Major, Reclau Viver, Plansallosa I, La Draga et La Tardive. La valeur chronologique de l'axe 1 semble envisageable. Ia projection des individus sur cet axe respecte parfaitement l'évolution stratigraphique de plusieurs siles: (Gazel B-C, Frare c. 6-c. 5, Camprafaud c. 19-c. 18-16. On retrouve de plus l'opposition Cardial/Épicardial, généralement considérée comme le résultat d'une séquence évolutive plus ou moins complexe (Guilaine, 1986; Manen, à paraître).

Pour l'axe 2, les contributions relatives montrent une forte participation des critères peigne et cordon lisse dans la construction de celui-ci, et une participation plus faible du rardium qui leur est opposé. Les contributions des individus sur l'axe 2 sont réparties entre les assemblages de la Font Major, de Plansallosa I et de Bourbon. 
Profils lignes et profils colonnes sur axe 1 et $2(67 \%)$
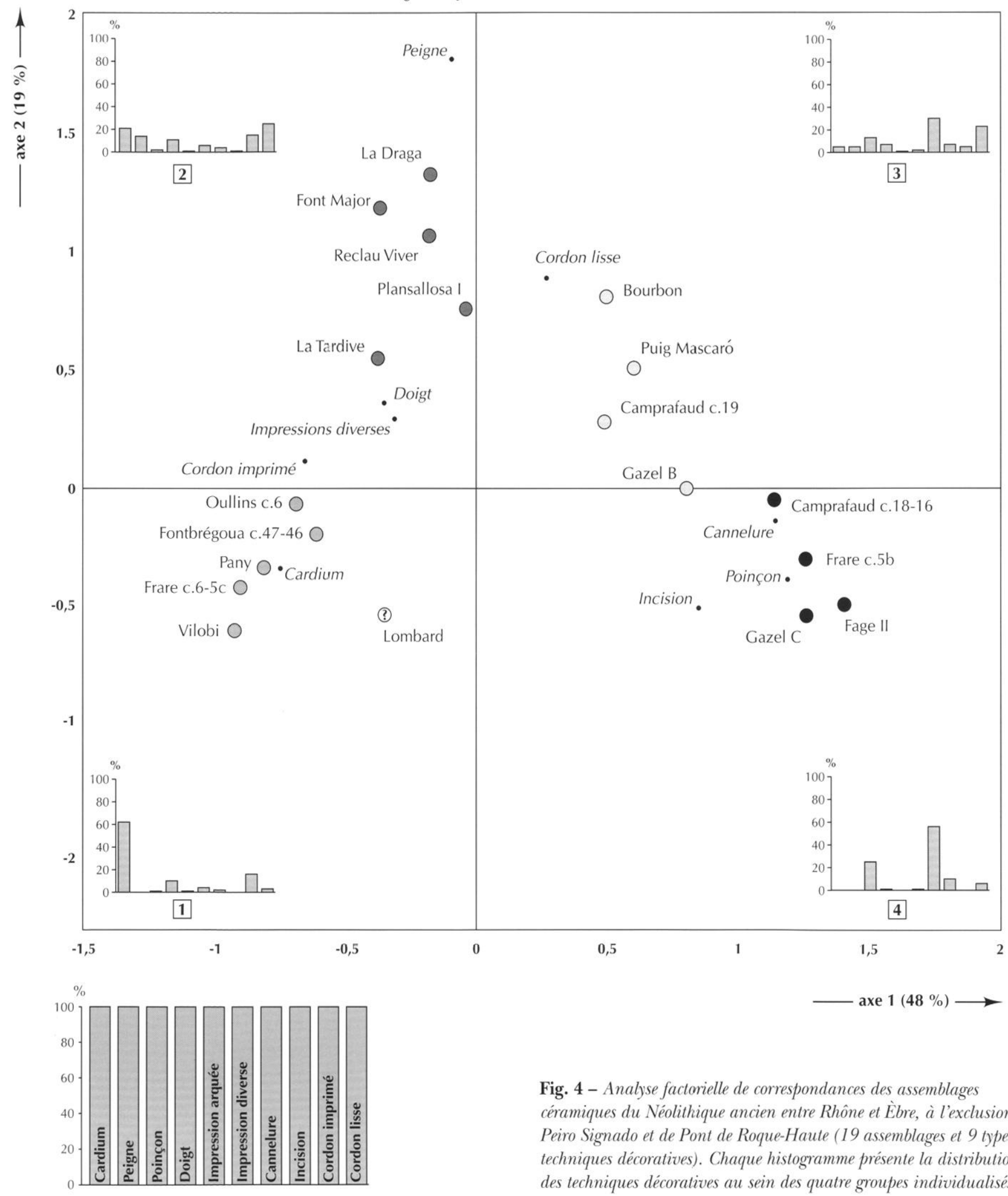

Fig. 4 - Analyse factorielle de correspondances des assemblages céramiques du Néolithique ancien entre Rhône et Èbre, à l'exclusion de Peiro Signado et de Pont de Roque-Haute (19 assemblages et 9 types de techniques décoratives). Chaque histogramme présente la distribution des techniques décoratives au sein des quatre groupes individualisés. 


\begin{tabular}{|c|c|c|}
\hline Groupe stylistique & Sites & Caractéristiques \\
\hline Groupe 1 & $\begin{array}{l}\text { Vilobi } \\
\text { Pany } \\
\text { Oullins c.6 } \\
\text { Fontbrégoua c.47-46 } \\
\text { Frare c.6-5c }\end{array}$ & $\begin{array}{l}\text { Cardium } \\
\text { Cordon imprimé } \\
\text { Impressions diverses }\end{array}$ \\
\hline & Grotte Lombard & \\
\hline Groupe 2 & $\begin{array}{l}\text { Font Major } \\
\text { La Tardive } \\
\text { La Draga } \\
\text { Reclau Viver } \\
\text { Plansallosa I }\end{array}$ & $\begin{array}{l}\text { Peigne } \\
\text { Doigt } \\
\text { Pastille } \\
\text { Cordon lisse }\end{array}$ \\
\hline Groupe 3 & $\begin{array}{l}\text { Bourbon } \\
\text { Puig Mascaró } \\
\text { Camprafaud c.19 } \\
\text { Gazel B }\end{array}$ & $\begin{array}{l}\text { Cordon lisse } \\
\text { Cannelure } \\
\text { Poinçon } \\
\text { Rares impressions }\end{array}$ \\
\hline Groupe 4 & $\begin{array}{l}\text { Camprafaud c.18-16 } \\
\text { Gazel C } \\
\text { Frare c.5b } \\
\text { Fage II }\end{array}$ & $\begin{array}{l}\text { Cannelure } \\
\text { Poinçon } \\
\text { Incision }\end{array}$ \\
\hline
\end{tabular}

Tabl. III - Proposition de regroupement des assemblages céramiques étudiés d'après les résullats de l'analyse factorielle.

Si la valeur de l'axe 1 est peu ambiguë, celle de l'axe 2 reste plus difficile à interpréter. La lecture de la projection des variables sur cet axe confirme l'individualisation du groupe Tardive, Draga, Reclau Viver et Plansallosa I par rapport à « l'ensemble cardial ». Ces sites sont généralement interprétés comme appartenant à un Cardial récent ou final (Bosch i Lloret, 1994 ; Beeching, 1995). L'axe 2 pourrait donc également posséder une valeur chronologique, montrant une distinction entre les sites du Cardial ancien et du Cardial final. En projection sur l'axe 1, ces sites sont d'ailleurs légèrement décentrés par rapport à «l'ensemble cardial ancien ». La céramique de ces assemblages est caractérisće par une décoration effectuée au peigne, au doigt ou selon diverses matrices et par des cordons lisses. Le décor au cardium ainsi que le cordon imprimé sont, bien que de façon minoritaire, présents.

Un même type d'observation pourrait être effectué en ce qui concerne les assemblages situés sur la droite de l'axe 1 . On observe en effet un détachement des assemblages de Gazel B, Camprafaud c. 19, Puig Mascaró et Bourbon sur l'axe 1. Ils sont caractérisés par une décoration à base de cordons lisses, et de cannelures, mais également, de manière moins importante, d'impressions de divers types. C'est ainsi que ce groupe tend vers «l'ensemble épicardial " si l'on observe la projection sur l'axe 1 . On notera que l'assemblage de Gazel B est décalé vers le bas en raison de sa forte liaison avec la variable incision. Il en est de même pour l'assemblage de la grotte Lombard.

Nous serions donc en présence, d'après l'analyse des techniques décoratives, de quatre groupes stylistiques ordonnés dans le tableau III.

Comme nous l'avons signalé au début de cette partie, les thèmes décoratifs n'ont pu faire l'objet d'une quantification et n'ont ainsi pu être traités selon la même méthode que les techniques décoratives. En effet, en accord avec la méthode de classement choisie, il nous était indispensable de raisonner à partir de thèmes décoratifs quasi complets. Or, ces derniers sont numériquement peu nombreux et le tableau d'effectifs obtenu pour chaque assemblage n'était pas utilisable. Nous avons donc choisi de le transformer en matrice de présence/absence et de le traiter par le biais de la sériation automatique (fig. 5). On retrouve ici le découpage proposé précédemment pour les groupes 3 et 4. Notons également que (iazel B et Gazel C sont clairement séparés. Cette sériation permet donc de confirmer la distinction entre les groupes stylistiques 3 et 4. Le groupe 3 est caractérisé par des décors asse\% variés réalisés à base de cannelures et de cordons lisses mais également, dans une moindre mesure, à l'aide de divers types d'impressions. Parmi les thèmes décoratifs, on trouve principalement les cannelures verticales organisées en ruban margé (C2) et les cannelures verticales ou horizontales rassemblées en un ruban non margé (C3). Les cannelures peuvent également former des thèmes géométriques (Cl). Le décor plastique concerne principalement le cordon lisse, utilisé de manière composée (D2) ou simple (D1) : pastilles et cordons, cordons perpendiculaires. Certains thèmes mêlant cannelures et cordons sont présents (E6). Parmi les techniques imprimées, on retrouve des thèmes en échelle: ruban vertical margé ou non (A6) et les lignes simples d'impressions (A4). Le groupe 4 est caractérisé par une restriction des techniques et des thèmes décoratifs. Le thème le plus utilisé est celui de cannelures bordées de coups de poinçon (E1, E2). De même, les plages couvrantes remplies de coups de poinçon (B3) sont très fréquentes. I.e décor de cannelure forme également des thèmes en ruban étroit margé ou non (C2 et C3). 


\begin{tabular}{|c|c|c|c|c|c|c|c|c|c|c|c|c|c|c|c|c|c|c|c|c|c|c|c|c|}
\hline & & E4 & B3 & E2 & E1 & C1 & C3 & E6 & C2 & C 8 & B1 & D1 & D2 & A6 & A4 & A11 & A2 & A3 & A7 & A9 & D3 & D4 & E5 & A1 \\
\hline 4 & $\begin{array}{l}\text { Gazel C } \\
\text { Fage II } \\
\text { Frare c.5b } \\
\text { Camprafaud c.18-16 }\end{array}$ & $\begin{array}{l}\bullet \\
\bullet\end{array}$ & $\begin{array}{l}\bullet \\
\bullet \\
\bullet \\
\bullet\end{array}$ & $\begin{array}{l}\bullet \\
\bullet \\
\bullet\end{array}$ & $\begin{array}{l}\bullet \\
\bullet\end{array}$ & $\bullet$ & $\begin{array}{l}\bullet \\
\bullet\end{array}$ & $\bullet$ & $\begin{array}{l}\bullet \\
\bullet\end{array}$ & $\bullet$ & $\bullet$ & & & & & & & & & & & & & \\
\hline 3 & $\begin{array}{l}\text { Camprafaud c.19 } \\
\text { Gazel B } \\
\text { Bourbon } \\
\text { Puig Mascaró }\end{array}$ & $\bullet$ & $\begin{array}{l}\bullet \\
\bullet\end{array}$ & $\begin{array}{l}\bullet \\
\bullet\end{array}$ & $\bullet$ & $\bullet$ & • & $\begin{array}{l}\bullet \\
\bullet\end{array}$ & $\begin{array}{l}\bullet \\
\bullet \\
\bullet\end{array}$ & & $\bullet$ & $\bullet$ & $\begin{array}{l}\bullet \\
\bullet \\
\bullet\end{array}$ & $\begin{array}{l}\bullet \\
\bullet\end{array}$ & $\begin{array}{l}\bullet \\
\bullet \\
\bullet\end{array}$ & & & • & & $\bullet$ & $\begin{array}{l}\bullet \\
\bullet\end{array}$ & $\bullet$ & & \\
\hline $\begin{array}{l}2 \\
\text { et } \\
1\end{array}$ & $\begin{array}{l}\text { Lombard } \\
\text { Oullins c.6 } \\
\text { Fontbrégoua c.47-46 } \\
\text { Reclau Viver } \\
\text { La Draga } \\
\text { Vilobi } \\
\text { Font Major } \\
\text { La Tardive } \\
\text { Pany } \\
\text { Frare c.6-5c }\end{array}$ & & & & & & & & $\begin{array}{l}\bullet \\
\bullet\end{array}$ & $\begin{array}{l}\bullet \\
\bullet\end{array}$ & $\begin{array}{l}\bullet \\
\bullet \\
\bullet\end{array}$ & $\bullet$ & $\begin{array}{l}\bullet \\
\bullet \\
\bullet \\
\bullet \\
\bullet \\
\bullet\end{array}$ & $\begin{array}{l}\bullet \\
\bullet \\
\bullet \\
\bullet\end{array}$ & $\begin{array}{l}\bullet \\
\bullet \\
\bullet \\
\bullet \\
\bullet \\
\bullet\end{array}$ & $\begin{array}{l}\bullet \\
\bullet \\
\bullet\end{array}$ & • & $\begin{array}{l}\bullet \\
\bullet \\
\bullet \\
\bullet \\
\bullet \\
\bullet \\
\bullet\end{array}$ & $\bullet$ & • & $\begin{array}{l}\bullet \\
\bullet \\
\bullet \\
\bullet \\
\bullet \\
\bullet \\
\bullet \\
\bullet \\
\bullet\end{array}$ & $\begin{array}{l}\bullet \\
\bullet \\
\bullet\end{array}$ & $\begin{array}{l}\bullet \\
\bullet \\
\bullet \\
\bullet \\
\bullet \\
\bullet\end{array}$ & $\begin{array}{l}\bullet \\
\bullet \\
\bullet \\
\bullet\end{array}$ \\
\hline
\end{tabular}

Fig. 5 - Sérialion en présence/absence des thèmes décoratifs du Néolithique ancien entre Rhône et Ėbre (à l'exclusion de Peiro Signado et de Pont de Roque-Haute).

La situation est en revanche moins nette dès lors que l'on observe la position de nos groupes 1 et 2. En effet, alors que l'analyse factorielle des techniques décoratives montrait une nette séparation (en projection sur l'axe 2) de ces groupes (cardium et cordon imprimé d'un côté/peigne, impressions diverses et cordon lisse de l'autre), la sériation des thèmes décoratifs ne propose pas la même image. On peut ainsi penser qu'en ce qui concerne les sites de " tradition cardiale ", c'est l'analyse des techniques décoratives qui s'avère pertinente en termes de sériation. Au contraire, pour les assemblages de "tradition épicardiale ", c'est la sériation des thèmes décoratifs qui permet de préciser les observations de l'analyse factorielle.

Il semblc donc indispensable, à l'avenir, de pouvoir traiter de concert, et selon une approche quantitative, les techniques et les thèmes décoratifs. Ce travail est en cours.

Nous ne proposerons pas un développement particulier des résultats obtenus par la confrontation des deux sous-systèmes céramiques des sites de Peiro Signado et de Pont de Roque-Haute, ceux-ci ayant déjà été publiés (Manen, 2000a). On rappellera que le système technique de ces sites, en rupture avec le Cardial ou l'Épicardial, renvoie directement et dans son intégralité au domaine italien. Cependant, les deux assemblages céramiques offrent des caractéristiques stylistiques bien différentes qui nous ont conduite à distinguer ces deux sites d'un point de vue culturel (Manen, 2000b et cf. p. 150-154).

\section{STRUCTURES ET IDENTITÉS DES STYLES CÉRAMIQUES}

Sur la base des résultats précédents, et après croisement avec les données radiocarbones, il nous a été possible de définir six principaux styles céramiques bien distincts (Manen, 2000b). Ceux-ci coexistent ou se succèdent entre 5750 et 4500 avant J.-C. en Languedoc et en Catalogne. La figure 6 présente notre hypothèse chronoculturelle, structurée en trois grandes phases. La figure 7 confirme la réalité chronologique de ces trois phases. Chacun des histogrammes ${ }^{3}$ a été construit en

3. La réalisation d'histogrammes correspond à " une manipulation synthétique d'un ensemble de dates considérées comme aỵant la même signification (une culture par exemple), obtenuc par addition du nombre de dates selon des plages de temps déterminées, le plus souvent en classes de 50 ou 100 ans " (Voruz, 1995, p. 13). Afin de pallier la surreprésentation des dates imprécises, les histogrammes ont été graphiquement pondérés. L'axe du temps étant figuré à l'horizon- 


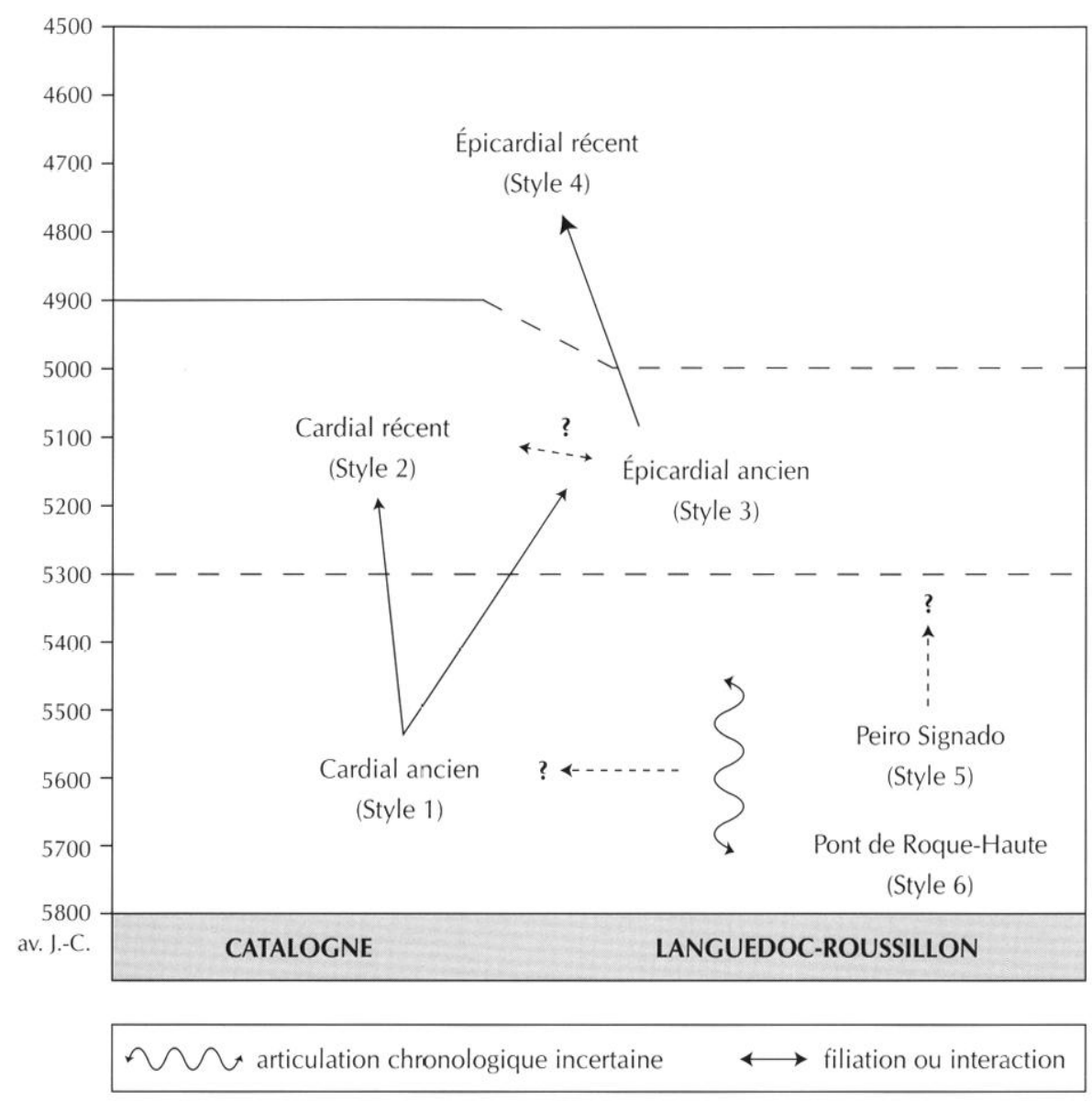

Fig. 6 - Hypothèse chronoculturelle du déoloppement du Néolithique ancien entre Rhône et Èbre. cumulant les datations des styles céramiques contemporains. L'histogramme de la phase 1 est construit à partir des datations du Cardial ancien, de Pont de Roque-Haute et de Peiro Signado. L'histogramme de la phase 2 est construit à partir des datations du Cardial récent et de l'Épicardial ancien. Enfin, l'histogramme de la phase 3 est construit à partir des datations de l'Épicardial récent.

Avant de développer le schéma chronoculturel envisagé pour le développement du Néolithique ancien entre le Rhône et l'Èbre (fig. 6), nous souhaitons revenir sur chacun des styles individualisés. Les caractéristiques

tale, chaque datation se trouve représentée par un rectangle d'égale surface, dont la hauteur est inversement proportionnclle à l'amplitude de la fourchette de calibration, qui domne la base du rectangle. I.es classes de durée sont ramenées à cinq ans (Sabatier, 1997). (ee sont les fourchettes de calibration à I sigma qui ont été retenues, cette prise en compte des résultats semblant adéquate dès lors que l'on tavaille sur des séries (Manen, Sabatier, à paraitre). Les donnćes chronologiques (corpus, critique du catalogue, etc.) utilisées dans cet article font référence à un travail à paraître (Manen, Sabaticr, à paraitre). présentées doivent, comme les indications en pourcentage, être prises en termes de tendances.

\section{STYLE 1 OU CARDIAL ANCIEN}

Les sites languedociens et catalans ayant livré un assemblage céramique que l'on peut rattacher à ce style sont les suivants :

- grotte de L'Aigle, couche `s (Méjannes-le-Clap, (arard), Roudil et al., 1979;

- baume d'Oullins, couche 6 (Le Garn, Gard), Roudil, 1987 ;

- grotte Gazel, phase A (Sallèles-Cabardès, Aude), Guilaine, 1970, 1986 ;

- station de La Corrège (Leucate, Aude), Guilaine et al., 1984 ;

- cova del Frare, couches 6 et 5c (Matadepera, Barcelona), Martín el al., 1981, 1985;

- cova del Toll (Moiá, Barcelona), Guilaine, 1986 ; 


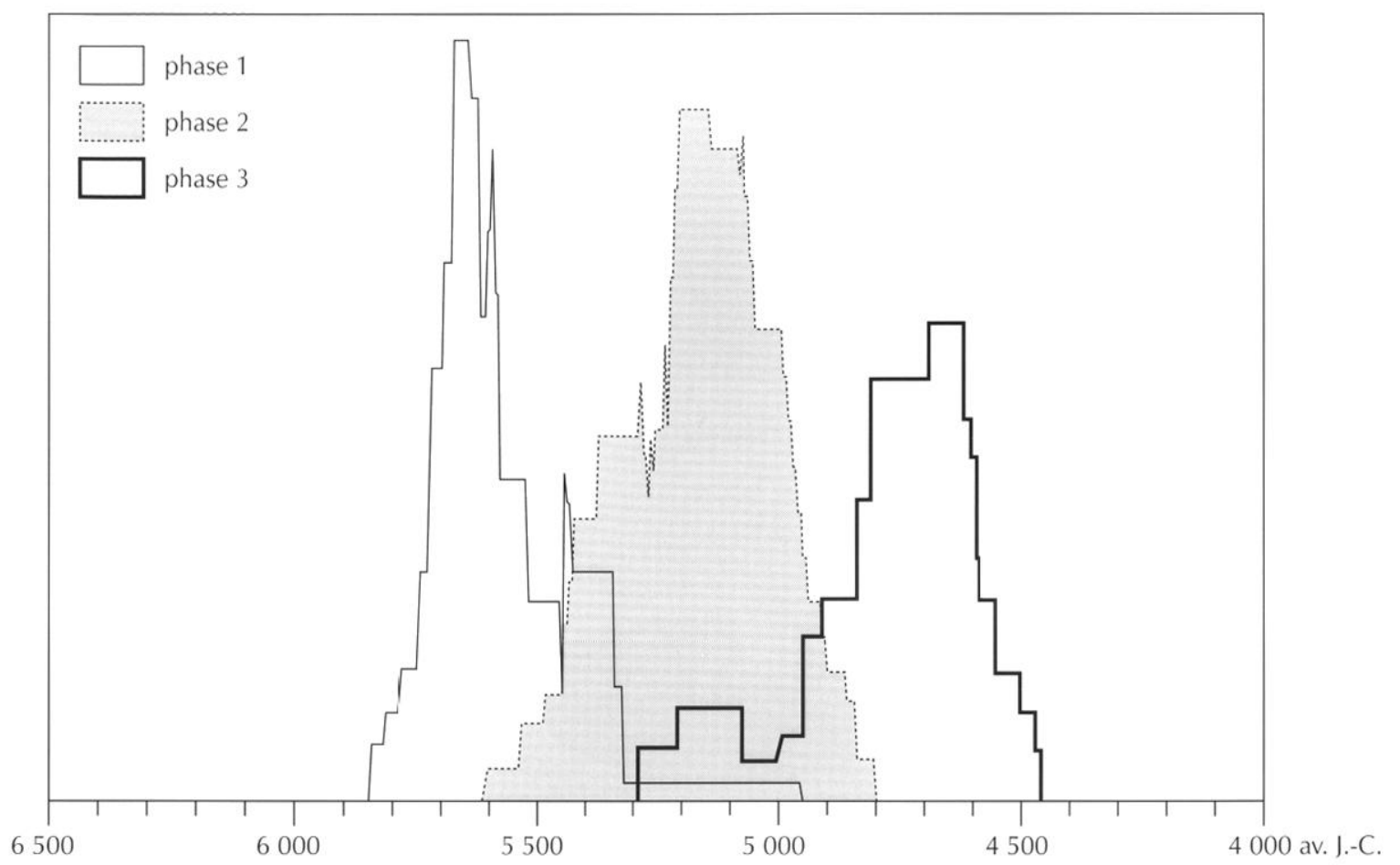

Fig. 7 - Histogrammes cumulés pondérés des datations des trois phases chronoculturelles du Néolithique ancien entre Rhône el litre.

- cova Gran, cova Freda et cova Bonica (Collbató, Barcelona), Colomines, 1925 ; Baldellou et al., 1989;

- Les Guixeres de Vilobi (Sant Martí Sarroca, Barcelona), Baldellou, Mestres, 1981 ;

- Esquerda de les Roques del Pany (Torrelles de Foix, Barcelona), Baldellou et al., 1989 ;

- cueva de Chaves, niveau lb (Bastarás, Huesca), Baldellou, Utrilla 1999.

Les données de la chronologie absolue placent ce style entre $5700 / 5600$ et 5300 avant J.-C.

Nous avons ajouté, en Catalogne, les assemblages livrés par les grottes de la région de Montserrat (cova Gran, cova Freda, cova Bonica...). Ces sites, dont les données céramiques sont inutilisables statistiquement en raison de l'absence totale de repères stratigraphiques, offrent cependant un matériel très abondant. On peut notamment y reconnaître les décorations typiques du Cardial ancien, d'ailleurs proches du point de vue de leur exubérance de celles du Pays valencien. Le cardium, majoritaire, est utilisé de diverses manières: bord, crochet, envers du bord, fragment de coquille, etc. Beaucoup d'autres sites sont attribués au Cardial en Catalogne (Martín Colliga, 1992). Cependant, l'absence de contexte stratigraphique et/ou la faiblesse numérique des échantillons ne permettent pas de préciser cette attribution culturelle (Cardial ancien ou récent).

Les formes céramiques du Cardial ancien appartiennent aux divers types des classes petites et moyennes: jattes, marmites, bouteilles, bols et petits pots globuleux. Les fragments de vases de stockage sont rares. Les lèvres sont très majoritairement arrondies $(60 \%)$ mais les lèvres amincies sont également bien représentées $(30 \%)$.

Parmi les grandes catégories de décors (fig. 8), c'est l'impression qui domine largement $(78 \%)$ suivic du décor plastique $(20 \%)$. On trouve très ponctuellement quelques incisions ou cannelures $(2 \%)$.

Parmi les impressions, le cardium constitue la technique décorative dominante (plus de $60 \%$ ). Différentes modalités d'utilisation de la coquille peuvent être distinguées. On remarquera en premier lieu que l'impression du bord perpendiculairement à la pâte (fig. 3, 1.1.1.1) est rare, fait tranchant avec ce que l'on peut observer dans les faciès italiens. Ici, c'est l'impression de l'envers de la coquille, obliquement par rapport à la pâte, (fig. 3, 1.1.1.2) qui domine (plus de $50 \%$ ), et ce, plus on s'approche de la sphère catalane. Les impressions pirotantes du bord de la coquille (fig. 3, 1.1.1.3) 


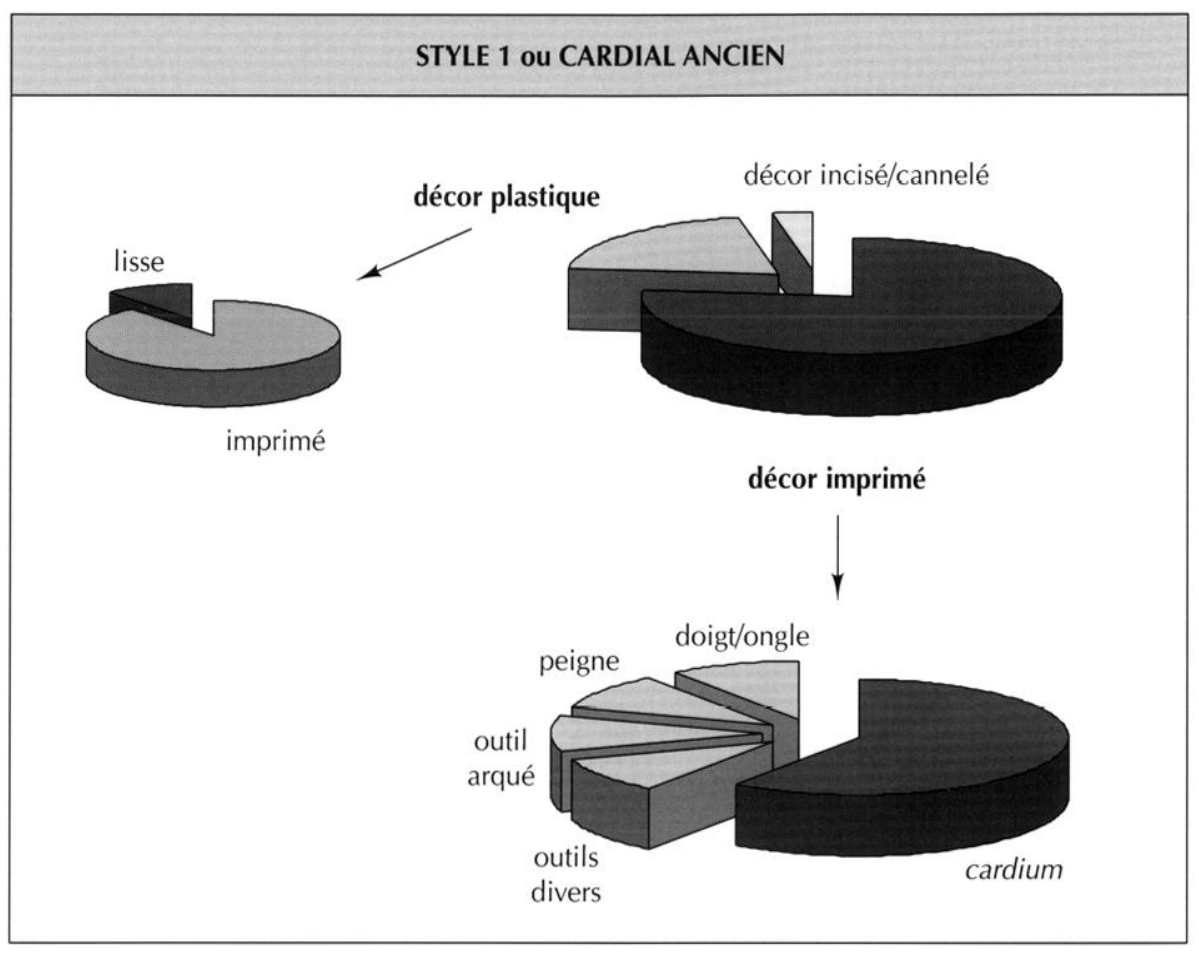

Fig. 8 - Les techniques décoratives $d u$ Cardial ancien. sont rares. Les impressions traînées (fig. 3, 1.1.1.4) sont bien représentées, notamment dans les assemblages catalans (environ $10 \%$ ). Il en est de même pour l'utilisation du crochet de la coquille (fig. 3, 1.1.2).

Ces différences, qui pourraient correspondre à certains faciès régionaux d'un même style, sont encore difficiles à systématiser étant donné le peu de sites répertoriés. La décoration de la céramique de Leucate, riche en impressions traînées et en impression du crochet, semble d'ailleurs plus proche des sites catalans (Les Guixeres de Vilobi ou Esquerda de les Roques del Pany) que de ceux du Languedoc oriental (Aigle c. 5 ou Oullins c. 6). Ces derniers se rapportent davantage à la sphère rhodano-provençale. On ne doit cependant pas conclure trop rapidement en faveur d'une frontière culturelle séparant la zone Provence-Languedoc oriental de la zone Languedoc occidental-Catalogne. Les grottes de la région de Montserrat présentent en effet des céramiques dont les thèmes décoratifs sont souvent proches de ceux rencontrés en Provence, tout en gardant une certaine individualité notamment en ce qui concerne l'utilisation du crochet et la profusion des motifs décoratifs. De même, l'utilisation de l'impression tangentielle de la coquille de cardium constitue une composante importante de la stylistique décorative du site des Petites Bâties à Lamotte-du-Rhône, Vaucluse (Binder et al., 2002). La question de l'existence de faciès stylistiques géographiques reste à approfondir.

C'est donc au travers de la forte utilisation de la coquille de cardium que se caractérise le style céramique du Cardial ancicn. On nc doit cependant pas ignorer les autres techniques imprimées présentes en proportions diverses. Ces impressions sont réalisées à l'aide d'outils variés, parfois non identifiables. On trouve par exemple le doigt, l'ongle, le peigne, l'outil arqué, etc. L'assemblage de la baume d'Oullins c. 6 présente une diversité remarquable par rapport aux autres gisements. Celle-ci est peut-être due à l'éloignement de ce site du littoral, engendrant la nécessité de pallier le manque de coquille. Nous avons pu observer cette même diversité (profusion dans la variété des techniques imprimées) sur le site de la cueva de Chaves, en Aragon, également éloigné de la côte méditerranéenne.

Le décor plastique est fréquemment utilisé. Dans la majorité des cas, il est représenté par les cordons imprimés (89\%). Ces derniers sont imprimés à l'aide de divers outils (coquille, doigt, etc.) sans préférence particulière. Il semble exister un lien particulier unissant les vases de grande taille au décor de cordon. Ce lien semble persister au cours du temps, ce qui peut être expliqué par un système d'évolution plus lent des grands vases par rapport aux petits (Bosch et al., 1998). 


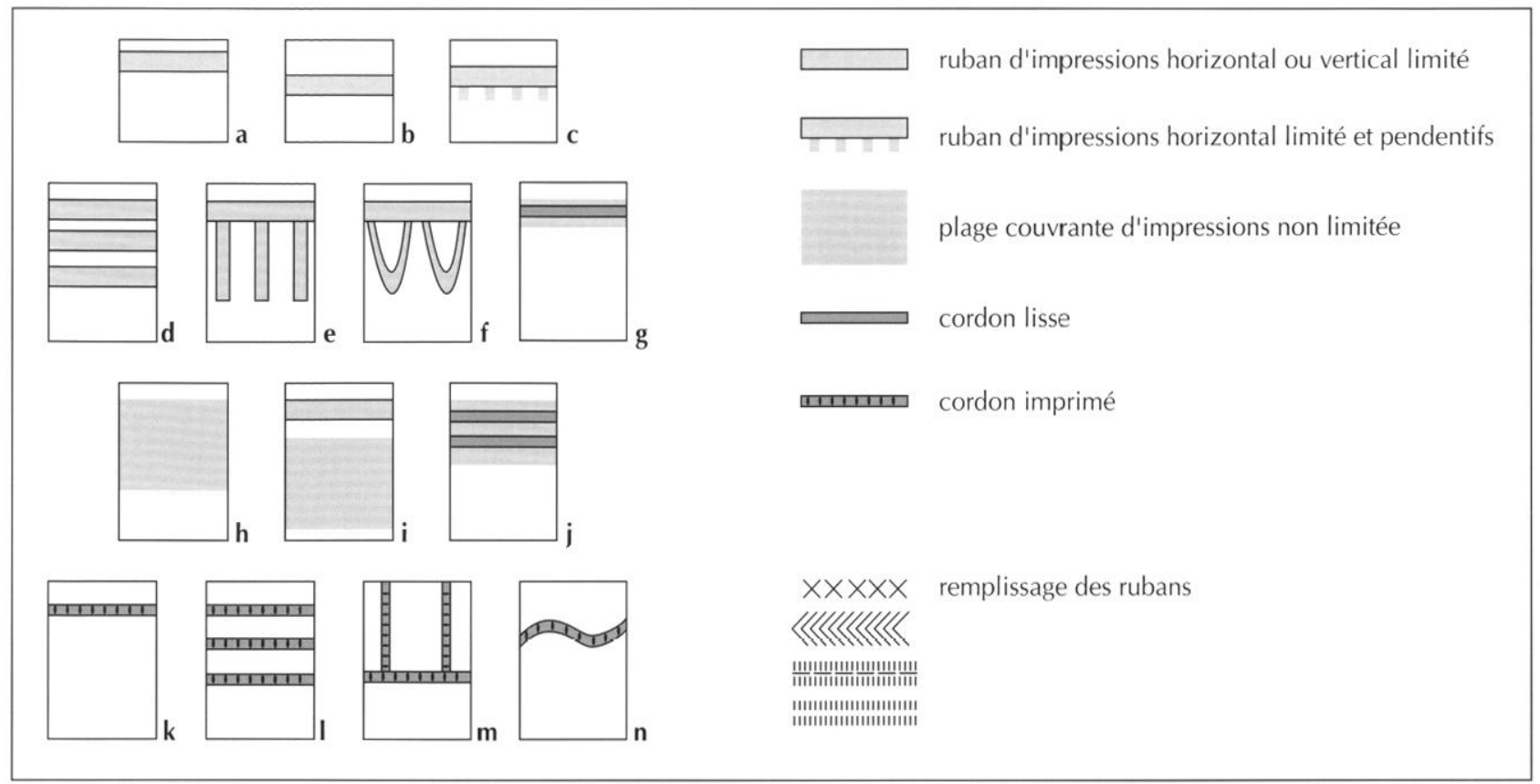

Fig. 9 - Schématisation des principaux thèmes décoratifs du Cardial ancien.

Les thèmes décoratifs du Cardial ancien sont schématisés sur la figure 9 et représentés sur les figures 10 et 11 . Ils sont formés par divers types d'impressions organisées en ruban horizontal (fig. 9 a, b, c). Sur les vases de taille moyenne, ce ruban est répété une ou plusieurs fois (fig. 9 d). Ces rubans horizontaux sont fréquemment remplis de motifs géométriques (croisillons, zigrags, chevrons, traits obliques...) et limités ou interrompus par un encadrement. Plus rarement, les rubans sont accompagnés de pendentifs (fig. $9 \mathrm{c}$ ). Les rubans horizontaux peuvent également être remplis de simples lignes d'impressions de types variés. Les rubans verticaux et les plages couvrantes sont également utilisés mais de manière très minoritaire (fig. $9 \mathrm{~h}, \mathrm{i}$ ). Les plages couvrantes sont généralement remplies d'impressions au cardium très serrées. Les rubans verticaux, sc répćtant autour du vase, sont remplis de motifs géométriques et sont généralement margés. On compte également quelques thèmes constitués de rubans verticaux et horizontaux (fig. $9 \mathrm{e}, \mathrm{f}$ ).

Les décors plastiques (cordons imprimés essentiellement) forment des thèmes souvent simples : cordon horizontal ceinturant le vase et se répétant parallèlement de haut en bas (fig. $9 \mathrm{k}, \mathrm{l}$ ). I es cordons font parfois partie intégrante d'un ruban d'impressions (fig. $9 \mathrm{~g}$, j). Ils peuvent alors servir d'éléments d'encadrement ou d'in- terruption. Les thèmes composés (cordons perpendiculaires, guirlandes) sont plus rares (fig. $9 \mathrm{~m}, \mathrm{n}$ ).

\section{STYLE 2 OU CARDIAL RÉCENT}

Les sites ayant livré un assemblage céramique que l'on peut rattacher à ce style sont les suivants :

- abri de La Tardive (Berrias-et-Casteljau, Ardèche), Roudil et al., 1991 ;

- grotte de Saint-Marcel (Bidon, Ardèche), Gilles, 1988 ;

- La Resclauze (Cabian, Hérault), Mailhe, 1979 ;

- La Draga (Banyoles, Gerona), Bosch i L.loret et al., 2000 ;

- Reclau Viver (Serinyà, Gerona), Bosch i Lloret, 1991;

- Plansallosa I (Tortellà, Gerona), Bosch et al., 1998 ;

- cova de la Font Major (Conca de Barberá, Tarragona), Miró, 1995 ;

- cova del Vidre (Roquetes, Tarragona), Bosch i Argilagós, 1993 ;

- cueva de Chaves, niveau la (Bastarás, Huesca), Baldellou, Utrilla, 1999.

Les données de la chronologie absolue placent ce style entre 5300 et $4900-4800$ avant J.-C.

Les formes céramiques associées au Cardial récent sont, comme précédemment, de divers types : marmites, jattes, bols, bouteilles, etc. Les vases de stockage sont 

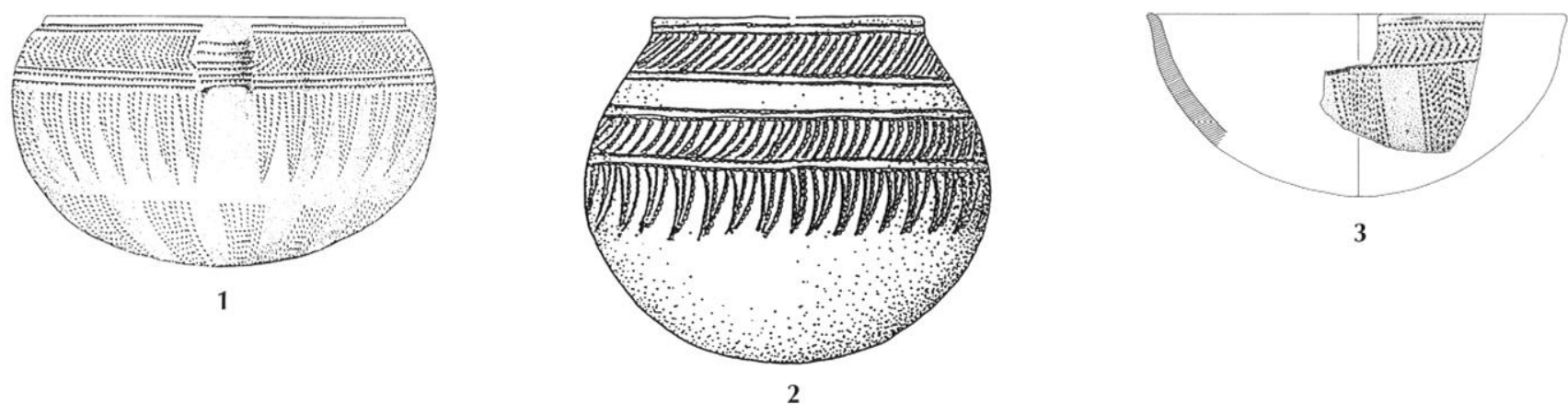

3
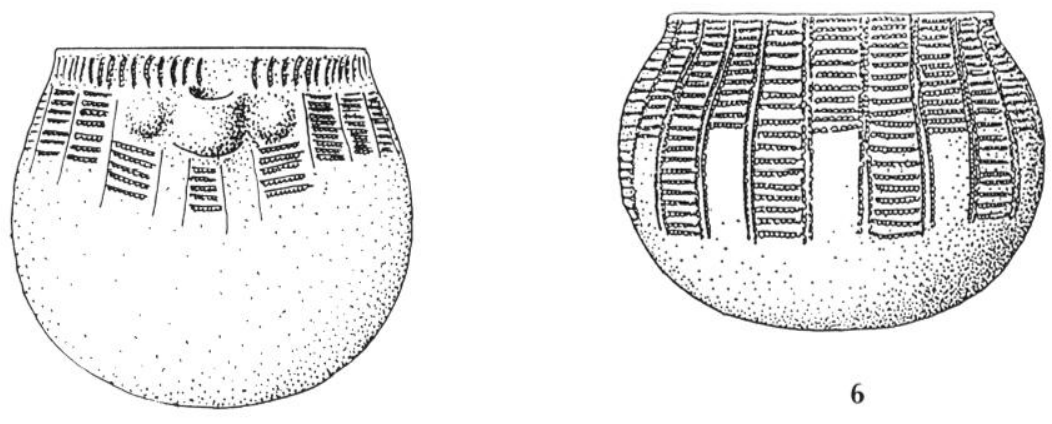

6

4

5
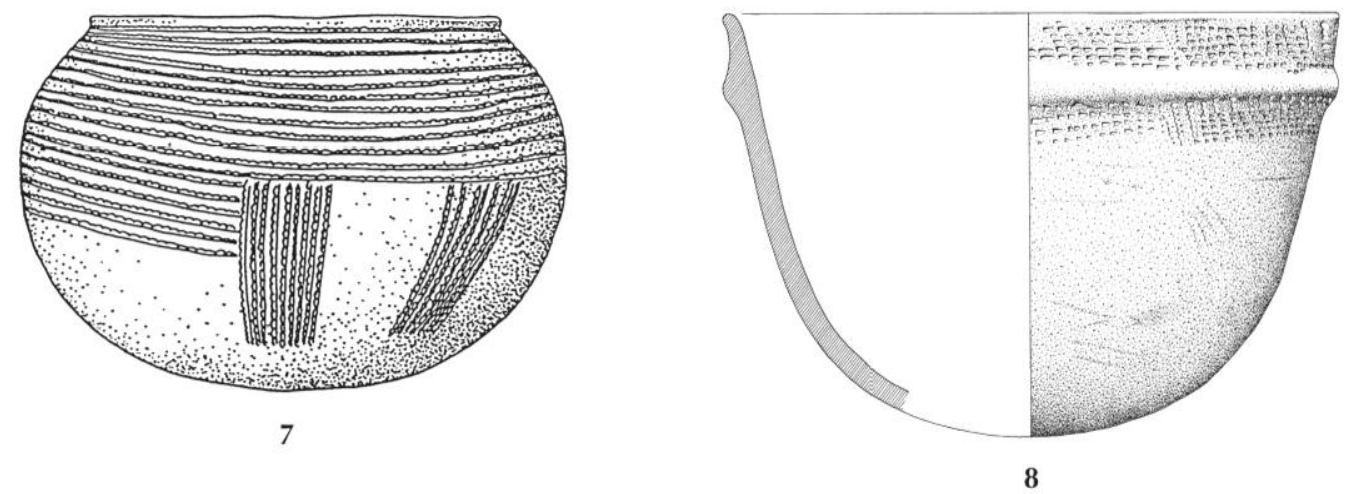

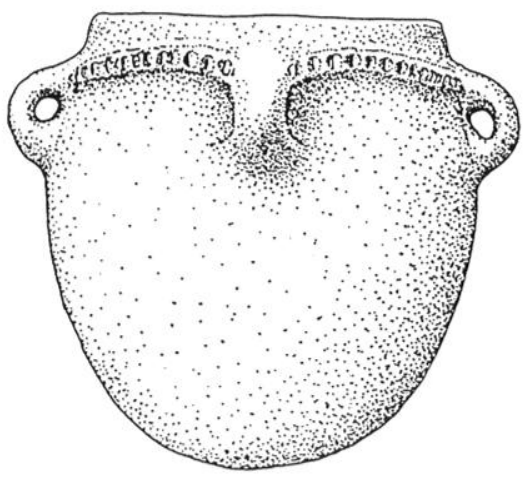

9

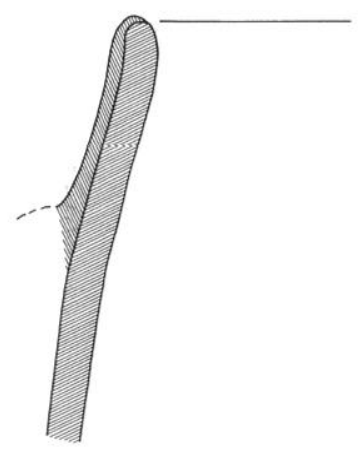

10

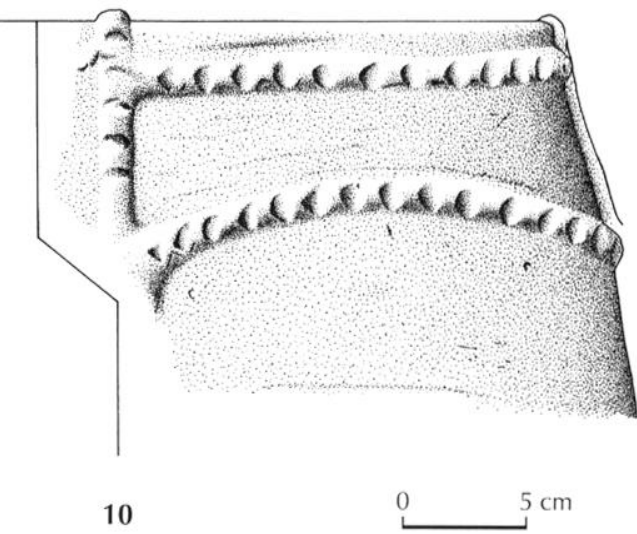

Fig. 10 - Formes et décors du Cardial ancien languedocien : 1, 5, grotte de l'Aigle (Roudil et al., 1979) ; 2, 4, 6, 7, 9, baume d'Oullins (Roudil, 1990) ; 3, Leucate (Guilaine et al., 1984); 8, 10, grotle (iazel (inédit, fouille J. (iuilaine), dessins J. Coularou. 

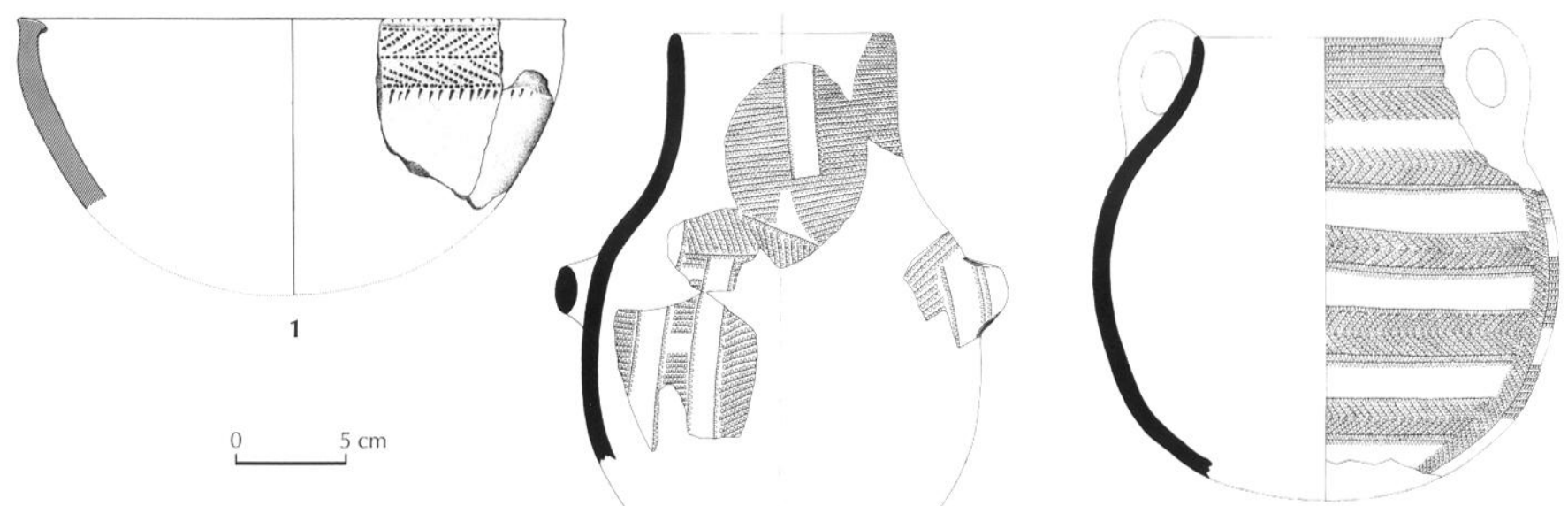

3
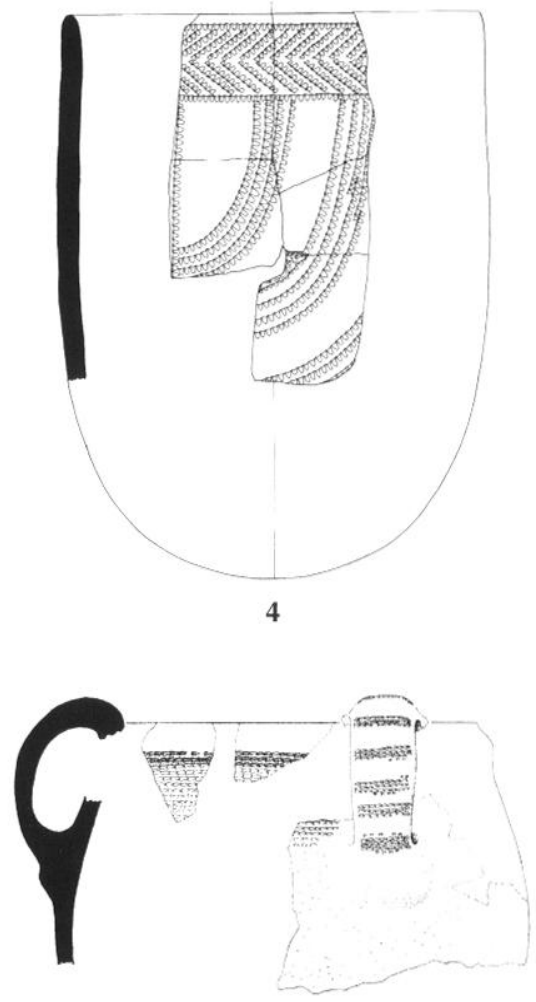

6
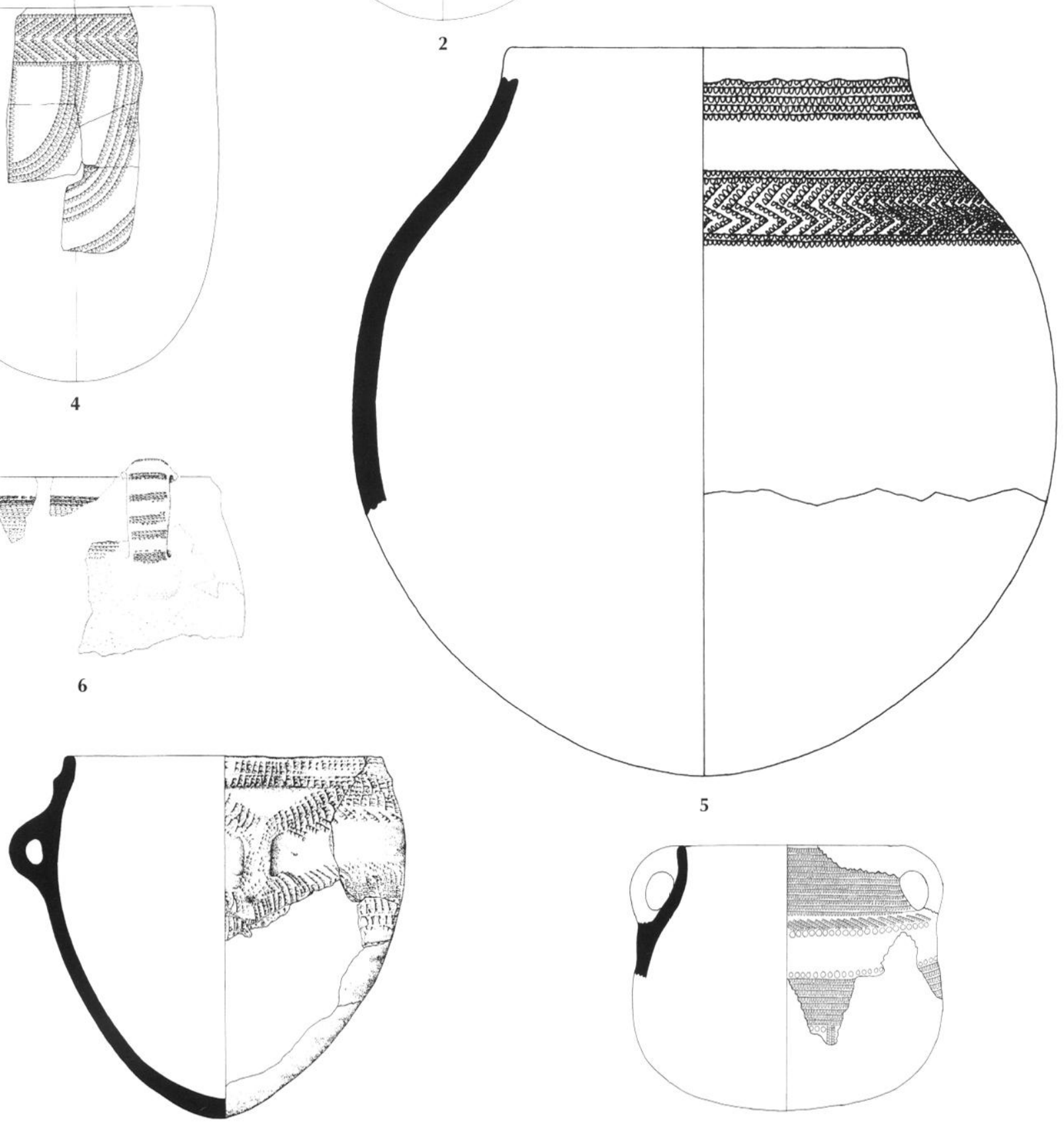

Fig. 11 - Formes et décors du Cardial ancien calalan et aragonais : 1, cov'a del Frare (inédit, fouille A. Marlin) ; 2, conra Freda (Baldellou et al., 1989); 3, Lsquerda de les Roques del Pany (ibid.) ; 4, 5, 8: cova (iman (ibid.); 6, Guixeres de Vilobi (Mestres, 1982) : 7, curva de (chares (Baldellou, Ramón, 1995). 


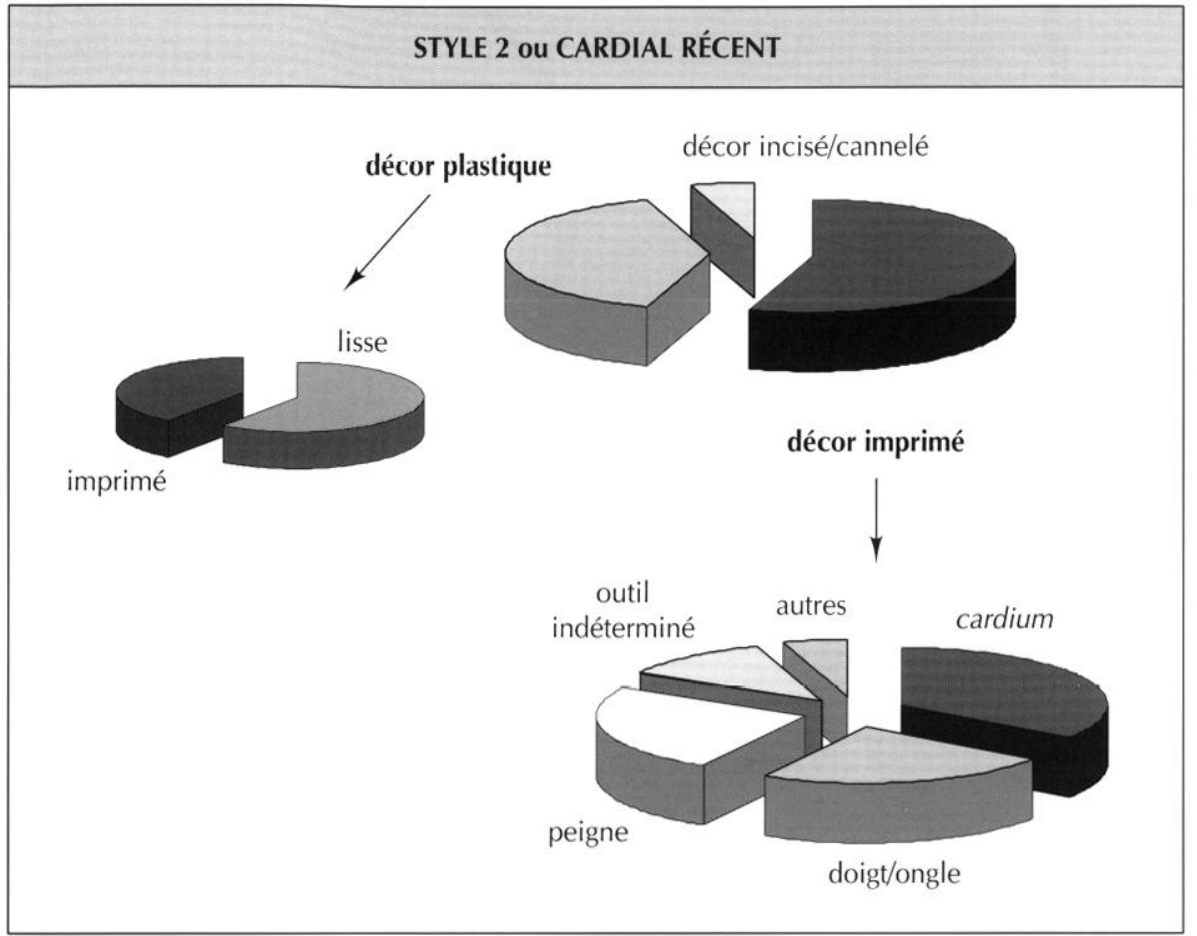

Fig. 12 - Les techniques décoratives du Cardial récent. rares. Les lèvres arrondies dominent (50\%) et sont suivies par le type lèvres amincies $(30 \%)$. Les lèvres aplaties et ourlées sont rares.

Parmi les grandes catégories de décors (fig. 12), c'est l'impression qui domine $(57 \%)$ suivie de près par le décor plastique $(40 \%)$. Les cordons sont lisses $(60 \%)$ ou imprimés $(40 \%)$. On trouve ponctuellement des incisions et des cannelures $(3 \%)$.

Parmi les techniques imprimées, le cardium domine (35\%) mais est suivi de très près par le doigt et le peigne (25\% et $23 \%$ ). On trouve également diverses impressions dont le type n'est pas déterminable (12\%). Les impressions arquées (fig. $3,1.7$ ) et celles effectuées à la coquille lisse (fig. 3, 1.3.1) ou au poinçon (fig. 3, 1.5.1) sont utilisées très ponctuellement. On observe donc une grande diversité de techniques imprimées sans que l'une d'entre elles ne se dégage plus particulièrement. Parmi les impressions au cardium, c'est toujours l'envers du bord de la coquille qui est majoritairement utilisé (fig. 3, 1.1.1.2). Les peignes sont de tailles et de formes diverses. Enfin, c'est généralement le bout du doigt plutôt que l'ongle qui est imprimé dans la pâte.

Les décors plastiques comprennent les cordons lisses, les cordons imprimés et quelques cas de pastilles.

Les thèmes décoratifs du Cardial récent sont schématisés sur la figure 13 et représentés sur les figures 14 et 15.
Ils sont toujours structurés en rubans horizontaux se répétant ou non de haut en bas du vase (fig. $13 \mathrm{a}, \mathrm{b}, \mathrm{c}$ ). Les thèmes en rubans verticaux et les plages couvrantes sont également bien représentés (fig. 13 d, e). C’est surtout dans le remplissage des rubans que l'on observe des différences avec le style précédent. En effet, ce remplissage est principalement constitué de lignes simples d'impressions. Les motifs géométriques typiques du style 1 sont peu fréquents. De plus, les rubans sont rarement limités par un encadrement. I.es plages couvrantes constituées de lignes d'impressions jointives sont assez bien représentées. Notons enfin que les thèmes associant rubans horizontaux et verticaux sont plus rares. Les cordons offrent les mêmes thèmes que précédemment mais sont la plupart du temps lisses (fig. $13 \mathrm{~g}-\mathrm{n}$ ).

Pour résumer, on peut dire que la stylistique décorative du Cardial récent du Languedoc et de la Catalogne est caractérisé par une grande diversité des techniques imprimées et par des thèmes en ruban ou en plage couvrante à remplissage simple.

\section{STYLE 3 OU ÉPICARDIAL ANCIEN}

Les sites ayant livré un assemblage céramique que l'on peut rattacher à ce style sont les suivants : 


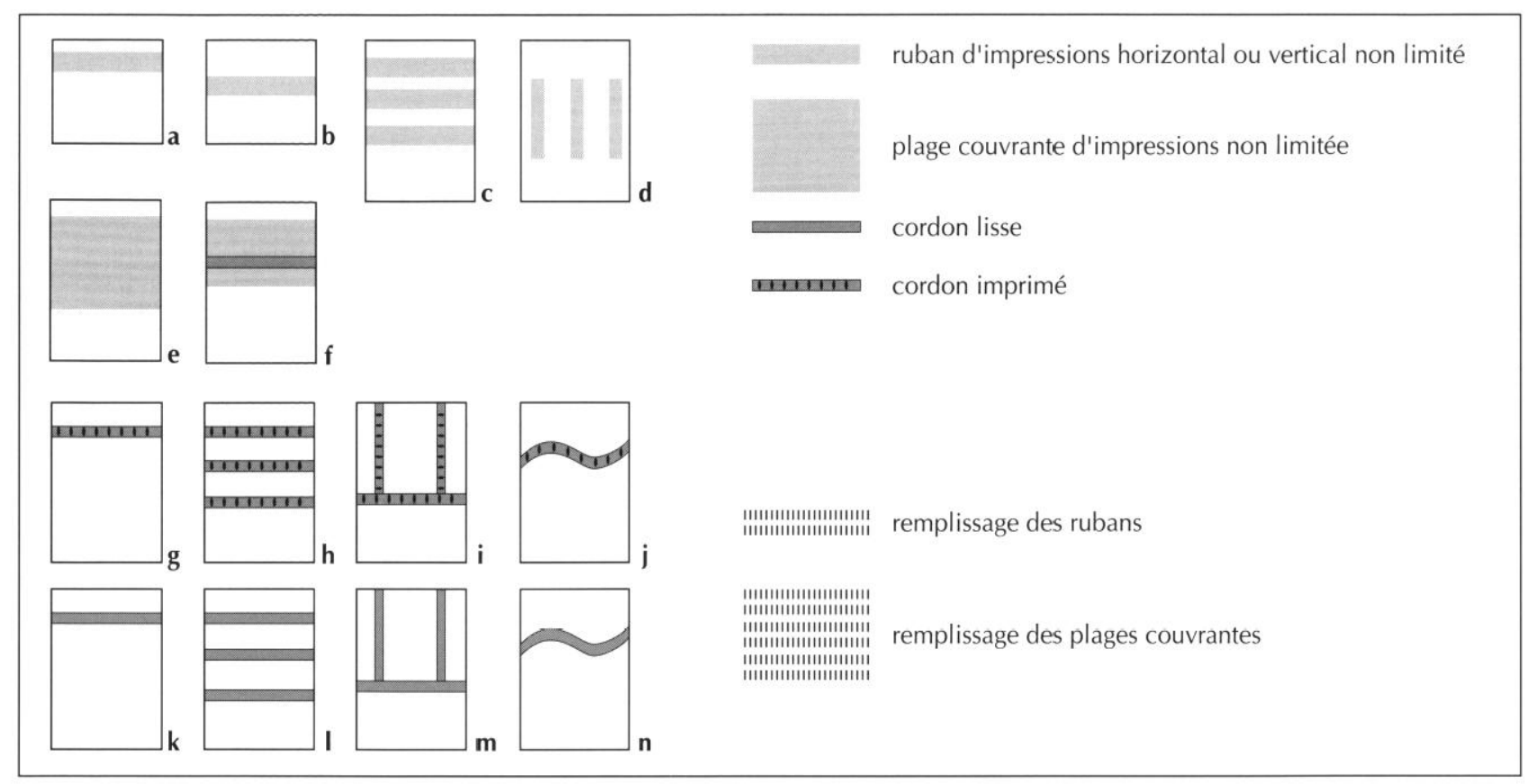

Fig. 13 - Schématisation des principaux thèmes décoratifs du Cardial récent.

- grotte de Chazelles, couche VIIa (Saint-André-deCruzières, Ardèche), Roudil, 1996 ;

- baume d'Oullins, couche 5 (Le Garn, Gard), Roudil, 1987 ;

- baume de Montclus, couches 3 et 5 (Montclus, Gard), Escalon de Fonton, 1969 ;

- baume Bourbon, couches 5a et 5b (Cabrières, Gard), Coste, Gutherz, 1976 ;

- abri de Brugas (Vallabrix, Gard), Roudil et al., 1979;

- grotte du Taï (Remoulins, Gard), Coste, Gutherz, 1976 et inédit, fouille en cours ;

- Grotte IV, couches 3A, 3B et 3C (Saint-Pierre-de-laFage, Hérault), Arnal, 1983 ;

- Camprafaud, couche 19 (Ferrières-Poussarou, Hérault), Rodriguez, 1984 ;

- Gazel B (Sallèles-Cabardès, Aude), Guilaine, 1970, 1986 ;

- abri du Roc de Dourgne, couche 5 (Fontanès-de-Sault, Aude), Guilaine et al., 1993 ;

- coves de Malvet (Santa Cristina d'Aro, Gerona), Bosch i Lloret, 1991 ;

- cova del Pasteral (La Cellera de Ter, Gerona), Bosch i Lloret, 1991 ;

- Puig Mascarò (Torroella de Montgri, Gerona) Bosch i Lloret, 1991.

Les données de la chronologie absolue placent ce style entre 5300 et 4800 avant J.-C.
Les formes céramiques associées à l'Épicardial ancien sont de divers types et ne tranchent pas avec ce qui a été précédemment observé : bols, petits pots globuleux, marmites, jarres, etc. On retrouve le même lien entre les vases de grandes dimensions et les décors plastiques.

Parmi les techniques décoratives utilisées (fig. 16), ce sont les catégories cannelure et incision qui dominent (36\%). Vient ensuite le décor plastique (29\%). Les décors imprimés (excepté le poinçon) sont encore présents (24\%). Enfin, le poinçon représente $11 \%$ des techniques décoratives utilisées. On constate donc que les différentes grandes catégories de la décoration du Néolithique ancien méridional sont représentées dans ce style, en proportions relativement équilibrées. La cannelure domine largement sur l'incision. Le décor plastique est formé de pastilles et de cordons. Ces derniers sont très majoritairement lisses $(75 \%)$. Parmi les techniques imprimées, on trouve, en proportions à peu près équilibrées, le cardium, le peigne, l'outil arqué, le doigt, les impressions diverses, etc.

Les thèmes décoratifs des décors cannelés consistent principalement en rubans horizontaux formés de cannelures verticales parfois margées ou interrompues par une ou plusieurs cannelures horizontales (fig. $17 \mathrm{a}, \mathrm{c}$ ). Ce thème est fréquemment associé à un cordon lisse (fig. $17 \mathrm{~b}$ ) ; dans ce cas, le ruban de cannelures verticales 

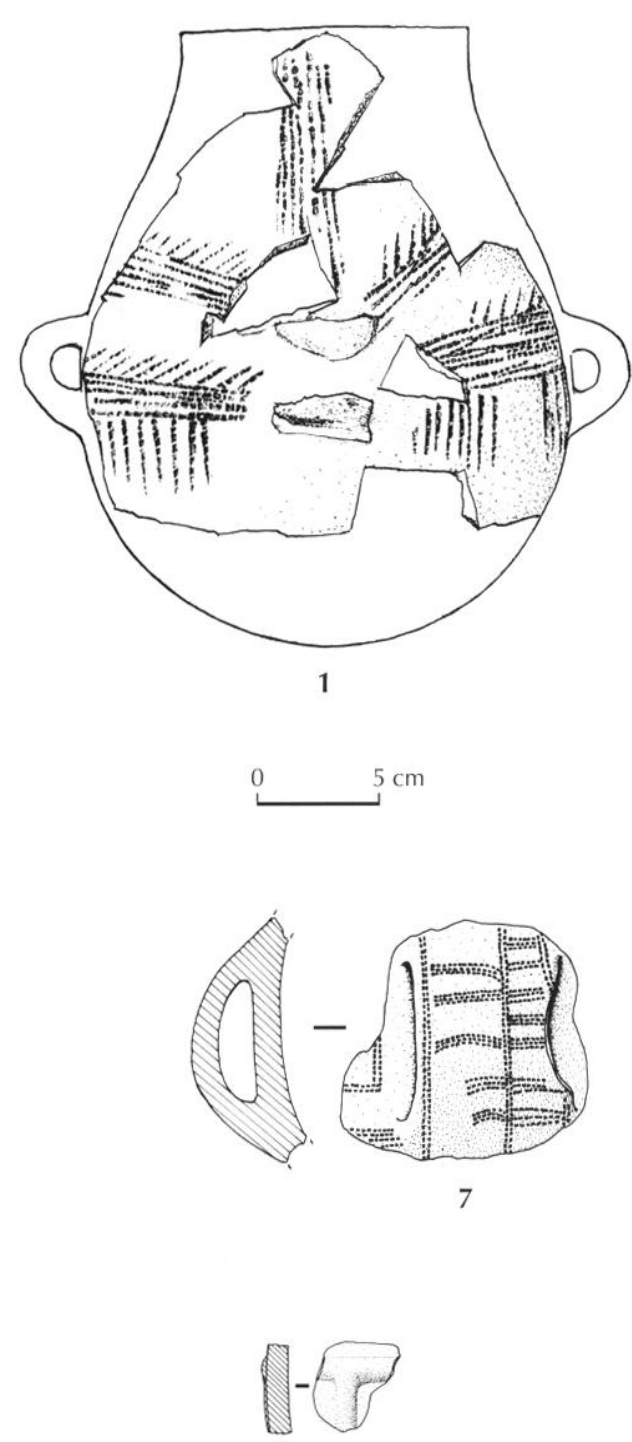

9

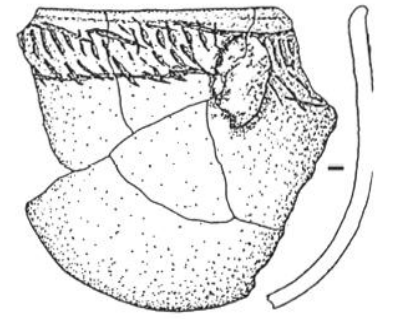

2
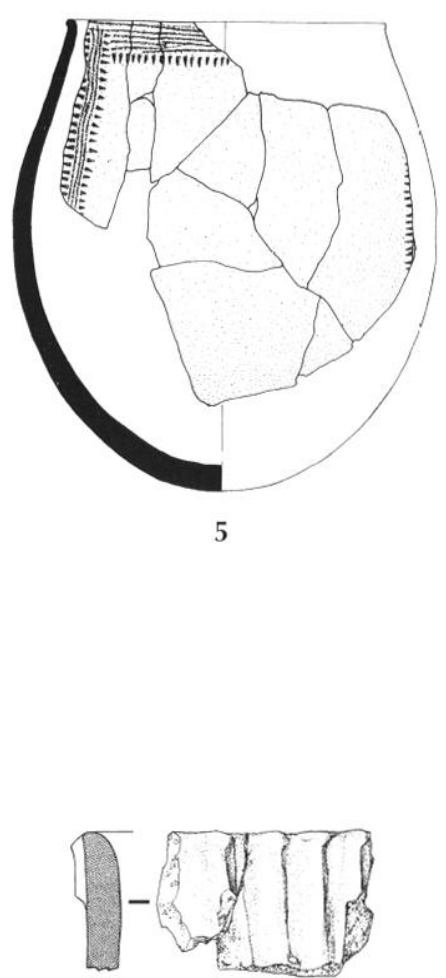

10

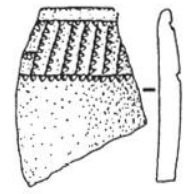

3

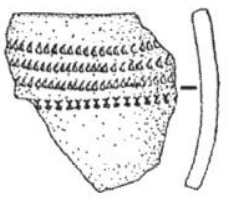

4

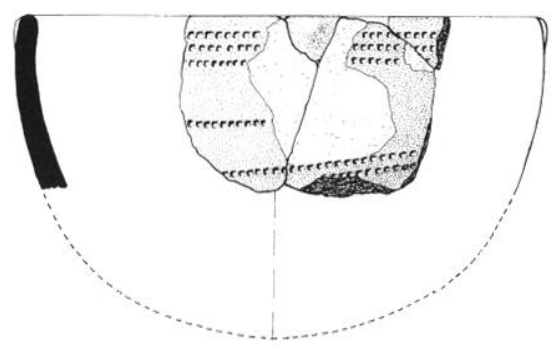

6

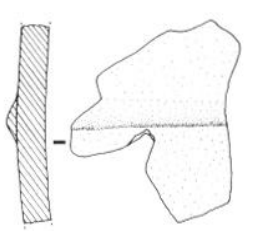

8

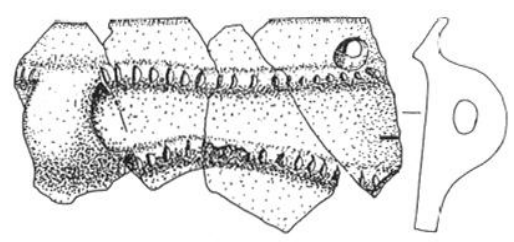

11

Fig. 14 - Formes el dérons du (ardial récent languedocien et catalan : 1, 10, grotle de Saimt-Marel (Gilles, 1988) ; 2-4, 11, abri de La Tardiue (Roudil et al., 1991) ; 5-9, I. I)raga (Bosch i Lloret et al., 20(0)).

est ceinturé dans sa partie inférieure par le cordon. On trouve plus rarement des rubans constitués de motifs géométriques cannelés (fig. 17 d). Le décor plastique propose des thèmes composés, parfois très complexes. On trouve fréquemment une série de cordons lisses verticaux courts, dépassant souvent le bord, soulignée ou non dans sa partie inférieure d'un cordon lisse horizontal (fig. 17 e, f). Il est difficile de décrire les thèmes plus complexes, rarement complets. Pastilles et cordons se mêlent parfois pour former un décor chargé (fig. 17 h). Les cordons imprimés sont utilisés de manière plus classique (fig. 17 i). Enfin, les impressions forment, comme dans le style 2, des rubans verticaux ou horizontaux, rarement limités, à remplissage simple (fig. $17 \mathrm{j}, \mathrm{k}$ ).

Ia structuration du décor sur le vase montre une nette préférence pour le registre supéricur (fig. 18 et 19). L.es lèvres sont fréquemment encochées. On peut noter quelques cas de plages couvrantes et d'associations de rubans verticaux et horizontaux. C'est alors la surface entière du vase qui est décorée. Enfin, l'élément de préhension semble jouer un rôle particulier dans la construction de certains thèmes où il devient élément de svmétrie. Sur certains vases, la préhension possède d'ailleurs son propre décor. 

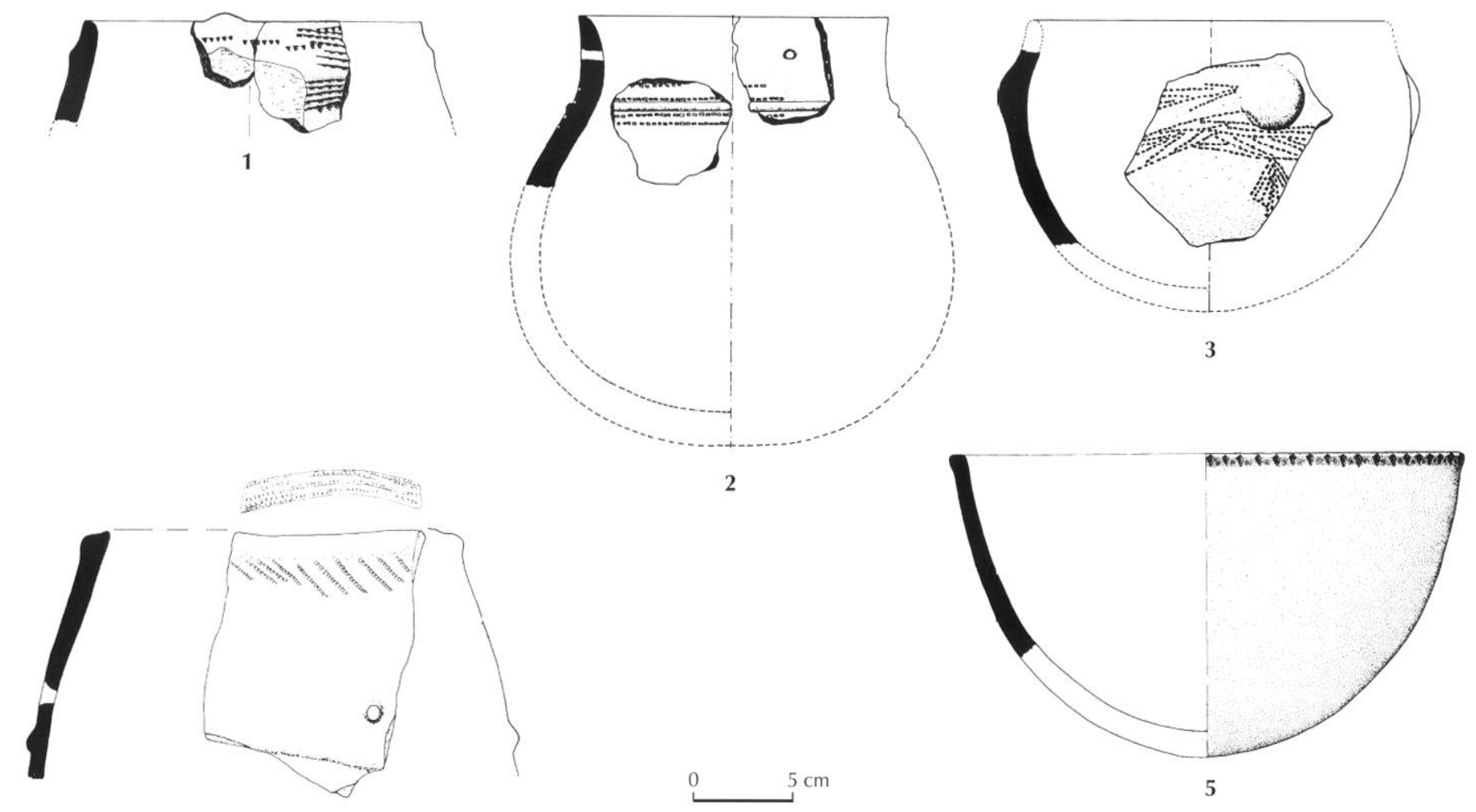

4
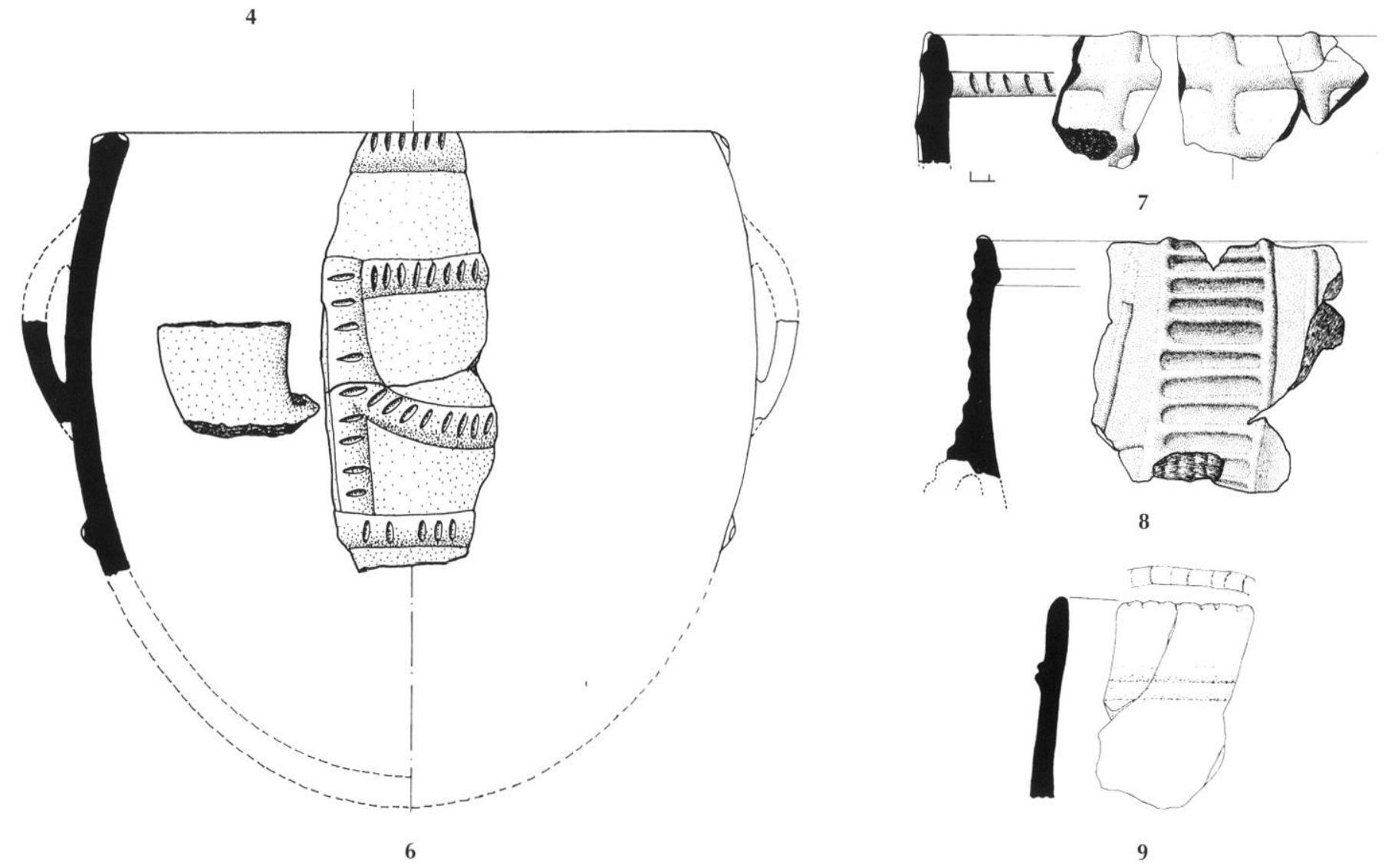

Fig. 15 - Formes et décors du Cardial récent catalan : 1, 5, 7, 8, Plansallosa I (Bosch et al., 1998);

2, 3, 6, Reclau Viver (Bosch i Iloret, 1991) ; 4, 9, cova de la Font Major (Miro, 1995). 


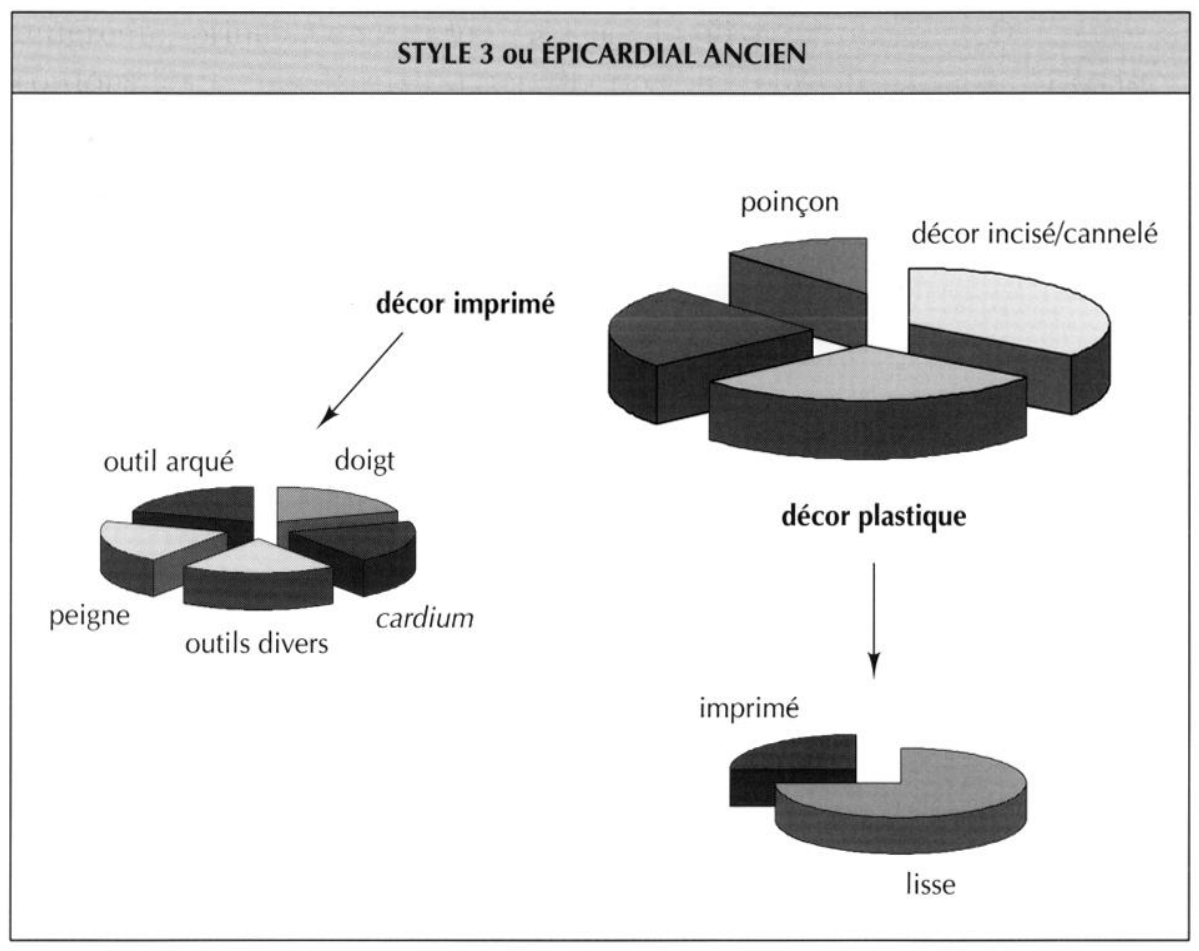

Fig. 16 - Les techniques décoratives de l'Épicardial ancien.

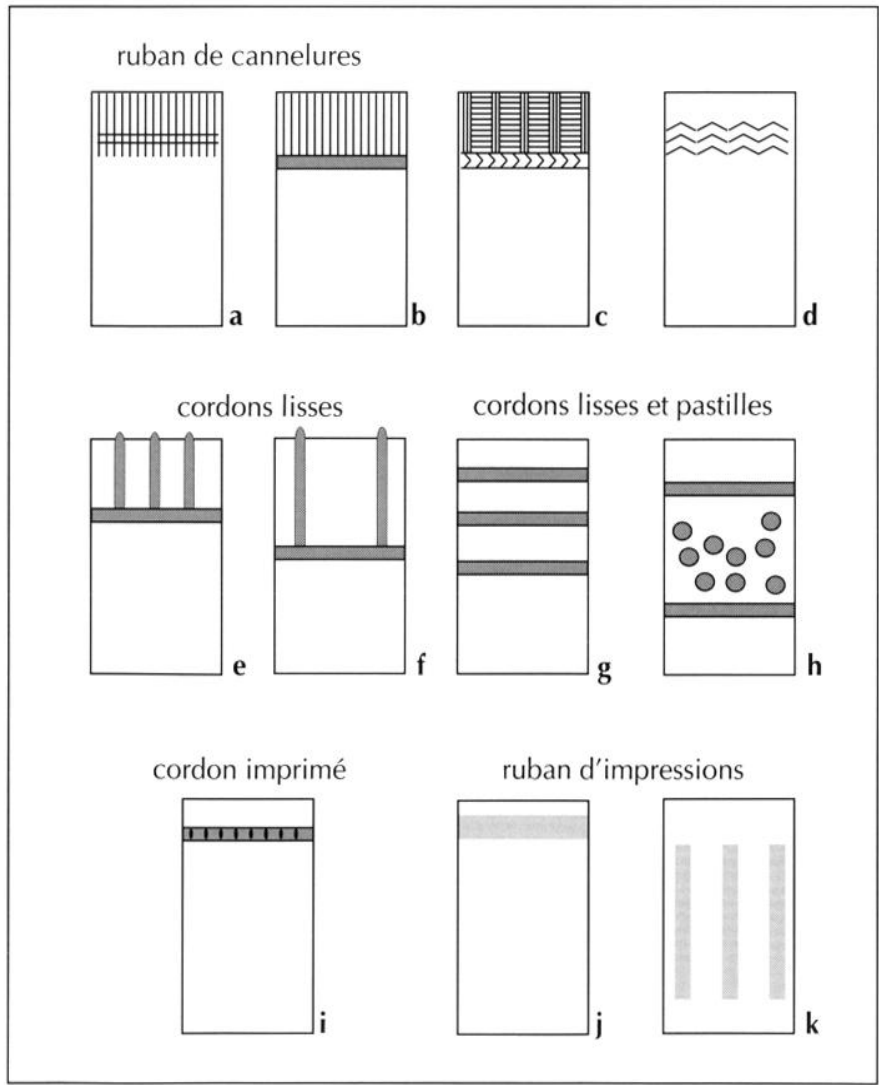

Fig. 17 - Schématisation des principaux thèmes décoratifs de l'Épicardial ancien.

\section{STYLE 4 OU ÉPICARDIAL RÉCENT}

Les sites ayant livré un assemblage céramique que l'on peut rattacher à ce style sont les suivants :

- Espeluche-Lalo (Montélimar, Drôme), Beeching et al., 2000 ;

- Grotte IV, couches 3D, 3E et 4A (Saint-Pierre-de-laFage, Hérault), Arnal, 1983 ;

- Camprafaud, couches 18 à 16 (Ferrières-Poussarou, Hérault), Rodriguez, 1984 ;

- Gazel C (Sallèles-Cabardès, Aude), Guilaine, 1970, 1986 ;

- Abeurador, couche 2A (Félines-Minervois, Hérault), inédit, fouille J. Vaquer ;

- Font-Juvénal, couche 12 (Conques-sur-Orbiel, Aude), Guilainc et al., 1976 ;

- grotte de l'Ourtiguet (Sainte-Eulalie-de-Cernon, Aveyron), Boutin et al., 1997 ;

- grotte de la Crouzade (Gruissan, Aude), Guilaine, 1985 ;

- station de La Corrège (Leucate, Aude), Guilaine et al., 1984 ;

- cova del Parco (Alòs de Balaguer, Lleida), Petit i Mendizabal éd., 1996 ;

- cova del Frare, couche 5b (Matadepera, Barcelona), Martín el al., 1981, 1985 ; 

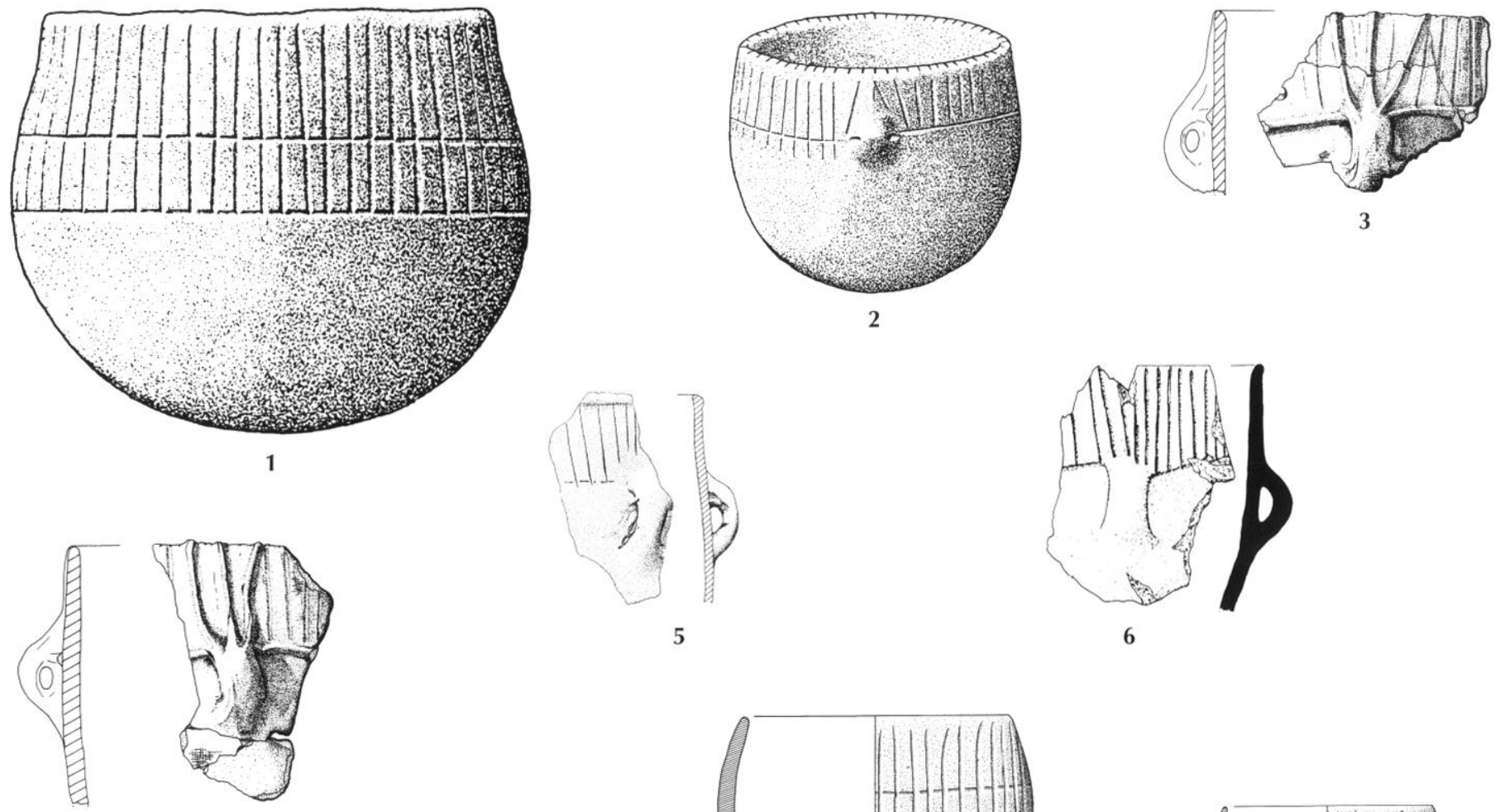

6
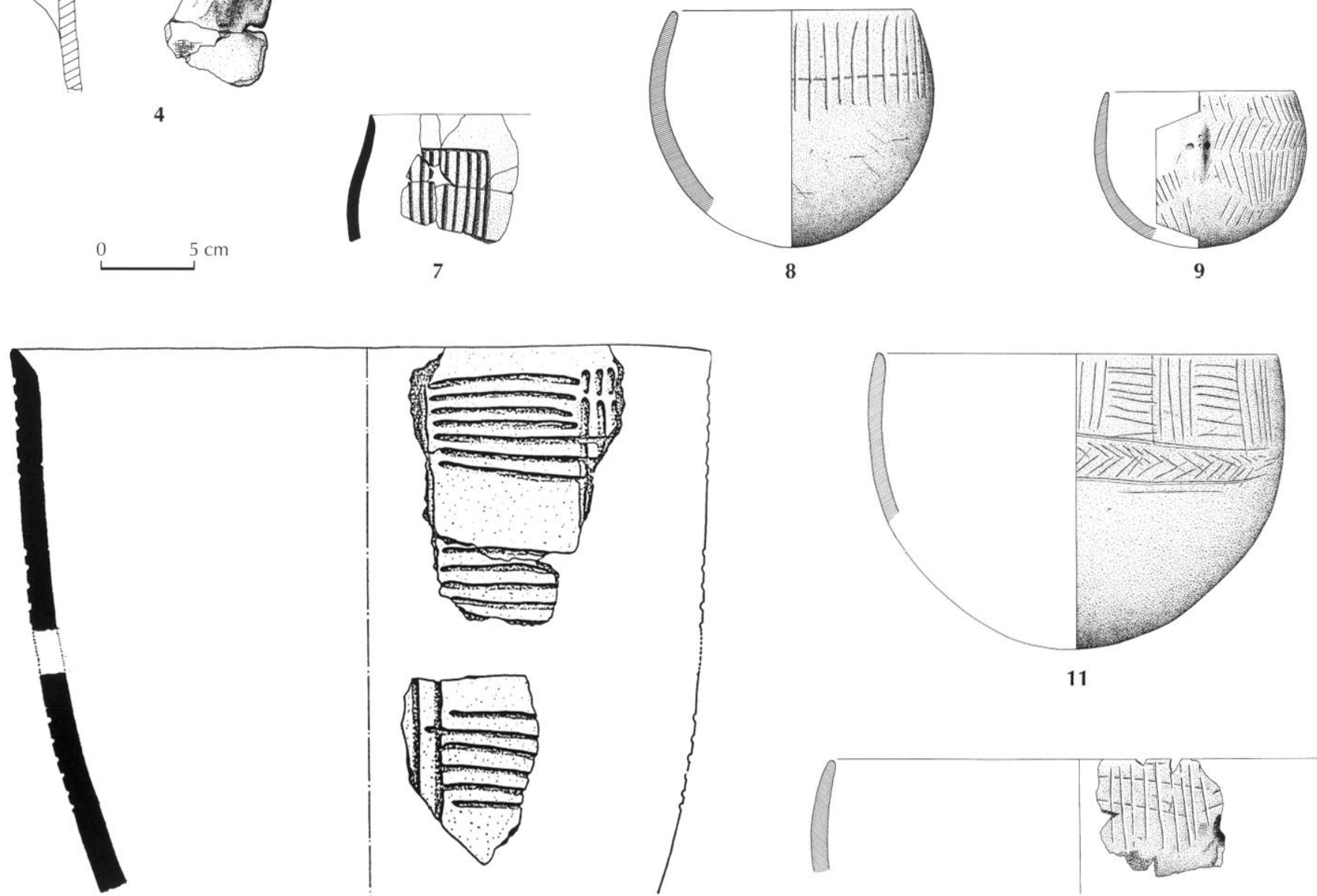

10

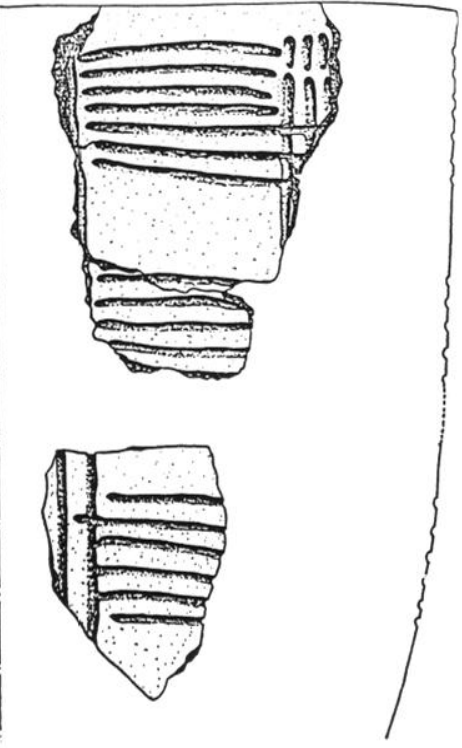

Fig. 18 - Formes et décors de l'Epicardial ancien languedocien et catalan : 1, 2, baume de Montclus (Kscalon de Fonton, 1971) ; 3, 4, Camprafaud (Rodriguez, 1984) ; 5, abri de Brugas (Roudil et al., 1979) ; 6, baume Bourbon (Coste, (iutherz, 1976) ; 7, coves de Malvet (Bosch i l.loret, 1991); 8, 9, 11, 12, grotte (iazel (inédit, fouille J. Guilaine), dessins J. Coularou; 10, cousa del Pasteral (Bosch i Lloret, 1991). 

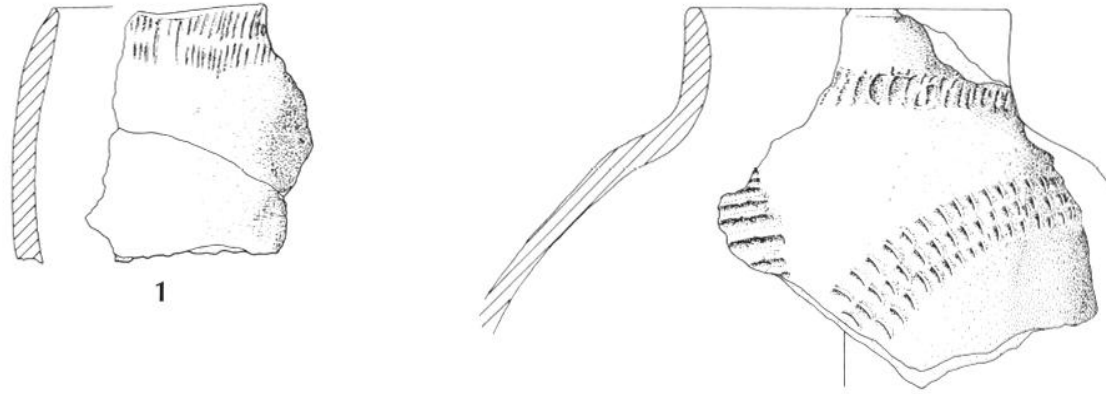

2

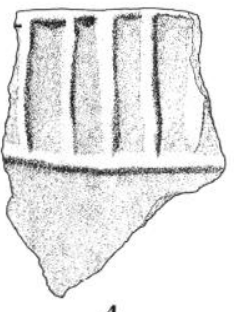

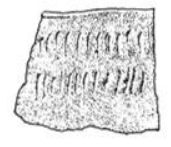

5
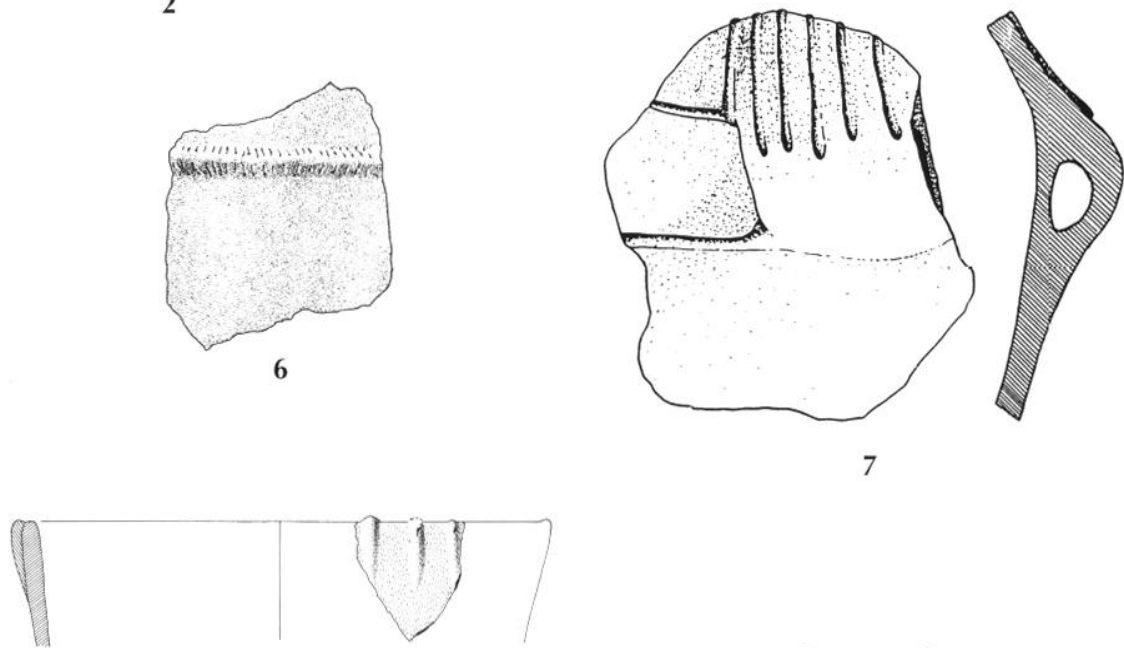

9

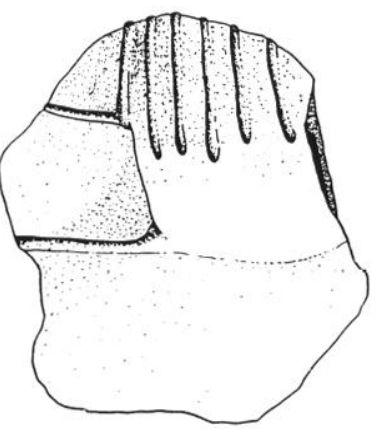

7

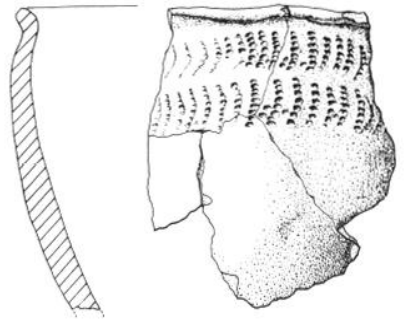

3 $5 \mathrm{~cm}$

Fig. 19 - Formes el décors de lFpicardial ancien languedocien et catalan : 1-3, Camprafaud (Rodriguez, 1984) ; 4-6, baume de Montclus (Esscalon de Fonton, 1971); 7, covu del P'asteral (Bosch i I.loret, 1991);8, 9, grolle (razel (inédil, fouille J. Guilaine), dessins J. Conularou.

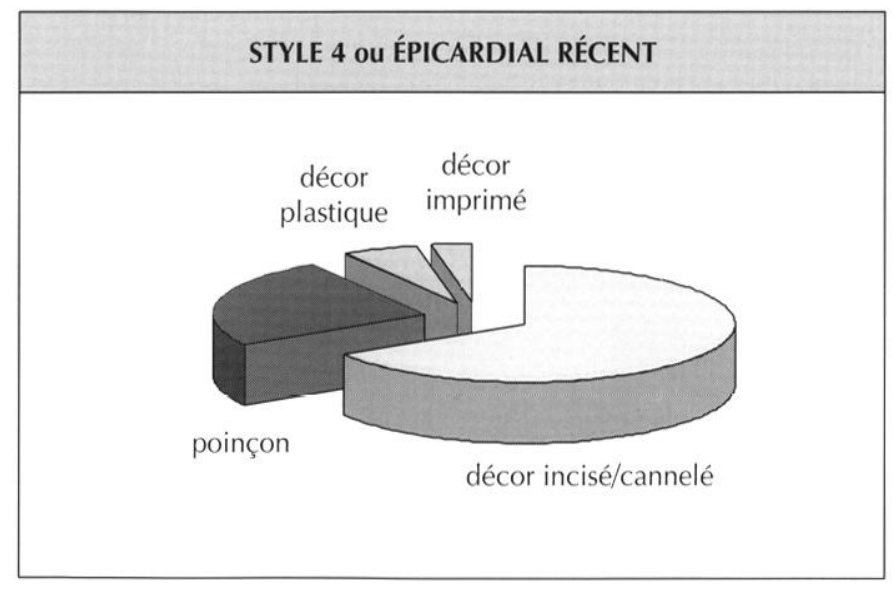

Fig. 20 - Les techniques décoralizes de l'́picicardial récent.

Fig. 21 - Schématisation des principaux thèmes décoratifs de l'ifpicardial récent.
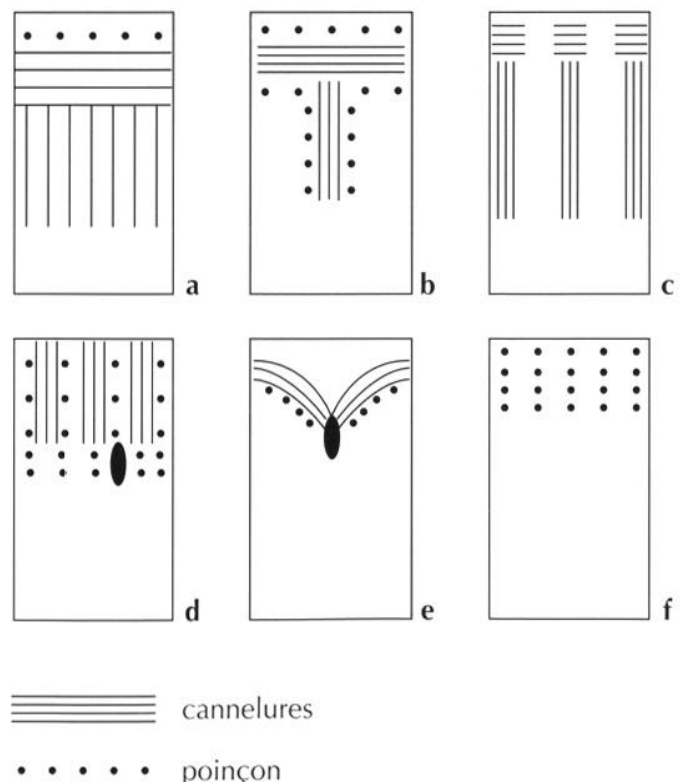


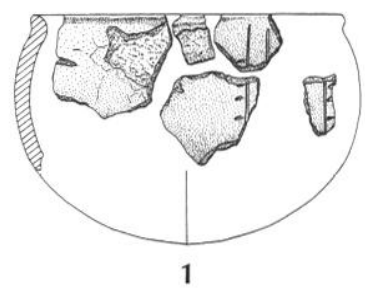

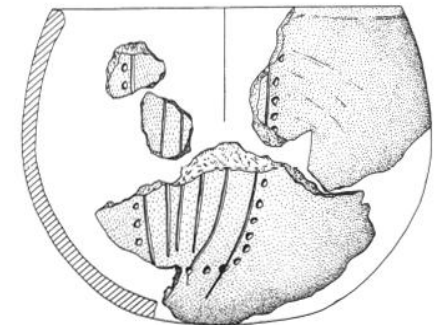

2

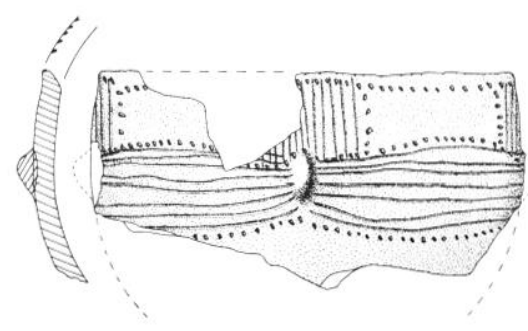

3

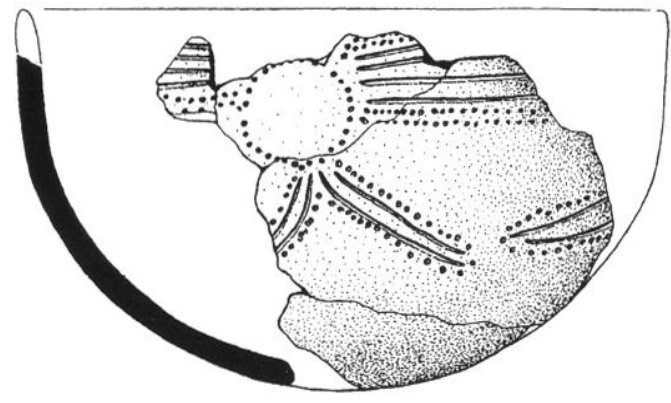

4
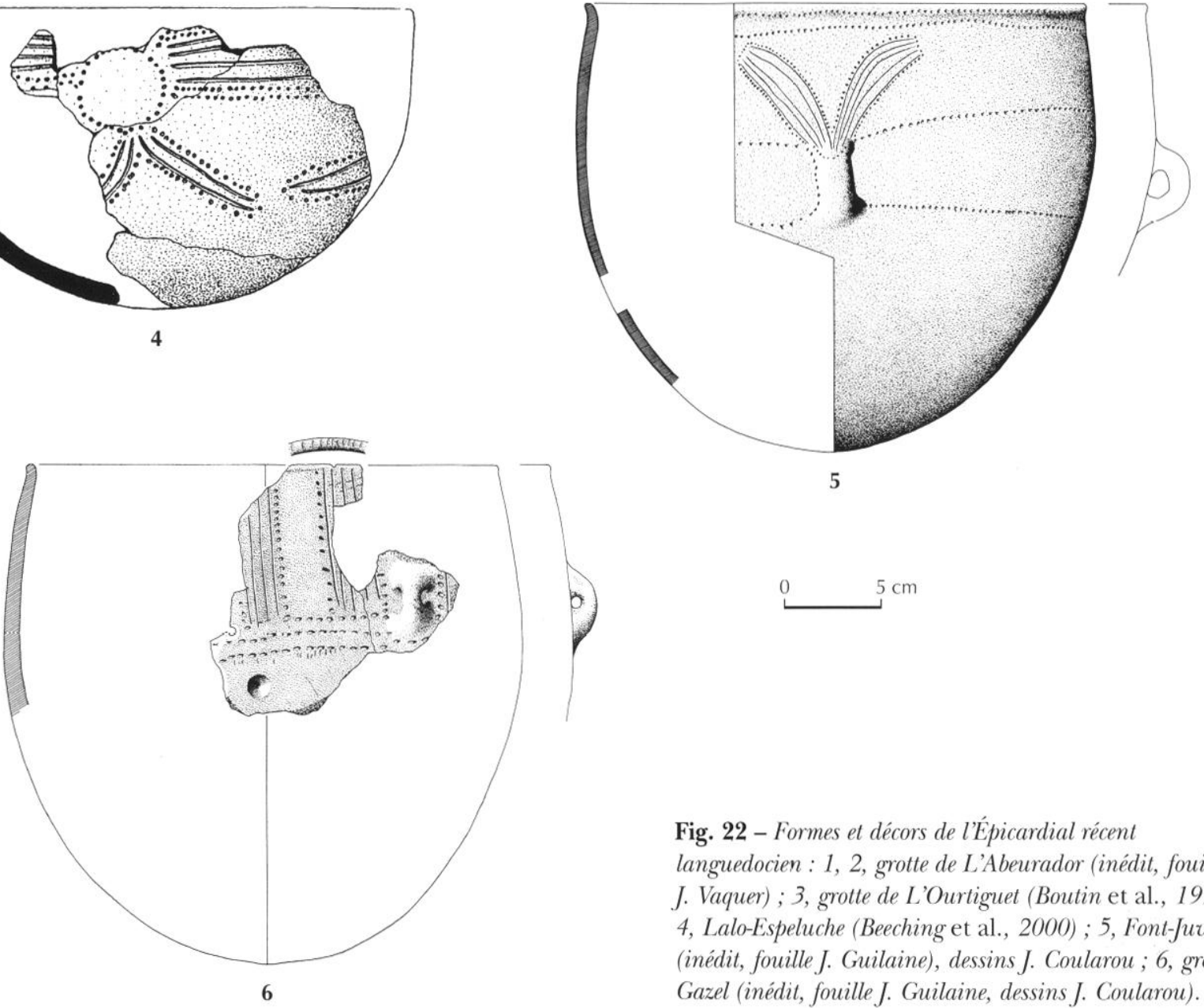

5

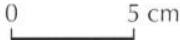

Fig. 22 - Formes et décors de l'Épicardial récent languedocien: 1, 2, grotte de L'Abeurador (inédit, fouille J. Vaquer) ; 3, grotte de L'Ourtiguet (Boutin et al., 1997) ; 4, Lalo-Espeluche (Beeching et al., 2000) ; 5, Font-Juvénal (inédit, fouille J. Guilaine), dessins J. Coularou; 6, grotte Gazel (inédit, fouille J. Guilaine, dessins J. Coularou).

- cova dels Lladres (Vacarisses, Barcelona), Pla, Junyent, 1970 ;

- Timba d'en Barenys (Riudoms, Tarragona), Vilardell i Pascual, 1992 ;

- Espluga de la Puyascada (San Juan de Toledo, Huesca), Baldellou, 1987 ;

- El Torrollón I (Ĺsón, Huesca), Rey Lanaspa, Ramon Fernande $\%, 1992$;

- cueva de (haves (Bastarás, Huesca), Baldellou, L'trilla, 1999.
Les données de la chronologie absolue placent ce style entre 5000 et 4500 avant J.-C.

On retrouve la même diversité morphologique que pour les styles précédents, sans pouvoir établir de distinction particulière.

La décoration (fig. 20) de ce style est très majoritairement réalisée à l'aide de cannelures et d'incisions avec une nette préférence pour la cannelure $(66 \%)$. Vient ensuite le poinçon imprimé qui représente $25 \%$ des techniques décoratives. Le décor plastique et les impressions 

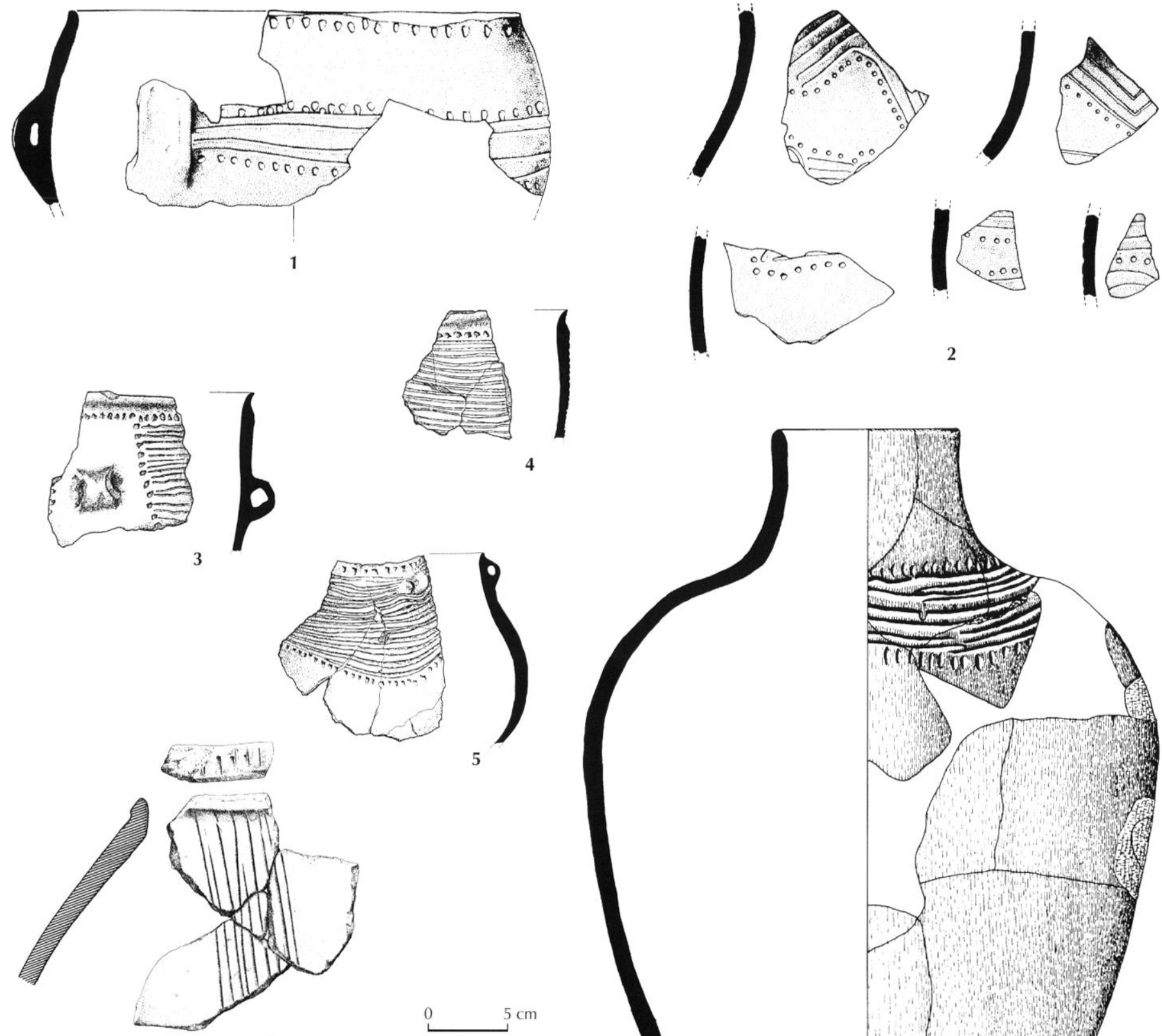

6

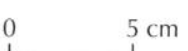
$5 \mathrm{~cm}$

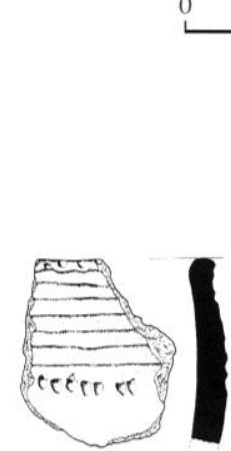

8

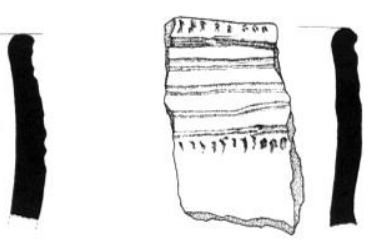

9

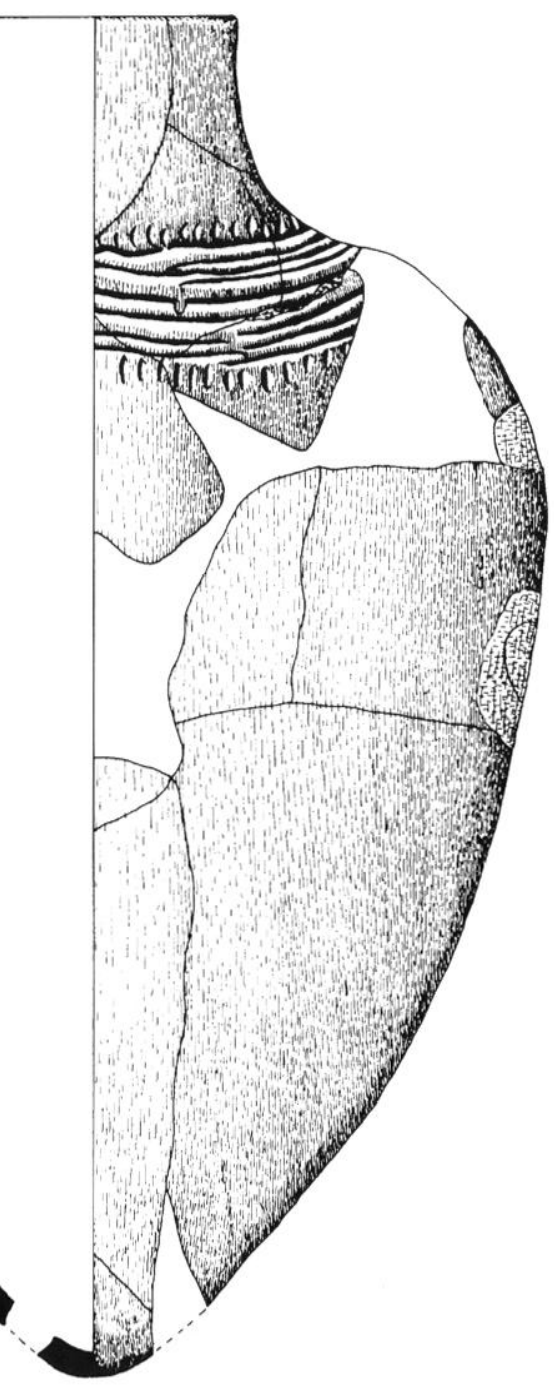

10

Fig. 23 - Formes et décors de l'́fípicardial récent catalan el aragonais : 1, 2, Timba d'en Barenys (Vilardell i Pascual, 1992) ; 3-5, Lispluga de la Puyascada (Baldellou, 1987); 6, cova del Frare (Martín Colliga, Estevez i Escalera, 1992); 7-9, cueva de Chaves (Baldellou, Ramón, 1995) ; 10, Lil Torrollón (Rey Lanaspa, Ramon Fernandez, 1992). 
sont très peu utilisés (respectivement $6 \%$ et $3 \%$ ). Parmi les quelques décors plastiques, seul le cordon lisse subsiste. Les décors imprimés, rares, sont réalisés au doigt, avcc un outil arqué ou à l'aide d'outils non identifiés.

$\mathrm{Du}$ point de vue des thèmes décoratifs (fig. 21, 22 et 23), on remarque un changement dans le zonage du décor sur le vase. Les rubans verticaux et les plages couvrantes dominent en effet ce style. De même, rubans verticaux et horizontaux sont souvent liés pour former un « $T$ ». Chacun des rubans ou plages couvrantes est généralement rempli de cannelures elles-mêmes bordées d'impressions réalisées au poinçon. Celles-ci sont parfois organisées en ruban mais plus fréquemment en plage couvrante, de manière désorganisée. Les lèvres sont frćqucmment encochées.

\section{STYLE 5 OU NÉOLITHIQUE ANCIEN À SILLON D'IMPRESSIONS}

Les styles 5 et 6 ne sont pas équivalents aux précédents puisqu'ils sont définis à partir d'un site seulement : Peiro Signado pour le style 5 et Pont de Roque-Haute pour le style 6. Cependant, ils correspondent à deux entités bien distinctes, fait que l'on peut corroborer par l'analysc de l'cnscmble du système technique de chaque site (Manen, 2000a). Il faudra s'attacher, à l'avenir, à compléter nos connaissances sur ces stylistiques par la confrontation directe avec les assemblages italiens.

Le style 5 est défini à partir de l'abondante série céramique récoltée sur le site de Peiro Signado (Portiragnes, Hérault). Cet assemblage provient des fouilles anciennes de J.-L. Roudil et des fouilles récentes de F. Briois.

Les formes de ce style céramique présentent des jattes à fond plat mais également des bols, bouteilles et marmites. Lcs ćlćmcnts dc préhensions semblent peu utilisés à Peiro Signado. Ils ne représentent que $5 \%$ de la totalité des différents types de tessons (anses en ruban, boutons, languettes, mamelons parfois perforés).

La grande majorité (78 \%) des tessons étudiés présente une décoration effectuée selon la technique du sillon d'impressions (fig. 24). Celle-ci est obtenue en appuyant un outil tangentiellement à la pâte et en le déplaçant par petits sauts successifs tout en restant en contact avec la surface du vase (fig. 3, 1.8.3). On obtient ainsi un sillon dont le fond garde les

\section{STYLE 5 ou NÉOLITHIQUE ANCIEN À SILLON D'IMPRESSIONS}

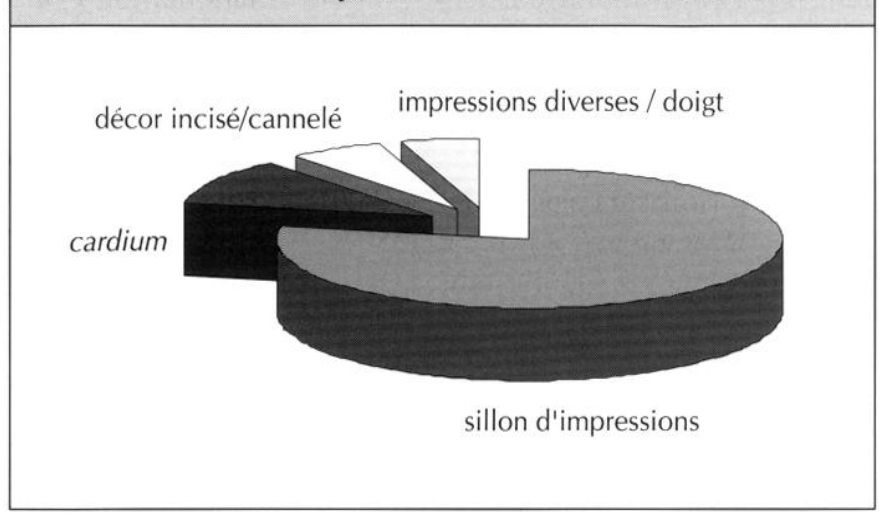

Fig. 24 - Les techniques décoratives de Peiro Signado (Portiragnes, Hérault).

sillon d'impressions
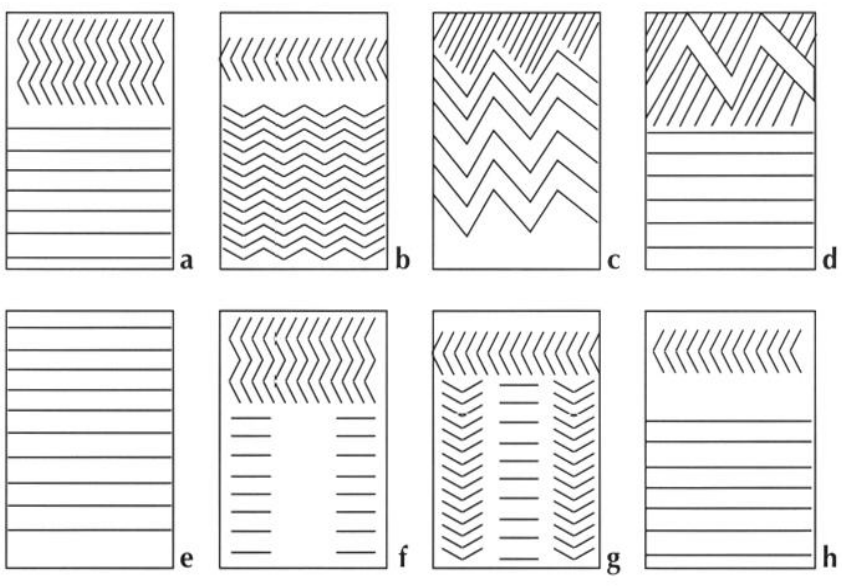

cardium, impressions circulaires et sillons
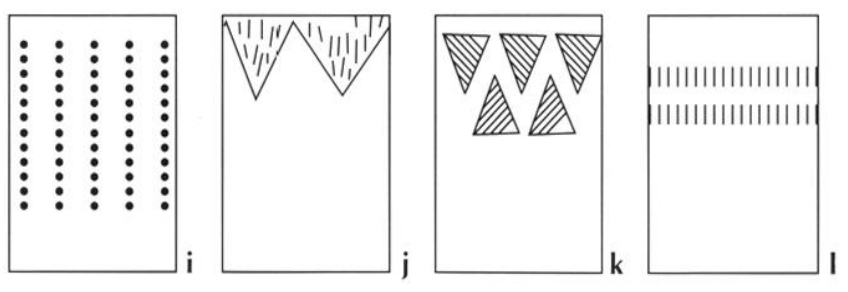

Fig. 25 - Schématisation des principaux thèmes décoratifs de Peiro Signado (Portiragnes, Hérault).

empreintes successives de la pointe de l'outil (Roudil, Soulier, 1983).

Environ $11 \%$ des tessons décorés sont imprimés à l'aide d'une coquille de cardium. Cette technique livre des impressions courtes fines ou très épaisses et des impressions continues réalisées en faisant rouler la coquille sur la pâte. Quelques tessons (4\%) sont décorés 

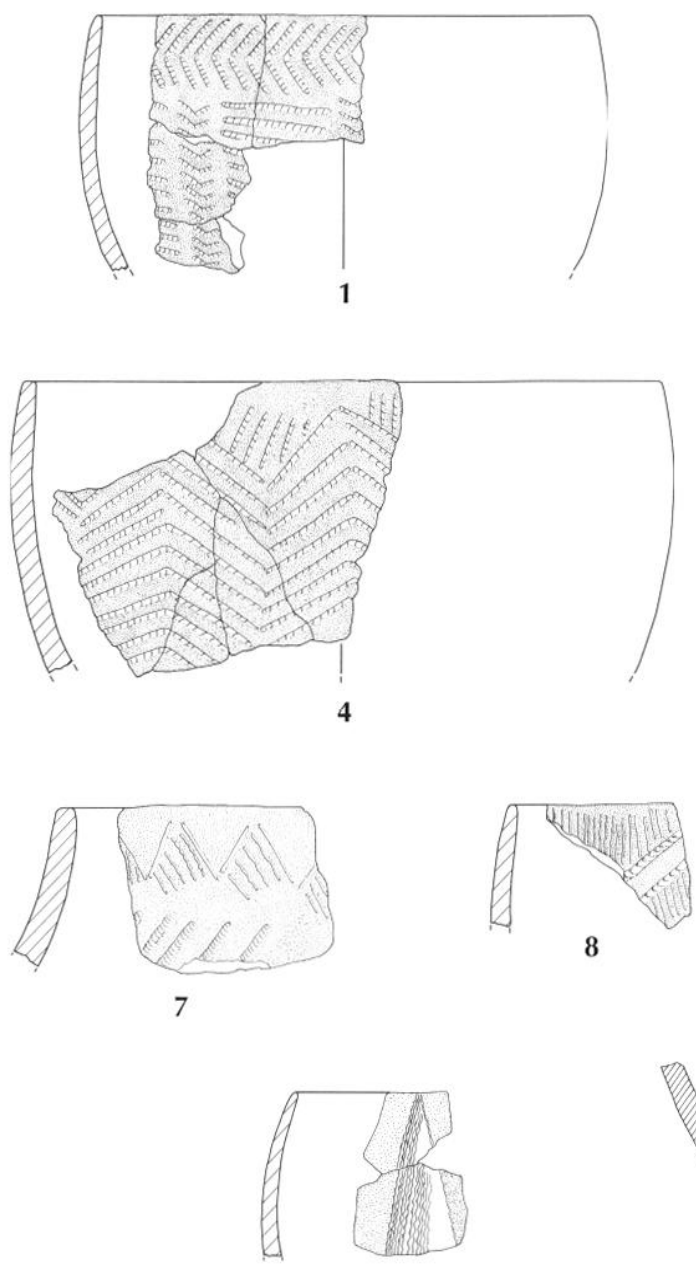

11
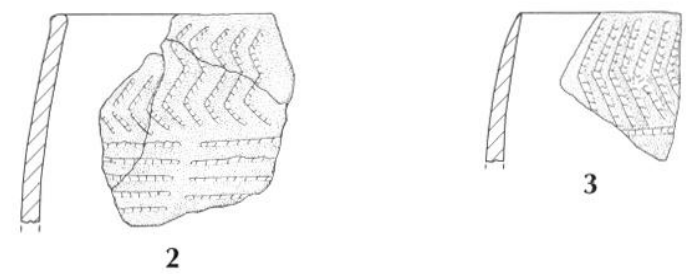

3

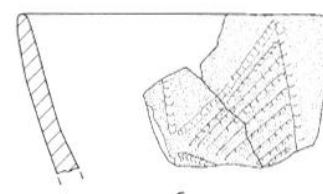

6
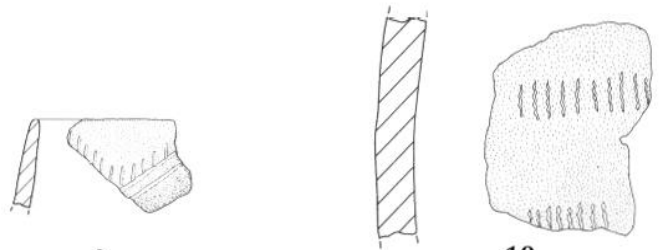

10

Fig. 26 - Formes et décors des vases de Peiro Signado (inédit, fouille Fr Briois).

d'incisions courtes verticales ou arquées (rappelant le coup d'ongle) alors que $2 \%$ des tessons sont décorés de cannelures. Quelques tessons (3\%) sont décorés d'impressions diverses, plus ou moins circulaires, allongées ou en forme de demi-lune. Enfin, $2 \%$ des tessons montrent une décoration pincée au doigt.

I es figures 25 et 26 décrivent brièvement les différents thèmes décoratifs de la céramique de Peiro Signado. La technique du sillon d'impressions est utilisée pour former des thèmes variés. La majorité d'entre eux consiste en des chevrons verticaux ou horizontaux alignés en bandes horizontales ou verticales (fig. $25 \mathrm{a}, \mathrm{g}$ ). Ces deux types peuvent être associés sur un même récipient et il est également fréquent qu'une série de chevrons de petite taille borde une autre série de taille beaucoup plus importante. Le thème en zigzags verticaux ou horizontaux alignés en bande est tout aussi fréquent (fig. 25 b). Un bon nombre de tessons est décoré de simples lignes horizontales, verticales ou obliques et parallèles (fig. $25 \mathrm{~d}, \mathrm{e}, \mathrm{h}$ ). Ces lignes peuvent également être discontinues, formant ainsi des panneaux de motifs horizontaux ou obliques parallèles (fig. $25 \mathrm{f}, \mathrm{g}$ ). Enfin, quelques rares tessons sont décorés de triangles hachurés et d'angles généralement situés près du bord (fig. $25 \mathrm{c}, \mathrm{d}$ ). Ces divers thèmes décoratifs sont parfois mêlés. Les chevrons peuvent être bordés de lignes horizontales ou verticales (fig. $25 \mathrm{~h}$ ). Celles-ci bordent systématiquement, de façon oblique, les angles et parfois les triangles. Enfin, les bandes horizontales de zigzags sont parfois bordées de panneaux verticaux formés de courtes lignes parallèles (fig. $25 \mathrm{f}$ ).

Les impressions courtes effectuées au carlium forment des lignes horizontales, verticales ou obliques qui s'étendent parallèlement sur la panse du récipient. 
Fig. 27 - Les lechniques décoratives de Pont de Roque-Ilaute (Portiragnes, Hérault).

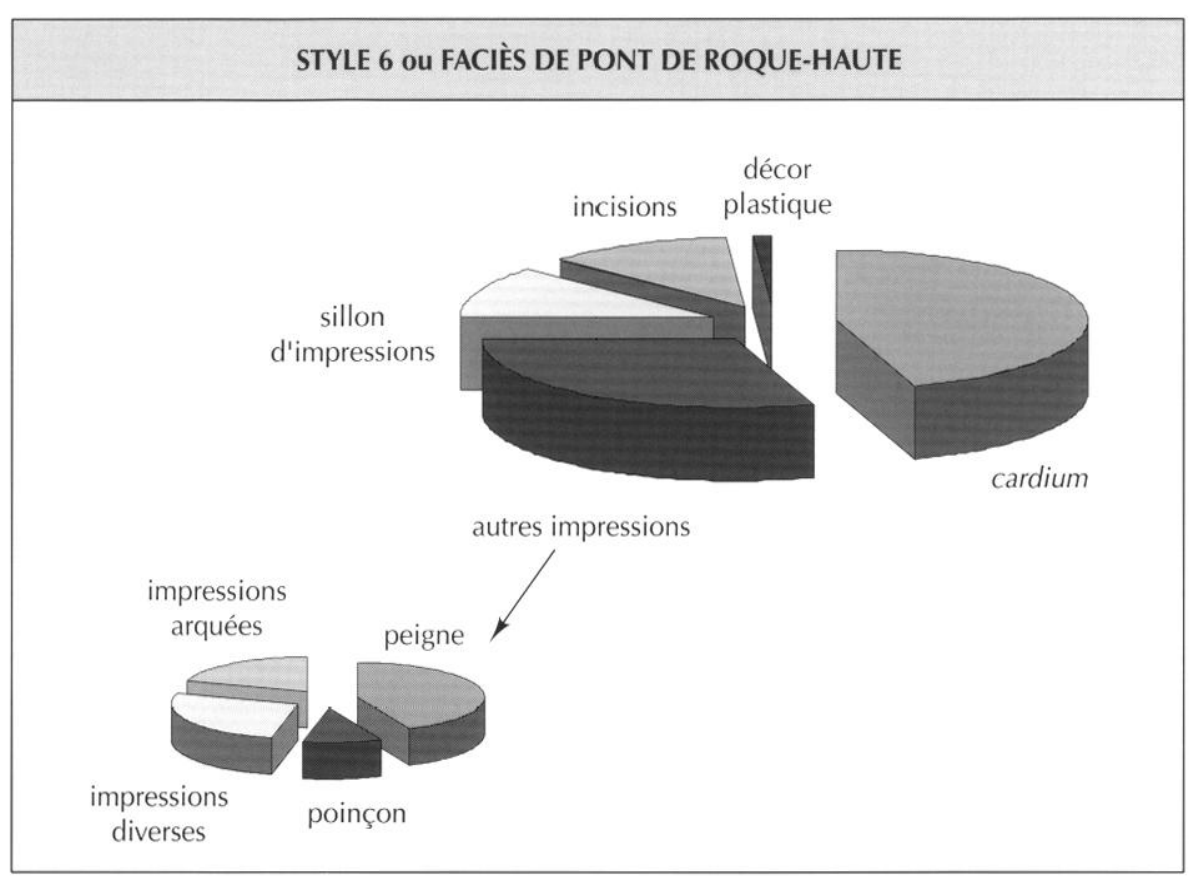

Les impressions plus longues forment des thèmes plus structurés de triangles vides ou hachurés se développant près du bord et sur la panse. On retrouve les mêmes thèmes réalisés à partir d’impressions circulaires, au doigt, ou de sillons.

Les datations de Pciro Signado placent ce style entre 5700 et 5600 avant J.-C.

\section{STYLE 6 OU FACIÈS DE PONT DE ROQUE-HAUTE}

Ce style est défini à partir de la série céramique récoltéc sur le site de Pont de Roque-Haute (Portiragnes, Hérault) fouillé en 1995 par J. Guilaine et J. Coularou.

Les formes présentent parfois un fond plat. On trouve également des bols, des marmites et des bouteilles. Les ćlćmcnts de préhensions semblent peu utilisés à Pont de Roque-Haute. Ils ne représentent que $8 \%$ de la totalité des différents types de tessons (anses en ruban, en boudin, bouton, oreille et languette, tous sont non perforés).

L'utilisation de la coquille de cardium à Pont de Roque-Haute (fig. 27) est bien représentéc puisqu'elle est utilisće sur un peu moins de la moitić des tessons décorés (42\%). Les impressions obtenues à l'aide d'un cardium imprimé perpendiculairement par rapport à la pâte (fig. 3, 1.1.1.1) sont largement majoritaires (près de $90 \%)$. On trouve plus ponctuellement des impressions obtenues à l'aide de l'envers de la coquille ou avec le crochet. Notons que lorsque l'impression est réalisée avec la crénelure du cardium, il s'agit souvent d'impressions courtes certainement réalisées à l'aide de fragments de coquilles ou de très petites coquilles.

En complément, divers autres types d'impressions sont utilisés $(33 \%)$. Viennent ensuite l'incision (12\%), le sillon d'impressions ( $11 \%$ ) et le décor plastique (2\%).

Les thèmes décoratifs associés au style de Pont de Roque-Haute sont donnés sur les figures 28 et 29 . Ils sont très majoritairement simples, formés de lignes ou bandes parallèles (fig. $28 \mathrm{a}-\mathrm{g}$ ). L'observation des fragments et des formes plus complètes montre que le décor est généralement très couvrant. Dans quelques cas, un décor plus géométrique (triangles ou angles) orne la partie supérieure du vase (fig. $28 \mathrm{~h}$-j).

Les datations de Pont de Roque-Haute placent ce style entre 5750 et 5500 avant J.-C.

\section{LE NÉOLITHIQUE ANCIEN ENTRE RHÔNE ET ĖBRE : UN ESSAI DE MODÉLISATION}

Comme nous l'avons su, le Néolithique ancien entre Rhône et Èbre est caractérisé par un polymorphisme stylistique important. Celui-ci peut être interprété en termes diachroniques, mais l'analyse des données radio- 

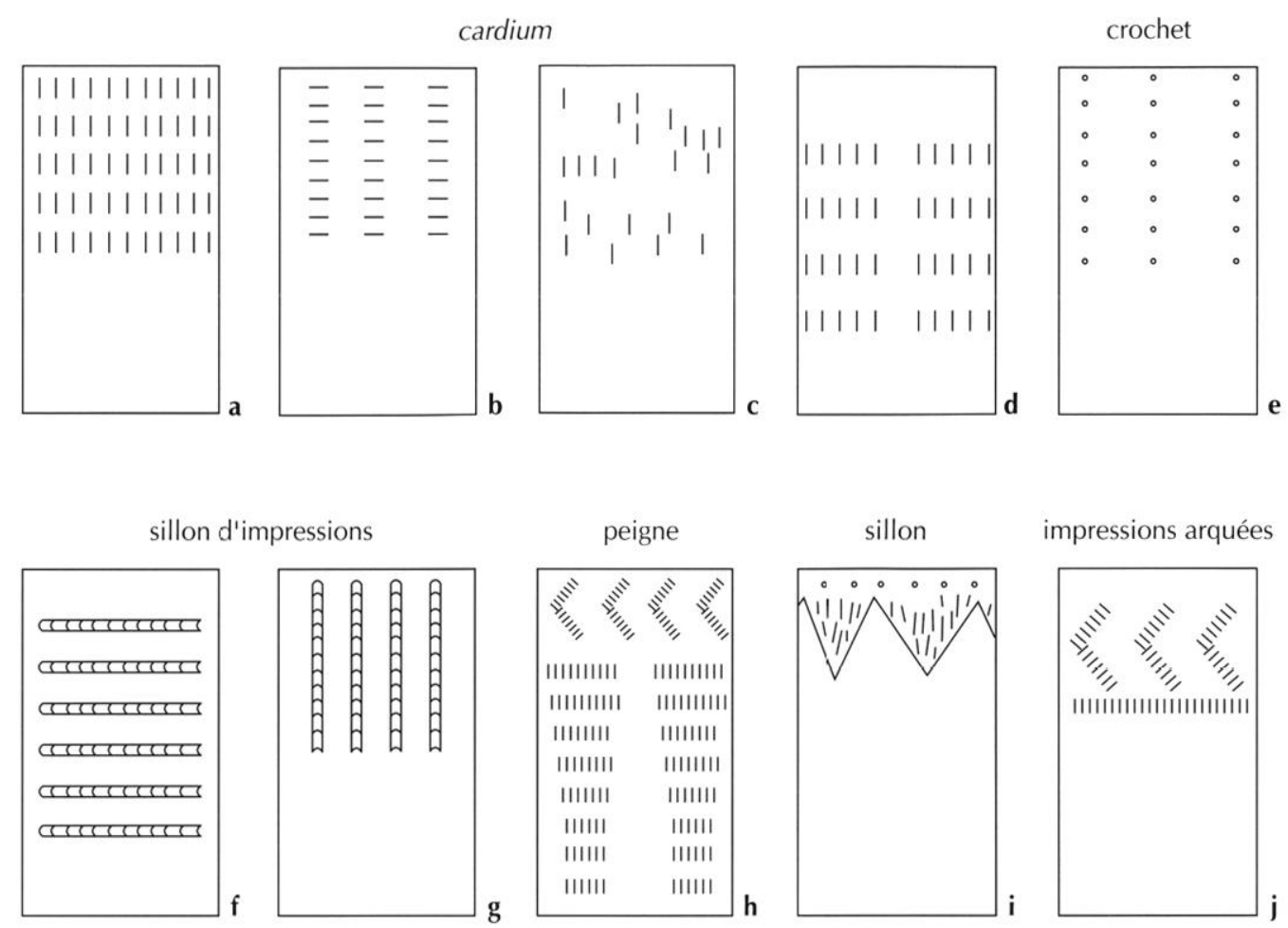

Fig. 28 - Schématisation des principaux thèmes décoratifs de Pont de Roque-Haute (Portiragnes, Hérault).

carbones montre qu'il est également possible d'envisager des phénomènes de synchronie. La présentation qui suit est découpée en trois grandes phases chronologiques pendant lesquelles coexistent souvent plusieurs styles céramiques (fig. 6 et 7). Partant du principe que ceux-ci rendent compte de stratégies identitaires exprimées par différentes communautés, nous chercherons à modéliser l'occupation de la région concernée au travers de l'identification d'ensembles culturels, de faciès régionaux, etc. On notera au préalable que notre discussion repose sur des périodes chronologiques encore très larges et que les indices relatifs aux questions d'implantation des sociétés dans le territoire, par exemple, sont très faibles. En conséquence, le modèle que nous proposons doit être pris en termes de tendances qu'il conviendra d'affiner et de compléter ultérieurement.

\section{PHASE 1 : DE 5750 À 5300 AVANT J.-C. IMPLANTATION DES PREMIERS ENSEMBLES CULTURELS À CÉRAMIQUES IMPRIMÉES}

Cette première étape du Néolithique ancien est caractérisée par un polymorphisme important. Celui-ci s'ex- plique par la diversité des cas engendrée par le processus de néolithisation (colonisation, expansion démographique, diffusion, acculturation, etc.: Mazurié de Keroualin, 2000), mais également, d'un point de vue purement diffusionniste, par la variété des influences culturelles convergeant vers la zone qui nous occupe. Plusieurs faciès culturels caractérisent donc cette phase. Il s'agit de ce que l'on nomme Cardial ancien, Néolithique à sillon d'impressions (Peiro Signado) et faciès de Pont de Roque-Haute.

Avant de réfléchir à l'articulation de ces faciès et aux implications interprétatives de leur coexistence, nous présenterons de manière très générale les caractéristiques socio-économiques de chacun d'eux ainsi que, si cela est possible, les variantes régionales observées.

C'est durant cette phase de néolithisation que des contacts entre chasseurs et agriculteurs ont pu prendre place. Certains exemples sont particulièrement éloquents, en Aragon ou en Pays valencien (Barandiaran, Cava, 1989 ; Bernabeu Aubán, 1996). En revanche, dans la zone qui nous occupe, la situation est plus confuse et nécessite une révision globale des systèmes techniques impliqués (Marchand, 1999 ; Perrin, à paraître). 

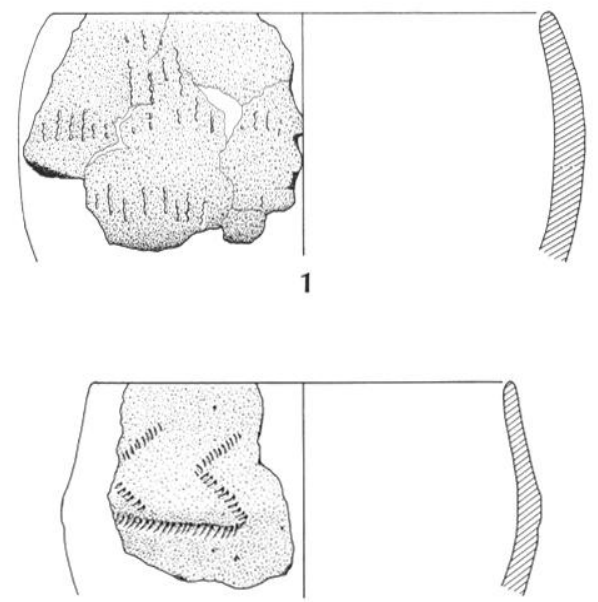

4

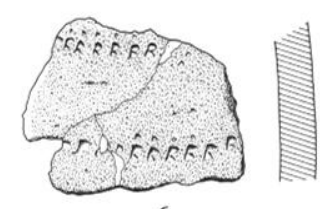

6

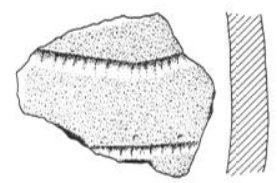

9
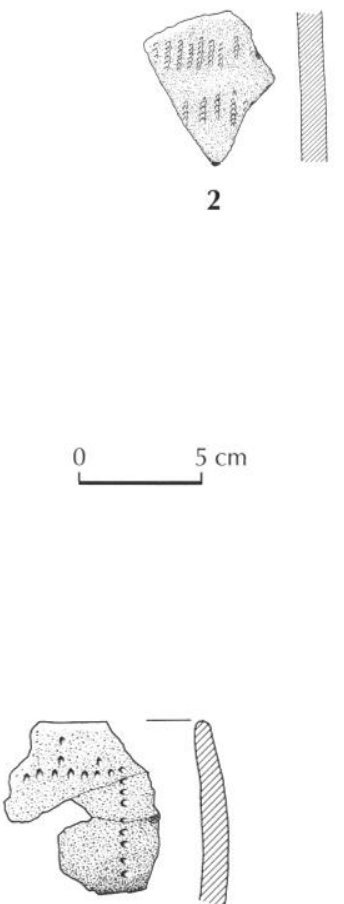

7

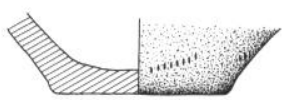

10
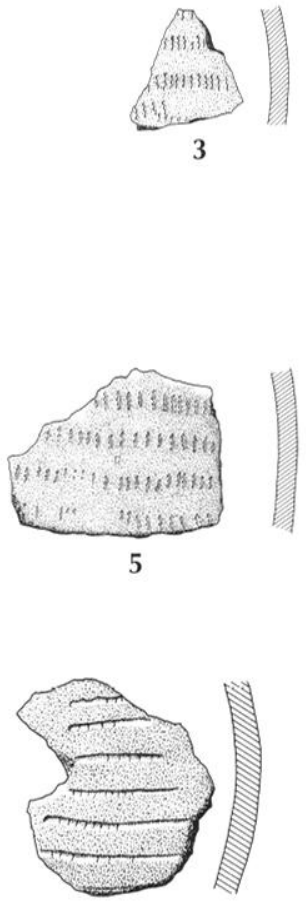

8

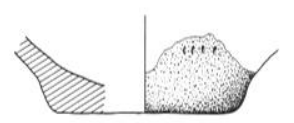

11

Fig. 29 - Formes et décors des vases de Pont de Roque-Haute (inédit, fouille J. (inilaine), dessins.J. Conularou.

\section{NÉOLITHIQUE ANCIEN À SILLON D'IMPRESSIONS ou faciès de Peiro Signado}

Parallèlement au site de Peiro Signado qui reste, dans la France méditerranéenne, la référence incontestable de ce style céramique, certains éléments typiques de ce faciès ont été découverts dans l'Aude, à la petite grotte de Bize et à la grotte des Fées (Guilaine, 1985). Ces éléments ont cependant été retrouvés hors de tout contexte stratigraphique. En Provence, ce style a été reconnu sur plusieurs sites (Binder, Maggi, 2001).

Plusieurs chercheurs ont tenté de replacer le Néolithique ancien à sillon d'impressions languedocien et provençal dans le cadre chronoculturel du Néolithique ancien méditerranéen. Les premiers fouilleurs du site de Peiro Signado (Roudil, Soulier, 1983) l'ont rattaché au gisement des Arene Candide, situé en Ligurie. Ils proposèrent, pour désigner ce faciès, le terme de "Néolithique ancien de faciès Portiragnien " remplacé ensuite par celui de « Ligurien » (Roudil, 1990, p. 386). J. Guilaine l'a un temps interprété comme contemporain de l'Épicardial d'une part, en raison de la première date, trop jeune, obtenue à Peiro Signado (Roudil, Soulier, 1983), et d'autre part en se fondant sur les données de la grotte des Fées qui montrent « la coexistence du décor de sillons d'impressions (parfois appelé "peigné"), du décor de sillons bordés d'impressions, de la décoration plastique, des cannelures, des sillons, de fines rayures. Le premier motif mis à part, tous ces thèmes sont caractéristiques de l'Épicardial " (Guilaine, 1985, p. 515). L'auteur appelle cependant à la prudence car rien ne prouve l'association stratigraphique de ces divers documents. J. Guilaine (1985, 1986) utilise la notion de faciès tyrrhénien définie, entre autres, par B. Bagolini et P. Von Eles (1978) pour distinguer les sites à céramique imprimée de motifs géométriques d'Italie du Nord, de Corse ou de Sardaigne, des sites du Cardial franco-ibérique. Selon D. Binder, il faut nuancer 
cette définition et distinguer à l'intérieur du premier groupe ceux qui utilisent en majorité le sillon d'impressions de ceux qui utilisent presque exclusivement le cardium (Binder et al., 1993). Il en découle une distinction pertinente séparant les sites de Sardaigne (Filiestru), de Corse (Basi) ou de Toscane (Pienza), rassemblés sous le terme de Cardial géométrique, des sites d'Italie du Nord (Arene Candide) et de France (Caucade, Peiro Signado), rassemblés sous le terme d'Impressa géométrique (Binder, 1995).

La reprise des fouilles de Pciro Signado, par F. Briois en 1996 et 1997, nous permet de réexaminer la question à la lumière d'un assemblage céramique particulièrement riche. Comme l'avaient déjà remarqué J.-L. Roudil et M. Soulier (1983), les caractéristiques des vestiges récoltés sur le site sont en rupture totale avec le complexe cardial : style céramique décoré au sillon d'impressions, technique de débitage axée vers une production lamellaire qui propose des lamelles régulières à talon facetté, présence d'obsidienne débitée selon la même technique (Briois, 2000), économie essentiellement basée sur l'élevage du mouton et la culture de l'amidonnier (études réalisées par I. Carrère et J.-D. Vigne pour les restes fauniques et P. Marinval pour la carpologie).

Si les meilleurs éléments de comparaison se trouvent sur le site ligurien des Arene Candide, il est difficile de dépasser ce rapprochement site à site et de rattacher Peiro Signado à une entité culturelle plus large. Les récents bilans liés au site des Arene Candide (Maggi éd., 1997 ; Tiné éd., 1999 ; Binder, Maggi, 2001) montrent les lacunes concernant la question du Néolithique ancien de Ligurie. Alors que des éléments ponctuels de comparaison se retrouvent au cas par cas sur une aire géographique étendue, il ne semble pas possible de définir un véritable faciès culturel homogène autour du site des Arene Candide. Divers gisements en grotte de l'ouest de la Ligurie, Arma dello Stefanin (Barker et al., 1990), grotta dell'Edera (Odetti, 1984), Arma dell'Aquila (Arobba et al., 1987), grotta Pollera (Odetti, 1991) et Arma di Nasino (Leale Anfossi, 1974), ont été rassemblés avec celui des Arene Candide sous le terme d'Impressa ligure (Bagolini, Biagi, 1990 ; Maggi, Starnini, 1997) qui désigne plus une localisation géographique qu'un faciès culturel. En outre, ces divers sites n'apportent pas de données satisfaisantes dans la mesure où le matériel qu'ils livrent est issu de fouilles anciennes et que l'homo- généité des assemblages est parfois douteuse. Cette situation confuse est renforcée par un ensemble de datations qui livre une fourchette chronologique large d'environ 700 ans, de 5800 à 5100 avant J.-C. (Maggi, 1997 ; Maggi, Chella, 1999).

La quasi-absence d'éléments stratigraphiques et l'incohérence des données radiocarbones ne permettent donc pas de caractériser ce faciès, tant au niveau de sa définition que de son origine. En l'état actuel des recherches, on ne peut donc que rassembler quelques sites sous un même vocable. C'est d'ailleurs ainsi que fut créé le concept de Arene Candide-Caucade-Portiragnes " au risque de confondre culture et procédé technique élémentaire" (Binder, 1995 p. 56).

En résumé, Peiro Signado doit donc être interprété comme appartenant à un faciès intrusif dans le standard du Néolithique ancien languedocien, faciès lié à la Ligurie, mais dont l'origine et le développement dans le temps et dans l'espace restent inconnus. De même, il nous est impossible de préciser la durée d'occupation du site ainsi que les relations entretenues entre ses occupants et leur région d'origine.

On doit également s'interroger sur l'incidence de ce faciès culturel italien sur le développement du Néolithique ancien cardial. Les données radiocarbones nous incitent à envisager un phénomène de contemporanéité avec le Cardial ancien, mais cette hypothèse repose sur des informations rares et peu précises (Manen, 2000a). Aucun impact n'est à l'heure actuelle visible dans les cultures cardiales. Nous élargirons la question, notamment en direction de la Provence où le site de Pendimoun, fouillé par D. Binder, livre certains éléments de réponse. Mais nous souhaitons au préalable présenter les données du site de Pont de Roque-Haute (Portiragnes, Hérault: Guilaine éd., à paraître) qui viennent enrichir et compliquer le débat.

\section{Faciès de Pont de Roque-Haute}

Bien que l'ensemble des caractéristiques conservées du système technique de Pont de Roque-Haute présente également de fortes affinités avec l'Italie, la décoration de la céramique diffère totalement de celle de Peiro Signado (Manen, 2000a). Sur ce dernier site, le décor de la céramique est réalisé au sillon d'impressions pour former des thèmes géométriques stéréotypés, alors qu'à Pont de Roque-Haute, mis à part quelques exceptions, 
tout n'est que bandes simples parallèles réalisées par l'impression d'ume coquille de cardium. Les dates de Pont de Roque-Haute sont très proches de celles de Peiro Signado (5750-5500 pour Pont de Roque-Haute et $5700-5600$ pour Peiro Signado). Elles sont également comprises dans la fourchette du Cardial ancien (Manen, 2000a). Plusieurs options se sont alors présentées pour interpréter la nature de l'assemblage de Pont de RoqueHaute au regard de ceux de Peiro Signado et du Ciardial languedocien.

Afin d'expliquer la forte proportion de cardium sur la céramique de Pont de Roque-Haute, on pourrait envisager, à titre d'hypothèse, que des contacts entre une population venant du golfe de Gênes (du style de Peiro Signado) ct unc population cardiale aient abouti à la formation d'un style céramique " hybride ", entre celui du Cardial et celui du Néolithique ancien à sillon d'impressions. I'étude planimétrique de la répartition du matériel sur le site ne présente pas d'exclusion entre les caractéristiques "cardiales " (décorations effectuées au cardium) et les caractéristiques "italiennes " (décor au sillon d'impressions, céramique à fond plat, obsidienne, etc.). Rappelons en revanche que les autres composantes du système technique ne montrent aucun lien avec le Cardial.

Pont de Roque-I laute pourrait également correspondre à un faciès particulier du Néolithique ancien de l'Italie que l'on ne peut encore définir faute, on l'a vu plus haut, de données suffisantes. Il faut cependant remarquer que l'assemblage céramique livé par le site de l'Isola del Giglio (Brandaglia, 1991), située au sud de l'île d'Elbe, semble montrer les mêmes caractéristiques que celui de Pont de Roque-Haute. On trouve en effet l'utilisation très majoritaire de la coquille de cardium, l'utilisation de techniques d'impressions variées (peigne, outil arqué, doigt) et également la non-géométrisation des thèmes décoratifs. Cet élément de comparaison nous rapproche plus particulièrement de la sphère méridionale de l'Italic où l'utilisation du cardium pour former des thèmes décoratifs simples et couvrants est fréquente (Tiné, Natali, 1996).

Enfin, on peut envisager que les mécanismes responsables de la formation de l'assemblage ceramique de Pont de Roque-Haute soient d'un autre ordre. Ices différences observées entre les céramiques de Pont de RoqueHaute et de Peiro Signado pourraient être attribuées à une fonction particulière du site (aire de stockage,...) entraînant l'utilisation d'une classe spéciale de céramique. Nous aurions donc une vision partielle du stock céramique. Cependant, cette hypothèse ne nous semble pas convaincante dans la mesure où, parmi les éléments céramiques récoltés, la totalité de l'éventail morphologique et stylistique présent à Peiro Signado est représentée à Pont de Roque-Haute. Dans l'état actuel des recherches, c'est l'hypothèse d'un rattachement culturel vers l'Italic centro-méridionale qui nous semble la plus probable. Cependant, il est difficile de relier Pont de Roque-Haute et l'Isola del Giglio à une entité culturelle plus large dans la mesure où le Néolithique ancien de l'aire tyrrhénienne est encore mal sérié (Grifoni Cremonesi, 2001).

Du point de vue économique, les faciès de Peiro Signado et de Pont de Roque-Haute présentent un Néolithique pleinement formé tel que l'on peut le retrouver en Italie. I.es animaux domestiques (ovicaprinés essentiellement) dominent largement les ressources carnées (plus de $90 \%$ ). Quelques restes de coquillages marins montrent la pratique de la collecte. Les ressources végétales cultivées sont également abondantes. Elles sont dominées par la culture du blé amidonnicr. L'industrie lithique des deux sites est très proche. L'outillage est principalement constituć à partir de lamelles régulières à talon facetté. Celles-ci sont retouchées ou utilisées pour fabriquer des perçoirs, des coches et des trapèzes symétriques par bitroncature (Briois, 2000). L'utilisation d'obsidienne, dont l'origine est en cours de détermination, renforce les liens avec l'Italie. Enfin, le macro-outillage est très bien représenté, notamment par un nombre important de meules.

Nous nous trouvons donc face à la présence sur les côtes languedociennes, dès 5750 avant J.-C., de deux styles céramiques pouvant, à notre sens, être interprétés comme caractéristiques de deux faciès culturels différents mais dont l'origine italienne est commune.

Ces sites nous incitent à envisager un cas de diffusioncolonisation typique, au minimum depuis la Ligurie et peut-être à partir du centre de l'Italie. Leur implantation côtière parle en faveur d'une diffusion par voie maritime, par exemple par cabotage, comme l'arait proposé Jean-Louis Roudil (1990), les sites provençaux (Caucade, etc. : Binder, Courtin, 1987) fournissant de bons jalons entre l'Italie et le languedoc. On ne peut cependant évacuer l'hypothèse d'une voie de pénétration continentale le long des côtes ligures, provençales et languedo- 
ciennes. La découverte de nouveaux sites tels que celui de Codoyères à Tavel (Gard) irait dans ce sens (Monnet, 2002). L'absence, à l'heure actuelle, de caractères rapprochant le Cardial languedocien des faciès italiens nous incite à nous interroger sur la nature des occupations de ces deux sites, ceci dans le cadre d'un processus "diffusionniste ". Les structures découvertes et la taille supposée des deux gisements ne plaident pas en faveur d'une occupation très longue. De même, le site de Peiro Signado propose une seule unité d'habitation témoignant de la faible ampleur du groupe humain l'occupant. La nature des deux sites permet d'imaginer une occupation ponctuelle du littoral languedocien.

Ces gisements relancent donc les concepts de diffusion et de colonisation sans pourtant permettre d'envisager un système figé évoluant toujours dans une même direction. Des liens complexes entre les sphères cardiales et impressa ont pu exister sans que nous puissions actuellement les identifier. Ils sont par ailleurs démontrés par la circulation importante de matières premières depuis la Ligurie (Ricq de Bouard, 1996). Quelles ont pu être les conséquences de cette contemporanéité ? Y a t-il réellement eu contemporanéité ? Le manque de précision du radiocarbone nous empêche de conclure. La position chronologique des deux sites est claire : 5700 à 5600 avant J.-C. L'hypothèse de la contemporanéité du Cardial ancien et des sites de Pont de Roque-Haute et de Peiro Signado repose sur une petite série de datations hautes qui est parfois ignorée. Il s'agit de la datation de Leucate, contestable en raison de la nature du gisement, mais également des datations cohérentes de la phase A de Gazel et des niveaux inférieurs de Fontbrégoua. D'autre part, la présence d'un véritable Cardial ancien dans la moyenne vallée du Rhône dès 5600 avant J.-C. (baume d'Oullins) nous pousse davantage à placer le début du Cardial ancien aux environs de 5700 avant J.-C. (Manen, Sabaticr, à paraître). Dans le cadre de cette réflexion on doit également faire référence aux données chronostratigraphiques livrées par le site de Pendimoun (Binder et al., 1993 ; Binder, Maggi, 2001). L'horizon de base de la séquence stratigraphique de ce site est proche de celui des faciès à impressa de l'Italie et donc de Peiro Signado et de Pont de Roque-Haute. Vient ensuite un horizon qui s'apparente au Cardial de Toscane, de Corse et de Sardaigne. Enfin, le dernier horizon est plus probablement comparable au Cardial provençal. Cependant, les solutions de continuité et termes de passage entre ces horizons restent à préciser.

\section{CARDIAL ANCIEN}

La répartition de ce faciès dans la zone considérée est assez diffuse. Certains points de concentration sont nets comme par exemple dans la vallée du Llobregat. La majorité des sites sont en grottes, mais deux exceptions sont cependant notables: celle de Leucate, Aude (Guilaine et al., 1984) et celle de Les Guixeres de Vilobi, Penedès (Baldellou, Mestres, 1981). Ces sites confirment l'existence d'un habitat de plein air. Aucun fait tangible ne permet cependant pour l'instant de préciser les relations entretenues entre les sites de plein air et les gisements en grotte.

On constatera que la pénétration dans les terres est déjà importante à cette époque. La baume d'Oullins (5600 et 5430 avant J.-C.) et la cueva de Chaves (5600 et 5300 avant J.-C.) sont en effet éloignées du littoral. Il en est de même pour les grottes de Valldan (Castany et al., 1993) situées au cœur de la province de Lleida. Les assemblages céramiques des deux premiers gisements offrent d'ailleurs une décoration très variée par rapport à celle des assemblages du littoral. Les techniques d'impressions rivalisent en effet dans leur multiplicité. Faut-il $y$ voir un phénomène de rupture entre les sites littoraux, offrant des assemblages plus stéréotypés, et ceux de l'intérieur des terres, rompant avec la "norme " pour acquérir une certaine liberté ?

D'un point de vue géographique toujours, il est possible de distinguer certains faciès au sein de ce que l'on nomme traditionnellement le "Cardial francoibérique ". Les sites du Languedoc oriental sont assez proches de ce que l'on trouve en Provence. En Languedoc occidental, le Cardial ancien est mal représenté. Nous pensons que cette mauvaise représentation est simplement due à un biais de la recherche ou plus certainement à un problème taphonomique (Manen, à paraitre). Quoi qu'il en soit, le site de Leucate offre un assemblage très intéressant, proche du Cardial catalan. Les différentes modalités d'emploi de la coquille (impression de l'envers complètement à l'oblique de la pâte, impression trânée du bord, emploi du crochet, le tout souvent simultanément) et certains thèmes décoratifs (beaucoup d'encadrement au crochet, guirlande) rappellent en effet les assemblages des sites de Les 
Guixeres de Vilobi et de l'Esquerda de les Roques del Pany. Un décor particulier, effectué au cardium imprimé, évoque par ailleurs les décors zoomorphes du Cardial valcncicn (Guilaine et al., 1984, p. 116).

En Catalogne, les grottes de Montserrat ont livré un très abondant mobilier malheureusement hors de tout contexte stratigraphique (Colomines, 1925). La céramique cardiale de ces sites présente une richesse dans la décoration très exceptionnelle qui rappelle celle du Cardial valencien. On la retrouve d'ailleurs dans le niveau inférieur de la cova del Frare (Martín et al., 1981, 1985) ou à la cova del Toll (Guilaine, 1986). Curieusement, et bien que beaucoup de liens les unissent, on n'observe pas cette richesse et cette exubérance dans les asscmblages dc Lcs Guixcres dc Vilobi ct de l'Esquerda de les Roques del Pany (Baldellou, Mestres, 1981 ; Baldellou et al. 1989). Restent à définir les mécanismes responsables de la formation de ces différents faciès. La différenciation géographique ou fonctionnelle pourrait être invoquée, mais il ne serait pas plus improbable d'envisager des mécanismes liés au temps. La tranche chronologique du Cardial ancien est en effet longue de près de 400 ans.

Du point de vue économique, le Cardial ancien du Languedoc présente un cortège classique dominé, pour la faunc, par lcs ovicaprinćs ct, pour le végétal, par le blé nu. La chasse et la cueillette gardent cependant une part importante. De manière plus singulière, la grotte de l'Aigle présente un rapport plus équilibré entre faune sauvage et domestique. Le site a été interprété comme " abri de chasse cardial " (Roudil et al., 1979). En Catalogne, de récentes synthèses proposent de dissocier les habitats de plein air, où les bovinés et les suinés dominent, des habitats en grotte, où l'on retrouve le cortège habituel dominé par les ovicaprinés (Molist Montaña et al., 1997; Saña Segui, 1997; Bosch et al., 1998). Cependant, les sites de plein air (La Draga, Plansallosa) appartiennent à une période plus récente du Cardial. Il se pourrait donc que cette différenciation soit d'ordre chronologique. La cova del Toll et la cova del Frare, sites en grotte et Les Guixeres de Vilobi, site de plein air, ne semblent pas montrer de différences majeures (Martín Colliga, Estevez i Escalera, 1992 ; Miró, 1992). On observe la domination des ovicaprinés domestiques (près de $60 \%$ ) sur les autres espèces. À Les Guixeres de Vilobi, la faune sauvage représente $25 \%$. À la cova del Frare, les suinés domestiques et les bovinés sont relativement bien représentés avec respectivement $17 \%$ et $16 \%$.

L'industrie lithique du Cardial ancien est caractérisée par un débitage lamellaire par percussion indirecte, à partir de roches locales. Bien que l'équipement varie en fonction de la nature économique des sites (Binder éd., 1991), on peut dire que l'outillage est généralement composé d'armatures tranchantes, de lamelles retouchées, de becs, d'encoches, de troncatures, de grattoirs et de denticulés. Les trapèzes et les triangles sont façonnés grâce à la mise en cuuvre de retouches rasantes directes postérieures à une ou deux troncatures inverses (Binder, 1987 ; Briois, 1997).

Pour conclure, on peut dire que la première phase du Nćolithique ancicn cntre Rhône et Èbre, que nous situons entre 5750 et 5300 avant J.-C., fait preuve d'un très important polymorphisme. Celui-ci semble induit par des processus très variés de néolithisation et par la diversité des systèmes économiques adoptés. De plus, la reconnaissance de plusieurs courants culturels, d'origine assez différente, présents sur le littoral dès 5750 avant J.-C., vient ajouter à la complexité d'un paysage culturel multiforme.

\section{PHASE 2 : DE 5400 À 4900 AVANT J.-C. DE LA COQUILLE AU POINÇON}

Nous avons pu montrer que deux styles céramiques (styles 2 et 3), dénommés Cardial récent et Épicardial ancien, cohabitaient entre 5400 et 4900 avant J.-C. dans notre zone d'étude (Manen, 2000b). Ces deux styles céramiques font référence à deux mondes culturels traditionnellement opposés : celui des céramiques à décor imprimé et celui des céramiques à décor cannelé. Au regard des données chronologiques disponibles, ces deux styles semblent avoir été partiellement contemporains sans qu'il soit possible d'observer, à l'heure actuelle, de partition géographique nette. Cette hypothèse avait déjà été émise (Binder, 1995; Van Willigen, 1999).

La filiation entre Cardial ancien et Cardial récent est nette puisque malgré certains changements les éléments clés constitutifs de ces deux faciès restent les mêmes. Le Cardial récent a bien été individualisé en Provence (Binder éd., 1991 ; Échallier, Courtin, 1994), dans la moyenne vallée du Rhône (Beeching, 1995), en Aragon 
(Baldellou, Utrilla, 1999) et également en Catalogne (Bosch i Argilagós, 1993; Bosch i Lloret, 1994). Les caractéristiques stylistiques de la céramique peuvent se manifester différemment suivant les régions, mais d'une manière générale l'utilisation de la coquille de cardium régresse au profit d'impressions de types variés. Les décors sont beaucoup moins structurés que pendant la phase ancienne. Les modalités d'implantation de ce faciès restent les mêmes que les précédentes. On trouve des habitats en grottes (grotte de Saint-Marcel, abri de La Tardive, cova de la Font Major) mais également des établissements de plein air (Plansallosa I, La Draga).

En revanche, la contemporanéité chronologique du Cardial récent avec un faciès de type épicardial reste plus difficile à expliquer. Si l'origine du Cardial récent ne pose pas de problèmes, qu'en est-il de l'Épicardial ancien ? Doit-on l'interpréter en terme de rupture ou de continuité avec le Cardial ancien? Le travail de S. Van Willigen (1999) envisage une rupture entre le Cardial et l'Épicardial, pris dans leur ensemble (sans distinction des phases ancienne et récente). Cette hypothèse repose sur la reconnaissance de différences d'ordres typologiques et technologiques au sein de la production céramique. La céramique cardiale serait soignée et présenterait des formes et des décors variés. La céramique de l'épicardial correspondrait à " une production de qualité généralement médiocre et peu différenciée au niveau des formes et des décors " (Van Willigen, 1999, p. 577). De plus, le Cardial et l'Épicardial montreraient, toujours selon l'auteur, des zones de répartition en grande partie très distinctes. L'Épicardial serait donc en rupture avec le Cardial et l'auteur propose de voir l'Épicardial comme résultant de l'évolution des groupes péricardiaux en contact avec le Cardial. Cette option avait également été utilisée par E. M. Lasserre-Martinelli (1979) qui interprétait l'Épicardial comme un groupe tampon entre le Cardial et les derniers Mésolithiques.

En ce qui concerne l'hypothèse d'une rupture typologique et technologique entre la céramique cardiale et épicardiale, l'observation d'assemblages riches et bien conservés, tels que ceux de la baume d'Oullins (c. 6 rapportée au (ardial ancien), de la grotte Gazel (F́picardial ancien et récent), de la grotte du Taï (Épicardial ancien, fouille en cours) et de la baume Bourbon (Épicardial ancien) par exemple, ne nous a pas permis d'observer de telles différences. Du point de vue de la technologie, les récipients de Gazel montrent dans certains cas un soin tout particulier des surfaces. Dans la plupart des cas, la surface est simplement mais soigneusement lissée comme elle peut l'être sur les vases d'Oullins. Ces observations sont corroborées par les analyses de W. K. Barnett (1989). Les formes sont à peu près identiques (Manen, à paraître). Enfin, en ce qui concerne le "peu de variété des décors épicardiaux ", on observe au contraire, pour l'Épicardial ancien, un style décoratif dominé par une profusion de techniques et de thèmes décoratifs. En effet, en plus de l'utilisation des techniques imprimées qui tendent à régresser, les techniques incisées et cannelées font leur apparition. De même, les thèmes décoratifs, bien qu'ils soient dominés par quelques types particuliers, offrent une grande variété. Nous l'avons déjà dit, la rupture stylistique entre le Cardial ancien et l'Épicardial ancien se situe principalement au niveau des fréquences d'utilisation des grandes classes de techniques décoratives. Bien que l'Épicardial ancien soit principalement caractérisé par une décoration faite de cannelures, il n'est cependant pas rare de trouver une décoration faite au cardium. De même, il est fréquent de retrouver, dans les assemblages de l'Épicardial ancien, des thèmes décoratifs rappelant ceux du Cardial ancien, mais réalisés à la cannelure: chevron, triangle, zigzag. En Catalogne, la continuité Cardial/ Épicardial a également été observéc. J. Tarrús i Galter (1981, p. 57) signale d'ailleurs que la qualité ainsi que la variété des céramiques augmentent entre le Cardial et l'Épicardial.

On n'observe pas non plus de changements radicaux dans l'industrie lithique (Briois, 1997). La phase B de Gazel propose un outillage peu diversifié principalement composé d'éclats retouchés et d'armatures tranchantes. Celles-ci sont de divers types: flèche de Jean Cros, armatures tranchantes triangulaires et trapézoïdales. En Catalogne, on observe le même phénomène de continuité entre les gisements du Cardial et de l'Épicardial (Bosch i Lloret, 1991 ; Martín Colliga, 1992). Tous ces indices, que nous avons développés ailleurs (Manen, à paraître), nous conduisent donc à envisager une logique de continuité culturelle entre le Cardial ancien et l'Épicardial ancien.

Selon cette hypothèse, il faut donc admettre que le Cardial ancien s'est développé parallèlement vers un Cardial récent et un Épicardial ancien. Comment cependant expliquer ces expressions stylistiques diffé- 
rentes? L'explication la plus simple pourrait reposer sur l'observation d'une différenciation dans les aires de répartition des deux styles céramiques. Comme nous l'avons déjà signalé, aucune partition géographique ne peut être réellement observée. En Catalogne, de nombreux travaux font référence aux modalités d'occupation du territoire. Ce type de démarche repose sur deux points principaux : l'observation de la répartition des sites et l'acceptation d'une forme de contemporanéité entre gisements. Ces deux points ne sont pas sans poser de difficultés quand on connaît les importants problèmes taphonomiques caractérisant le Néolithique ancien ainsi que la difficulté liée à la gestion du temps, c'est-à-dire à la reconnaissance de gisements récllement contemporains.

J. Mestres i Mercadé (1992) avait proposé une hypothèse intéressante. D'après l'observation de l'implantation géographique des gisements cardiaux et épicardiaux catalans, l'auteur envisageait une contemporanéité de ces deux faciès. I es premicrs correspondaient aux implantations de type " pionnic̀re " (selon la terminologie définie par A. (xallay en 1989), les seconds aux implantations de type "néo-pionnière " de la même communauté humaine. De même, A. Martín Colliga (1992) observe un changement dans l'occupation du territoire de la Catalogne à partir de l'épicardial. Selon l'auteur, on assiste à une colonisation de nouvelles terres vers l'intérieur du territoire. Les habitats de plein air deviennent alors plus fréquents. Divers travaux exposent le même phénomène pour des zones plus restreintes de la Catalogne (Miró, 1990) Bosch, Tarrús, 1991). En I anguedoc, le manque de sites cardiaux entrave ce type de réflexion. Il ne semble cependant pas exister de bipartition aussi nette qu'en Catalogne.

Quel(s) est ou sont le(s) mécanisme(s) ayant entraîné la formation de deux styles céramiques différents, sur la même zone, à partir d'un même fonds commun? I'hypothèse d'une dualité entre l'occupation du littoral et la pénétration à l'intérieur des terres pourrait paraitre séduisante. On aurait sur la côte les gisements du Cardial récent gardant une identité proche de celle du Cardial ancien. L'Épicardial ancien serait le résultat d'une colonisation plus à l'intéricur des terres aboutissant à un changement identitaire, le poinçon et la cannelure remplaçant le cardium. L.es faits archéologiques ne permettent pas, à l'heure actuelle, de valider cette hypothèse.

\section{PHASE 3 : DE 5000 À 4500 AVANT J.-C CONSOLIDATION ET HOMOGÉNÉISATION}

Cette dernière étape du Néolithique ancien roit le développement de l'Épicardial récent (style 4). Il s'étend avec une surprenante homogénéité, du point de vue de la stylistique céramique, surr toute la zone considérée et, plus loin, en Pays valencien et en Andalousie.

L'Épicardial récent correspond à la période de maturation du monde des céramiques à décor cannelé. Les décors imprimés sont quasi inexistants. I.es modalités d'occupation des terres sont très varićes : de la moyenne vallée du Rhône (Espeluche-Lalo) au littoral du sud de la Catalogne en passant par des milieux plus difficiles tels que ceux de la bordure sud du Massif central (grotte de l'Ourtiguet, grotte (iazcl, Camprafaud, etc.). Certaines nouveautés stylistiques apparaissent. I a céramique présente des formes et des décors qui annoncent la transition vers le Néolithique moyen, c'est-à-dire vers les horizons à poterie lisse (Chasséen ancien, Montbolo, etc.). I es formes basses sont plus courantes et certains décors plastiques annoncent les décors en "moustaches du Montbolo ». Parmi l'outillage lithique (Briois, 2000), on observe en Languedoc, l'apparition des premières flèches perçantes triangulaires, à base droite ou légèrement concave, du type fléchcttes du Martinct. Ia technique Jean Cros est en régression très nette et laisse la place à celle du double biseau. De plus, on note l'existence de quelques éléments de silex blond exogène introduits sous la forme d'outils ou de géométriques sur lames dans plusieurs assemblages de l'Épicardial récent (Camprafaud c. 16, Font-Juvénal c. 12, et Gazel phase C). Ces éléments annoncent les prémices de la mutation technologique qui s'opère au Chasséen ancien (Briois, 1997). En Catalogne, on n'observe pas de changements particuliers (Bosch et al., 1998). D. Geddès (1980, p. 128) remarque pour la phase finale du Néolithique ancien que les suinés, et plus faiblement les bovinés reprennent de l'importance par rapport aux caprinés. « Si l'apparition précoce des ovicaprinés domestiques est le premier facteur du développement de l'élevage dans la vallée de l'Aude, l'équilibrage de l'exploitation des ovicaprinés et de l'élevage du porc constitue le processus central de la deuxième moitié du Néolithique ancien ».

À côté de cette étomnante homogénéité, on retrouve dans le nord de la Catalogne un style céramique contemporain, s'exprimant au travers d'une décoration asse\% 
différente, principalement dominée par l'utilisation de cordons lisses. Les décors cannelés bordés de coups de poinçon sont présents mais en proportion moindre. Ce style correspond à l'Épicardial final d'Ángel Bosch i Lloret (1991). La coexistence de plusieurs styles céramiques épicardiaux avait déjà été remarquée par Josep Tarrús i Galter (1983). L'origine de l'Épicardial final de Catalogne reste cependant à définir.

Cette dernière phase annonce donc par de nombreux points les changements du Néolithique moyen (Jédikian et al., à paraître). Dans la région qui nous occupe, l'homogénéité culturelle de la dernière phase du Néolithique ancien fait place à une diversité régionale importante : Chasséen ancien en Languedoc, Montbolo dans la région des Pyrénées, Molinot et Amposta au sud de la Catalogne. Le passage entre les derniers horizons épicardiaux et les premiers faciès à céramiques lisses se situe aux environs de 4500 avant J.-C. La question des modalités de transition aboutissant à la rupture culturelle qui s'installe au milieu du cinquième millénaire reste entière.

* *

Au terme de cet article, plusieurs remarques s'imposent. Celles-ci concernent différents domaines de réflexion qui s'articulent autour des principaux thèmes abordés : le document céramique, la caractérisation du Néolithique ancien entre Rhône et Èbre et ses relations avec celui de la Méditerranée occidentale.

Longtemps utilisée comme traceur culturel, la céramique du Néolithique ancien, et plus particulièrement sa décoration, permettait à l'archéologue de jeter les bases d'une discussion à partir de quelques tessons isolés, en terme de présence/absence. Parmi les nombreux excès inhérents à cette pratique, on peut par exemple citer celui qui consiste à rattacher au complexe Cardial l'ensemble des décors effectućs au cardium, même si ceux-ci sont associés à d'autres éléments peutêtre plus pertinents (poinçon, cannelure, peigne, etc.). Nous avons montré au contraire l'importance de la quantification et insistons sur le fait que le décor céramique n'est signifiant qu'abordé en série, au même titre que les ensembles lithiques ou les restes fauniques (Vigne, 1988). Le décor au cardium, puisque c'est essentiellement de lui qu'il s'agit, ne possède de valeur que s'il est confronté aux autres types de décoration, et ceci en termes quantitatifs.
Dans cette optique quantitative, on doit abandonner, pour la construction des modèles explicatifs, les petits assemblages céramiques dont la valeur chronoculturelle est hasardeuse. En accord avec ces restrictions, on reconnaîtra la rareté des ensembles homogènes et significatifs, imposant le développement de nouvelles fouilles de plein air, mais aussi de grottes. Devant l'état actuel des connaissances, l'observation stratigraphique demeure en effet essentielle, notamment pour la compréhension de l'articulation des divers complexes culturels et de leurs termes de passage.

Le deuxième aspect que nous souhaitons aborder concerne le Néolithique ancien entre Rhône et Èbre. Nous avons pu définir trois phases chronologiques principales, durant lesquclles cohabitcnt ou se succèdent divers faciès dont l'origine et la nature restent parfois floues. La fourchette chronologique de chacune de ces phases demeure large, puisqu'elle n'est pas inférieure à 500 ans.

Le canevas que nous avons établi demande à être affiné. Cette recherche doit s'opérer à divers niveaux.

Le premier concerne différents domaines d'étude et fait appel à la notion de pluridisciplinarité. Une meilleure analyse de l'implantation de chaque site dans le territoirc facilitcra l'approche socio-économique de ces faciès culturels. De même, l'analyse et l'observation du comportement de différents types de vestiges devraient permettre l'étude de la complémentarité des systèmes techniques entre groupes humains contemporains. Les modalités de cohabitation entre le Cardial récent et l'Épicardial ancien pourraient à ce titre être précisées. Dans cette optique, la reconstitution des paléoenvironnements est également essentielle. En parallèle, l'affinement des critères descriptifs du document céramique, aussi bien en ce qui concerne l'étude des pâtes, des formes ou des décors (travaux en cours), devrait aboutir, par le biais de la sériation, à la précision du cadre chronoculturel du Néolithique ancien entre Rhône et Ėbre. Enfin, on pourra s'attacher à analyser la variabilité interne de chaque style, mieux cerner leur limite, et caractériser les phénomènes d'interaction (notions de transferts et d'incorporations d'éléments étrangers, etc.).

Si on élargit le débat au-delà de ce cadre géographique, c'est vers la compréhension de l'articulation chronologique des différents faciès culturels que devra 
s'orienter la recherche. Cet aspect pourra principalement être abordé par la fouille de gisements stratifiés. On devra également s'interroger sur l'origine de différents faciès, dont celui du Cardial franco-ibérique. Quels sont les liens qui l'unissent au Ciardial de l'aire tyrrhénienne, dont l'homogénéité est toute relative ? La bonne connaissance du Néolithique ancien de la Méditerranée occidentale souffre, entre autres, d'un manque de compréhension des termes de passage entre les différentes entités reconnues qui ne représentent, pour certaines, qu'une réalité géographique. Qu'indiquent les ruptures observées entre les complexes Impressa et cardiaux? Quels liens unissent l'Impressa sud-italienne à l'Impressa ligurienne? Ou encore, que représentent les assemblages tels que ceux de l'Isola del Giglio ou de Pont de Roque-Haute?
Les éléments de réponse sont encore rares mais nous espérons avoir montré que l'étude de plusicurs assemblages céramiques homogènes par le biais de l'analyse quantitative pouvait être instructive. En outre, ces résultats doivent pour prendre toute leur dimension être confrontés aux données des restes fauniques, de l'industrie lithique, etc. Ce type de travail demande une double approche : d'une part centrée sur une aire géographique relativement restreinte, afin de ne pas ignorer les particularismes locaux et les solutions de continuité (Languedoc-(atalogne par exemple), et d'autre part centrée sur une aire géographique beaucoup plus vaste (Méditerranée occidentale). Cet aller-retour permanent entre différentes échelles d'analyse est en effet essentiel à la bonne compréhension du Néolithique ancien de la Méditerranée occidentale. 


\section{BIBLIOGRAPHIE}

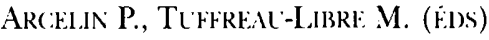

1998 : La quantification des céramiques. Conditions et protocole, Actes de la table ronde du Centre archéologique du Mont Beuvray, Glux-en-Glenne, avr. 1998, Bibracte, 2, $139 \mathrm{p}$.

Arnat. G.-B.

1983: La grotle IV de Saint-Pierre-de-latiage (Hérault) et le Néolithique ancien du Languedoc, Lodève, Centre de recherche archéologique du HautLanguedoc, Mćmoire du centre de recherche archéologique du HautI anguedoc, 3, $195 \mathrm{p}$.

Arobba D., Blagi P., Formicola V., Ode:tTI E., Nisbl:t R.

1987 : "Nuove osservazioni sull'Arma dell'Aquila (Finale Ligure, Savona)", in Il Neolitico in Italia, Atti della riunione scientifica, XXVI, Firenze, nov. 1985, Firenze, Istituto italiano de preistoria e protostoria, p. 541-551.

B.sionini B., Busil P.

1990: "The radiocarbon chronology of the Neolithic and Copper Age of Northern Italy ", Oxford Journal of Archaeology, 9, 1, p. 1-23.

B.IGOLINI B., VON EILS P.

1978 : “ L'insediamento neolitico di Imola e la corrente culturale della ceramica nel medio e alto Adriatico ", Preistoria alpina, 14, p. 33-63.

BALARLIOL $V$.

1987 : "Avance al estudio de la Espluga de la Puyascada ", Bolskan, 4, p. 3-42.

BALIDFII.OL V., MistRI:S J.

1981 : «Les Guixeres de Vilobi, hàbitat del Neolitic antic a l'aire lliure ", in $l i l$ Neolitic a Catalumya, Taula rodona de Montserrat, mai 1980, Montserrat, publicaciones de l'Abadia, p. 69-74.

Batdellol V., Mretres J., Martí B., J'AN-CABBANILLES J.
1989: El Neolitico antiguo : los primeros agricultores y granaderos en Aragon, Calaluna y Valencia, Huesca, Diputacion, $172 \mathrm{p}$.

Baideticol V., Rimón N.

1995 : " Estudio de los materiales ceramicos neoliticos del conjunto de Olvena ", in BaldFhou V., Utrilla P. (éds), La cueva del Moro de Olvena (Huesca), I, Bolskan, 12, p. 105-169.

BAIDETIOU V., UTRIILA P.

1999 : “ Le Néolithique en Aragon ", in Vigl'fr J. (éd.), Le Nélithique du Nord-Ouest médilerranéen, Actes du XXIV" congrès préhistorique de France, Carcassonne, sept. 1994, Jouć-les-Tours, Société préhistorique francaise, p. 225-237.

B.IRANDIARAN I., CALA A.

1989 : La ocupación prehistórica del Abrigo de Costalena (Maella, Zarragoza), Zaragoza, Diputación General de Aragon, Departemento de Cultura y Educación, Arqueología y Paleontología, 6, $167 \mathrm{p}$.

Bakki:R B., Biagi P., Chark G., Mkici R., NisBi:T R.

1990: "From hunting to herding in the Val Pennavaira (Liguria - northern Italy) ", in Blaci P. (éd.), The neolithisation of the Alpine Regiom, Brescia, Natura Bresciana, Monografice, 13, p. 99-121.

BARNYTT W. K.

1989 : The production and Distribution of Early Neolithic Pollery in the Aude Vallen, France, Ann Arbor, University Microfilm International, $545 \mathrm{p}$.

Bricoming: $A$

1995: "Nouveau regard sur le Néolithique ancien et moyen du Bassin rhodanien ", in V(ORI\% J.-L. (éd.), Chronologies néolithiques: de 6000 ì 2000 ans avam notre iere dans le
Bassin rhodanien, Actes du colloque d'Ambéricu-en-Bugey, scpt. 1992, Ambéricu-en-Bugey, Sociétć préhistorique rhodanienne, Document du Département d'anthropologie et d'écologie de l'université de Genève, 20, p. 93-111.

Bleching; A., Brochitr J.-I., Corditr F. 2000 : "La transition MésolithiqueNéolithique entre la plaine du Rhône moyen et ses bordures préalpines", Gielogie Alpine, Mémoire $\mathrm{SH}, 31$, p. 117-122.

Bl:RNABE: AUBAN J.

1989 : La tradición cultural de las cerimicas impresas en la zona oriental de la Peninsula Ibérica, Valencia, Servicio de investigación prehistórica, serie de trabajos varios, $86,158 \mathrm{p}$.

1996 : "Indigenismo y migracionismo. Aspectos de la neolitizacion en la fachada oriental de la Peninsula Iberica ", Trabajos de Prehistoria, 53, 2, p. $37-54$

BINIDER D.

1987 : I.e Néolithique ancien provensal: typologie et technologie des outillages lithiques, XXIV" suppl. à Gallia Préhistoire, Paris, éd. du CNRS, 212 p. 1995 : «Éléments pour la chronologie du Néolithique ancien à céramique imprimée dans le Midi ", in VORl\% J-I. (éd.), C'hromologies néolithiques: de 6000 is 2000 ans arvant notre ere dans le Bassin rhodamien, Actes du colloque d'Ambérieu-en-Bugey, sept. 1992, Ambérieu-en-Bugey, Société préhistorique rhodanienne, Document du Département d'anthropologie et d'écologie de l'université de Genève, 20, p. 55-65.

2000): "Mesolithic and Neolithic interaction in southern France and northern Italy : new data and current hypotheses ", in PRIC. T. D). (éd.), kurope's first farmers, Cambridge university press, p. 117-143. 
BINDER D. (F.l).)

1991 : Lnécomomie de chasse ane. Véolithique ancien : la grotte Lombard à Saint-Vallier. de-Thieg (Alpes-Maritimes), Paris, ćd. du CNRS, Monographie du CRA, 5, $252 \mathrm{p}$.

Binder D., Brochillik J.-E., Dinay H., Hrimer D., Marisial P., Thébaclit S., WatTl: J.

1993 : “Labri Pendimoun à Castellar (Alpes-Maritimes) : nouvelles données sur le complexe culturel de la céramique imprimée méditerranéenne dans son contexte stratigraphique ", Callia Préhistoire, 35, p. 177-251.

Binder D., Courtix J.

1987 : «Nouvelles vues sur les processus de néolithisation dans le Sud-Est de la France: "un pas en avant, deux pas en arrière" ", in Ginlase J., Col:kTIN J., Ro(t)h. J.-L., VERnet J.-L. (éds), Premières communautés paysannes en Méditerranée occidentale, Actes du colloque international du CNRS, Montpellier, avr. 1983, Paris, éd. du CNRS, p. 491-499.

Binder D., JAllot L., Thifibalit S.

2002 : "Les occupations néolithiques des Petites Bâties (Lamotte-du-Rhône, Vaucluse) ", in Archéologie du ToV Méditerranée, Fiches de synthèse -1La Préhistoire, Lattes, UMR 154 du CNRS, Monographies d'archéologic méditerranéenne, 8, p. 103-122.

Bindor:R D., Macigi R.

2001 : "Le Néolithique ancien de la région liguro-provençale ", Bulletin de la Société préhistorique française, 98, 3. p. 411-422.

Bosch Á., Bıxó R., Pinomo A., Bľch M., Matel J., TAberneko E. Casadevali. J.

1998 : El Poblat neolític de Plansallosa : l'explotació del territori dels primers agricultors-ramaders de l'Ala Carrotxa, La Garrotxa, Museu comarcal, Publicacions eventuals d arqueologia de la Garrotxa, $5,116 \mathrm{p}$.
Boscin Á., Tarkís J.

1991 : " Canvi cultural i habitat on el proces de neolitizacio de Catalunya ", Travaux de préhistoire catalane, 7 , p. $61-70$.

\section{Bosch I ARGillagós J.}

1993 : "Cronologia prehistòrica al curs inferior de l'Ebre. Primeres datacions absolutes ", Prenue, 24, p. 53-56.

\section{Boschl I LIORET Á.}

1991 : El neolitic antic al NE de Catalunya, Thèse de 3 cycle, Lniv. Autònoma de Barcelona, $687 \mathrm{p}$.

1994 : "I as primeras sociedades neoliticas del extremo nordeste de la Peninsula Iberica ", Archivo de Prehistoria Leouantina, 21, p. 9-31.

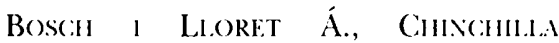
Sinche\% J., Tarrés I Gatter J.

2000 : Iil poblat lacustre neolitic de la Draga : excavacions de 1990 a 1998, Girona, Museu d'Arqueologia de Catalunya, Centre d'Arqueologia Subaquàtica de Catalunya, 2, $296 \mathrm{p}$.

Boctin J. Y., Cosmantial G., Pljol.J. 1997 : « I.e Néolithique ancien de la grotte de l'Ourtiguet (Sainte-Eulaliede-Cernon) ", Cahiers d'archéologie ateyronnaise, 11, p. 15-18.

\section{BRANI)ACIIIA M.}

1991 : «Il Neolitico a ceramica impressa dell'Isola del (jiglio. La ceramica ", Studi per llisologia del Quaternario, 13, p. 43-104.

\section{BRIOIS F.}

1997 : Les industries lithiques en Languedor méditerraméen (6000-2000) ar. J.-(:.). Rythmes el éolution dans la fabrication des mutillages de pierre taillée néolithiques entre mer et continent, Thèse de $3^{\circ}$ cycle, Toulouse, EHESS, $557 \mathrm{p}$.

2000) : "Variabilité techno-culturelle des industries lithiques du Néolithique ancien en Languedoc ", in Sociétés et espaces, Actes des III" rencontres méridionales de Préhistoire récente, Toulouse, nor: 1998, Toulouse, éd.
Archives d’écologie préhistorique, p. $43-50$.

(alstay J., Ranos M., G Gerkero I. 1993 : "Ia Bòtia de la Valldan (OrdènSolsonès) i el Neolític antic del Prepirineu Lleidatà ", Ilerda "Humanitats ", 50, p. 61-94.

CoLCMINES J.

1925: "Prehistoria de Montserrat", Analecta Montserratensia, VI, p. $225-349$

Costr. A., GLTHF: X.

1976: "Découverte de la phase récente de la culture cardiale dans les garrigues de Nîmes (Gard) ", Bulletin de la Sociélé préhistorique francaise, 7.3, 8, p. $246-250$.

É(HALIIER J-C., Col'RIIN J.

1994: "Approche minéralogique de la poterie du Néolithique ancien de la baume Fontbrégoua à Salernes (Var) ", Gallia Préhistoire, 36, p. $267-297$.

ESCAION DE. FONTON M.

1969 : «Recherches sur la préhistoire dans le Midi de la France. Campagne de fouilles 1968 ", Calhers ligures de préhistoire ot d'archóologie, 18 , p. 111-123.

1970 : " Devenir de l'Épi-Cardial ", in Les civilisations néolithiques du midi de la France, Actes du colloque de Narbonne, févr. 1970, Carcassonne, Laboratoire de préhistoire et de palethnologie, Atacina, 5, p. 9-10.

1971 : «Les phénomènes de néolithisation dans le midi de la France ", in Die Anfänge des Neolithikums zom Orient bis Nordeuropa, Köln, Institut für Lrund Frühgeschichte der Lniversität, Fundamenta, VI, p. 122-139.

\section{GiIILAYA.}

1989 : "La place des Alpes dans la néolithisation de l'Europe ", in Acrevcine O., Cilcix J. (éds), Néolithisations: Proche et Moyen Orient, Méditerranée orientale, Nord de lifrique, lurope méridionale, Chine, Amérique du Sud, Oxford, BAR, International 
Series, 516, archaeological series, 5, p. $227-254$.

Giddès D.

1980 : De la chasse au troupeau en Méditerranée occidentale. Les débuts de l'élevage dans le bassin de l'Aude, Toulouse, EHESS, Archives d'écologie préhistorique, $5,145 \mathrm{p}$.

\section{GILIGNY F.}

1994 : «Variabilité et transferts techniques dans le Jura à la fin du IV" et au III" millénaires av. J.-C. ", in Terre cuile et société : la céramique, document technique, économique, culturel, Actes des XIV" rencontres internationales d'archéologie et d'histoire d'Antibes, 21-23 oct. 1993, Juan-les-Pins, APDCA, p. 363-380.

GitLL.S R.

1988 : " La grotte de Saint-Marcel (Ardèche) ", Ardiche archénlogie, 5, p. 1-50.

Grifoni (kRMmonest R.

2001 : "Le Néolithique ancien de Toscane et de l'archipel toscan ", Bulletin de la Sociélé préhistorique fransaise, 98,3 , p. $423-430$.

GullaINE.J.

1970 : « Recherches de Préhistoire récente en Languedoc occidental et Roussillon. Campagne de recherche 1969. La grotte Gazel à SallèlesCabardès (Aude) ", Cahiers ligures de préhistoire et d'archéologie, 19 , p. 149-15.5.

1976 : « La neolitizacion de las costas mediterràneas de Francia y España ", Cuadernos de prehistoria y arqueologia castellonense, 3, p. 39-50.

1985 : "Néolithique ancien de la grotte des Fées à Leucate (Aude, France) et ses implications ", in LIviriri M. (éd.), Studi di Paletnologia in onore di Salvatore M. Puglisi, Roma, Universita di Roma La Sapienza, p. 505-516.

1986 : «Le Néolithique ancien en Languedoc et Catalogne: ćléments et réflexions pour un essai de périodisation ", in Dr.Motil. J.-P., GUILANE J. (éds), Le Néolithique de la
France. Hommage it (j. Bailloud, Paris, Picard, p. $71-82$.

2000 : « De l'orient à l'occident : la nćolithisation de la Méditerranée. Questions ouvertes ", in PEssisa A., Muscio G. (éds), La Neolitizzazione tra Oriente e Occidente, Convegno di Studi, Udine, aprile 1999, Udine, Museo Fruil. St. Nat., p. 11-21.

GuILAINEJ. (éd.)

A paraître: Pont de Roque-Haute (Porliragnes, Hérault): les influx italiques dans la néolithisation de la France méridionale, Toulousc, Monographic du Centre d'anthropologie des sociétés rurales.

GLilaine J., BarbaZA M., GASc(o) J., Gabdìs D., Coulakou J., Vaqler J., Brochiler J.-E., Briois F., ANDré J., Ja.uT G., Vernet J.-I.

1993 : Dourgne: derniers chasseurs-collecteurs et premiers éloneurs de la HauteVallée de l'Aude, Toulouse, Centre d'anthropologie des sociétés rurales, Carcassonne, Archéologic en terre d'Aude, 498 p.

Gimane J., Crhmonesi G., Radi G., collatol J

1991 : "Trasano et la céramique gravée matérane ", in GuIlaiNe J., Guthik\% X. (éds), Autour de Jean Arnal, Montpellier, Premières communautés paysannes, p. 123-137.

Guildine J., Freises A., Montjardin R., BARBAZA M., COLlakOU J., COLRTIN J.

1984 : Lencate-Corrège : habitat noyé du Néolithique Candial, Toulouse, EHESS, Centre d'anthropologie des sociétés rurales, $270 \mathrm{p}$.

Gomank: J., Gascó) J., Vaquir J., BARBAYA M.

1979 : L'abri Jean Cros: essai d'approche d'un groupe humain du Néolithique ancien dans son environnement, Toulouse, Centre d'anthropologie des sociétés rurales, $461 \mathrm{p}$.

GLILANE J., VAQLer J., Gascó J.

1976 : "L'abri de Font-Juvénal, une stratigraphie néolithique en
Ianguedoc ", Bulletin de la Sociélé d'éludes scientifiques de l'Aude, LXXV, p. 97-112.

HoUItRÉ J.-J., VITAI.J.

1984 : «Témoins du Néolithique ancien et passage au Néolithique moyen en Velay ", in Influences méridionales dans l'kst et le Centre-Lst de la France au Néolithique: le rôle du Massif central, Actes du $8^{c}$ colloque interrégional sur le Néolithique, Le Puy-en-Velay, oct. 1981, Clemont-Ferrand, Centre de recherches et d'études préhistoriques de l'Auvergne, p. 49-56.

Jídikian G., Manex C., Vaqulir J.

À paraître: "Échanges et territoires culturels entre Rhône et Garonne du $\mathrm{VI}^{\mathrm{c}}$ au $\mathrm{IV}^{\mathrm{c}}$ millénaire avant notre ère ", in Acles du $126^{\circ}$ congrès des sociétés historiques el scientifiques, Toulouse, 2001.

LASSERRE-MARTINELLII E. M.

1979 : Ia transition entre le Cardial et le Chasséen dans le Midi de la France. Groupes tampons ou termes de passage, mém. de Maîtrise, univ. Paris I, 139 p.

LFALE ANFossi M.

1974 : « L'Arma di Nasino (Savona). Gli strati con ceramica ", in Atti della XVI Riunione scientifica, Liguria, nov. 1973, Firenze, Istituto italiano de preistoria e protostoria, p. 131-140.

MAc;i) R.

1997 : "The radiocarbon chronology", in Macisi R. (éd.), Arene Candide: a functional and envirommental assessment of the Holocene sequence, Roma, Editrice « il (alamo ", Memorie dell'Istituto Italiano di Paleontologia Umana, 5, p. 31-52.

Maci(il R. (ÉD).)

1997 : Arene Candide: a functional and entironmental assessment of the Holocene sequence, Roma, Editrice " il Calamo ", Memorie dell'Istituto Italiano di Paleontologia Umana, 5, $644 \mathrm{p}$.

Magigl R., Chllila P.

1999 : «Chronologie par le radiocar- 
bone du Néolithique des Arene Candide (fouilles Bernabo Brea)", in VAQler J. (éd.), Le Néolithique du Nord-Ouest méditerranéen, Actes du XXIV congrès préhistorique de France, Carcassonne, sept. 1994, Joué-les-Tours, Société préhistorique française, p. 99-110.

MAcigi R., StARnini E.

1997 : « Some aspects of the pottery production ", in MAcici R. (éd.), Arene Candide: a functional and environmental assessment of the Holocene sequence, Roma, Editrice " il Calamo ", Memorie dell'Istituto Italiano di Paleontologia L'mana, 5, p. 280-299.

MAII.HE J.-P.

1979 : « Le gisement cardial de La Resclauze à Gabian (Hérault) ", Archéologie en Languedoc, 3, p. 13-16.

MANEN C.

1996 : La céramique du site néolithique ancien de Pont de Roque-Haute (Portiragnes, Hérauli), mém. de DEA, Toulouse, EHESS, 107 p.

2000a: " Implantation de faciès d'origine italienne au Néolithique ancien: l'exemple des sites "liguriens" du Languedoc ", in Sociétés et espaces, Actes des III" rencontres méridionales de Préhistoire récente, Toulouse, nov. 1998, Toulouse, éd. Archives d'écologie préhistorique, p. 35-42.

2000b : Le Néolithique ancien entre Rhône et Ètre: analyse des céramiques décorées, Thèse de $3{ }^{*}$ cycle, Toulouse, EHESS, $398 \mathrm{p}$.

À paraître: "Émergence, développement et évolution du Néolithique ancien en Languedoc-Roussillon ", in Temps el espaces cullurels, Actes des IV rencontres méridionales de Préhistoire récente, Nîmes, oct. 2000.

Manen C., Sabatikr P.

À paraître: Chronique radiocarbone de la néolithisation en Méditerranée occidentale.

MARC:HAND G.

1999 : Ia Néolithisation de l'ouest de la
France. Caractérisation des industries lithiques, Oxford, BAR, International Series, 748, $381 \mathrm{p}$.

\section{MARTI OLIN't: B.}

1978 : «El Neolitico de la Peninsula Iberica: estado actual de los problemas relativos al proceso de neolitizacion y evolucion de las culturas neoliticas ", Saguntum, 13, p. 59-98.

Martín A., Bioscia A., Al.bared) M. J. 1985 : «Excavacions a la Cova del Frare (Matadepera, Vallès Occidental). Dinàmica ecològica, seqüència cultural i cronologia absoluta ", Tribuna d'arqueologia, 1983-1984, p. 91-103.

Martín A., Guilaine J., Thommeret J., THOMMEREI Y.

1981 : " Estratigrafia y dataciones C14 del yacimiento de la "Cova del Frare" de St. Llorenç del Munt (Matadepera, Barcelona) ", Zephyrus, XXXIIXXXIII, p. 101-110.

\section{Martín Colidisa A.}

1992 : " Lectura de la distribucio i caracteritzacio dels jaciments cardials ", in Cura-Morera M. (éd.), listat de la investigació sobre el Neolitic a Catalunya, Actes du $9^{\text {c }}$ colloqui internacional d'arqueologia, Puigcerdà, 1991, Puigcerdà i Andorra, Institut d'estudis Ceretans, p. 68-71.

Martín Colligia A., Estevez i Escai.fra J. 1992 : " Funcio de la cova del Frare de St Llorenç de Munt (Matadepera, Barcelona) al Neolitic antic, en relacio a la ramaderia ", in CLRAMOrl:RA M. (éd.), Estat de la investigació sobre el Neolitic a Calahunya, Actes du $9^{c}$ colloqui internacional d'arqueologia, Puigcerdà, 1991, Puigcerdà i Andorra, Institut d'estudis Ceretans, p. 105-108.

Mazurife de Kerolatin K.

2000 : La première néolithisation de l'kurope: une répualuation des modalités de peuplement, Thèse de 3 cycle, univ: de Genève, Département d'anthropologie et d'écologie, $499 \mathrm{p}$.
MESTRI:S J.

1982 : “Avançament a l'estudi del jaciment de les Guixeres de Vilobí ", Pyrence, 17-18, p. 35-53.

Mestres I Mreciadé J.

1992: "Neolitizacio i territori ", in CuRAMorera M. (éd.), Estat de la investigació sobre el Neolitic a Catalunya, Actes du $9^{\text {c }}$ colloqui internacional d'arqueologia, Puigcerdà, 1991, Puigcerdà i Andorra, Institut d'estudis Ceretans, p. 72-75.

Miró J. M.

1990 : «El Neolític a la Catalunya meridional : una approximació espacial ", Acta arqueologica Tarraconense, III, p. 21-31.

1992 : " La fauna del jaciment de les Guixeres de Vilobí (Alt Penedès) en el context del Neolític antic a Catalunya ", in Cirs-Morrtet M. (éd.), Estat de la investigació sobre el Neolitic a Catalunya, Actes du $9^{\circ}$ colloqui internacional d'arqueologia, Puigcerdà, 1991, Puigcerdà i Andorra, Institut d'estudis Ceretans, p. 79-84.

1995 : « La cultura material del Neolític antic a la Conca de Barberà ", Pyrence, 26, p. 39-52.

Molist Montaña M., Ribri, Monge G., SaÑa Segui M.

1997 : « Les changements du Néolithique en Catalogne durant le

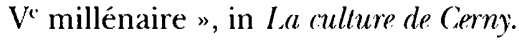
Nouvelle économie, nouvelle société au Néolithique, Actes du colloque international de Nemours, mai 1994, Mémoires du musée de Préhistoire d'lle-de-France, 6, p. 617-630.

Monnft C.

2002 : "Codoyères, Tavel (Gard). Du Néolithique ligurien en Languedoc rhodanien?", in Archéologie du TGV Méditerranée, Fiches de synthèse -1La Préhistoire, Lattes, UMR 154 du CNRS, Monographies d'archéologie méditerranéenne, 8, p. 261-264.

ODETTI G.

1984 : “ Ricerche preistoriche in Val 
Maremola: la Grotta dell'Edera ", Rivista Ingauna e Intemelia, XXXIX, p. 102-116.

1991 : « Saggio nei livelli neolitici della Grolla Pollera ", Rivista Ingauna e Intemelia, XIV-1-4, p. 107-147.

\section{Perrin T.}

A paraître : "Industries lithiques taillées et groupes culturels dans le haut Bassin rhodanien au Néolithique ancien ", in Temps et espaces culturels, Actes des IV" rencontres méridionales de Préhistoire récente, Nîmes, oct. 2000.

Ph:trt I Menditzabat. M. (Éd).)

1996 : El procés de neolitizació a vall del Segre. La cova del Parco (Alos de Balaguer, la Noguera). Estudi de les occupacions humanes del $V^{p}$ al $I I "$ millenni $A C, \quad$ Barcelona, Universitat, Monografies del Serp, 1, 69 p.

Pla J., JUNiner E.

1970 : "Noticia sobre el Hallazgo de un vaso en la cova dels Lladres (Vacarisses, Barcelona) ", Pyrenae, 6, p. $43-46$.

RFY LANASPA J., RIMON FERNANDE\% N. 1992 : "Un yacimiento del Neolítico Antiguo al aire libre en el llano oscense. El Torrollón I (Usón) ", in UtTRILIA Miranda P. (éd.), Aragon/Litoral mediterraneo: intercambos culturales durante la Prehistoria, Actes du colloque de Zaragoza, 1988, p. 309-318.

RIC(Q DE BOUARI) M.

1996 : Pétrographie et sociétés néolithiques en France médliterranéenne. L'outillage on pierre polie, Paris, CNRS Éditions, Monographie du CRA, 16, $272 \mathrm{p}$.

RODRIGUE: G.

1984 : La grotle de Camprafaud : contribnlion à l'étude du Néolithique en Languedoc central, Montpellier, Office régional de la culture du languedocRoussillon, $417 \mathrm{p}$.

RoLDIL I.-L

1987 : "Le gisement néolithique de la
Baume d'Oullins, le ('iarn, (jard ", in Gullaine J., Coliktin J., Rocdil. J.-L., VERnet J-L.. (éds), Promières communautés paysannes en Méditerranée occidentale, Actes du colloque international du CNRS, Montpellier, avr. 1983, Paris, éd. du CNRS, p. 523-529.

1990 : "Cardial et Néolithique ancien ligure dans le sud-est de la France ", in : Canf.x D., OTte M. (éds), Rubané ot Cardial, Actes du colloque de Liège, nov. 1988, Liège, Études et recherches archéologiques de l'université de Liège, 39, p. 383-392.

1996 : "Céramiques cardiales de la grotte de Chazelles, Saint-André-dcCruzières ", Ardèche Archéologie, 13, p. $30-35$.

Roudi, J.-L., Evesque R., Da Silya J. 1991 : "L'abri de la Tardive. Berrias Casteljau (Ardèche) ", Ardèche Arrhéologie, 8, p. 19-28.

Rothil. J.-L., Rounil. O., Solliter M. Errol:x J., Pollain T., Vliknet J-L.

1979 : La grotte de l'Aigle à Méjannes-le-Clap (Gard) el le Néolithique ancien du Languedoc oriental, Méjamnes-le-Clap, Mémoire de la Société languedocienne de préhistoire, 1, $87 \mathrm{p}$.

Rocidi. J.-L., Soul.Itr M.

1983 : "Le gisement néolithique ancien de Peiro Signado (Portiragnes, Hérault) : étude préliminaire ", in Actes du XXI congrès préhistorique de France, Quercy, 1979, Paris, Société préhistorique française, p. 258-279.

SABATIFR P

1997 : Représentation d'ensembles de dates radiocarbones sous la forme thistogrammes pondérés. La vallée du Rhône de $6000)$ à 2000 atuant notre ère, mém. de DEA, Toulouse, EHESS, 145 p.

\section{SAǸ SFCiti M}

1997 : "I a complexification des rapports entre les groupes humains of les ressources animales au Néolithique dans le Nord-Est de la Péninsule Ibérique ", in Proceedings of the $7^{\text {th }}$ ICA\% conference, Paris, p. 545-551.
TARRĹS I GALTTR J.

1981 : "El Neolitic Antic a les comarques gironines ", in El Neolitic a Catalunya, Taula rodona de Montserrat, mai 1980, Montserrat, publicaciones de l'Abadia, p. 33-57.

1983 : «El neolitico antiguo en elnordeste de cataluna y algunas consideracione sobre los grupos epicardiales catalanes ", in Le Néolithique ancien méditerranéen : archéologie en Languedoc, Actes du colloque international de préhistoire, Montpellier, 1981, $\mathrm{n}^{\circ}$ spécial de la Revue de la Fédération archéologique de l'Ilérault, p. $143-155$.

TINÍ: S. (ÉD).)

1999 : Il neolitico nella Caverna delle Arene Candide (scavi 1972-1977), Bordighera, Istituto Internazionale Studi Liguri, Collezione di Monografie Preistoriche ed Archeologiche, X, 620 p.

Tiví S., NATALI E.

1996: "Favella ", in: Tınf́ S. (éd.), Forme e tempi neolitizzacione in Italia meridionale e in Sicilia, Atti del Seminario internazionale, Rossano, 1994 , Rossano, Istituto Regionale per le Antichità Calabresi e Bizantine, p. $299-314$

Van Willilgen S.

1999 : «L'Épicardial et la Néolithisation de la France méditerranéenne ", in Btiknable Acbín J., Orozco Kön hler T., (éds), Actes du II congrés del Noolític a la Península Iberica, València, Abril 1999, Lniversitat de Valencia, Departement de prehistorria i d'arqueologia, Saguntum, extra-2. p. $571-579$.

VIGNE J.-D.

1988 : Les Mammiferes post-glaciaires de Corse. Etude archéozoologique, XXVI suppl. à Gallia Préhistoire, Paris, ed. du CNRS, $337 \mathrm{p}$.

Vilikdeli. I Pascinar. R.

1992 : «El Jaciment à l'aire lliure de la Timba d'en Barenys (Riudoms, Baix camp) ", in (Cura-Moreri M., (éd.), 
Estat de la investigació sobre el Neolitic a Calalumya, Actes du 9" colloqui internacional d'arqueologia, Puigcerdà, 1991, Puigcerdà i Andorra, Institut d'estudis Ceretans, p. 112-116.
V(ORL $\%$ J.-L.

1995 : "Introduction ", in VORL\% J.-I. (éd.), Chromologies néolithiques : de 6000) à $200(0)$ ans aruant notre ère dans le Bassin rhodamien, Actes du colloque d'Ambé-
ricu-en-Buger; sept. 1992, Ambéricuen-Buger, Société próhistorique rhodanienne, Document du Département d'anthropologic at d'ćcologie de l'université de Genève, 20, p. 11-15. 